An International Framework For Eco-Industrial Parks

December 2017

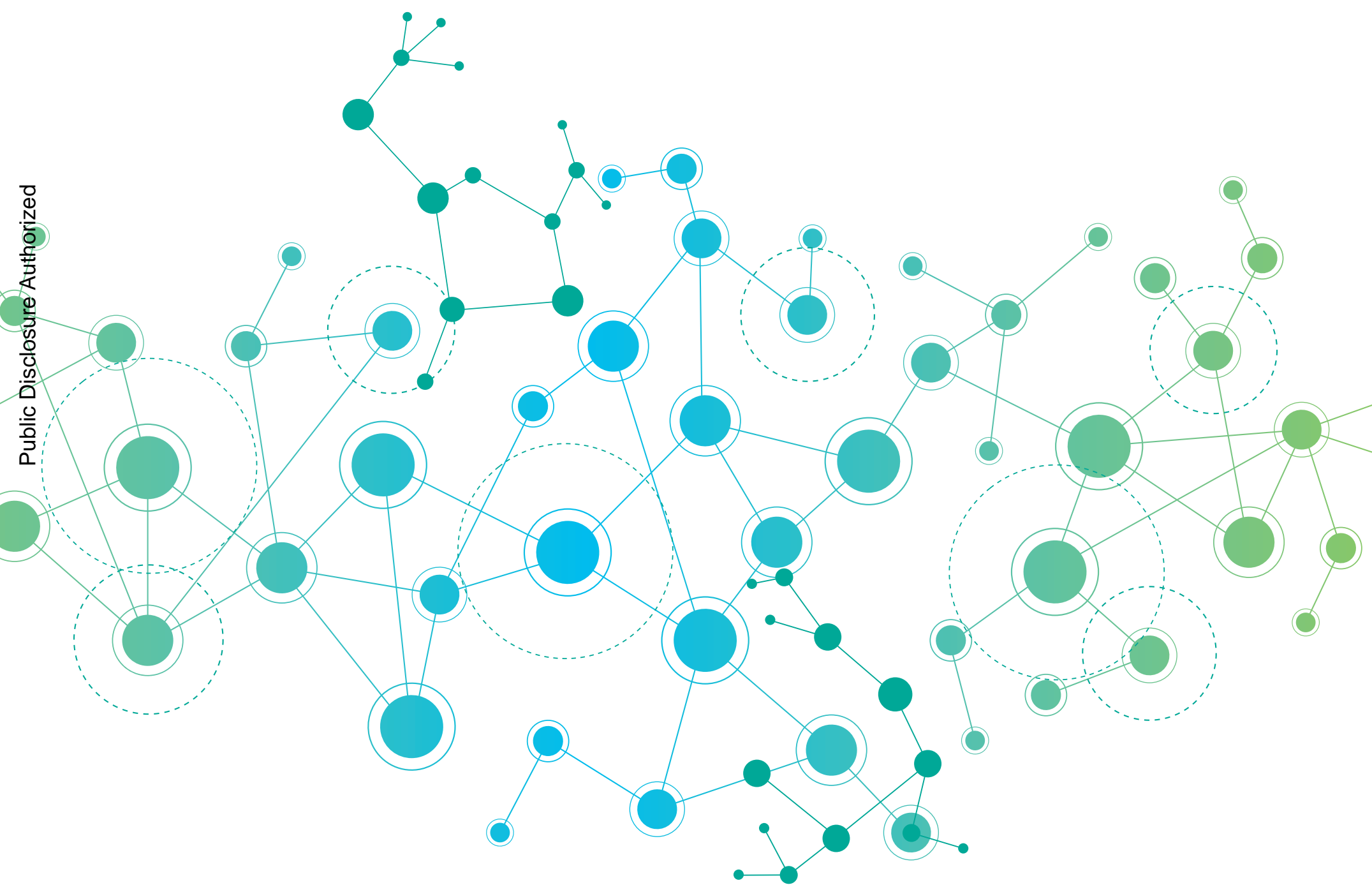





\section{An international framework for Eco-Industrial Parks}

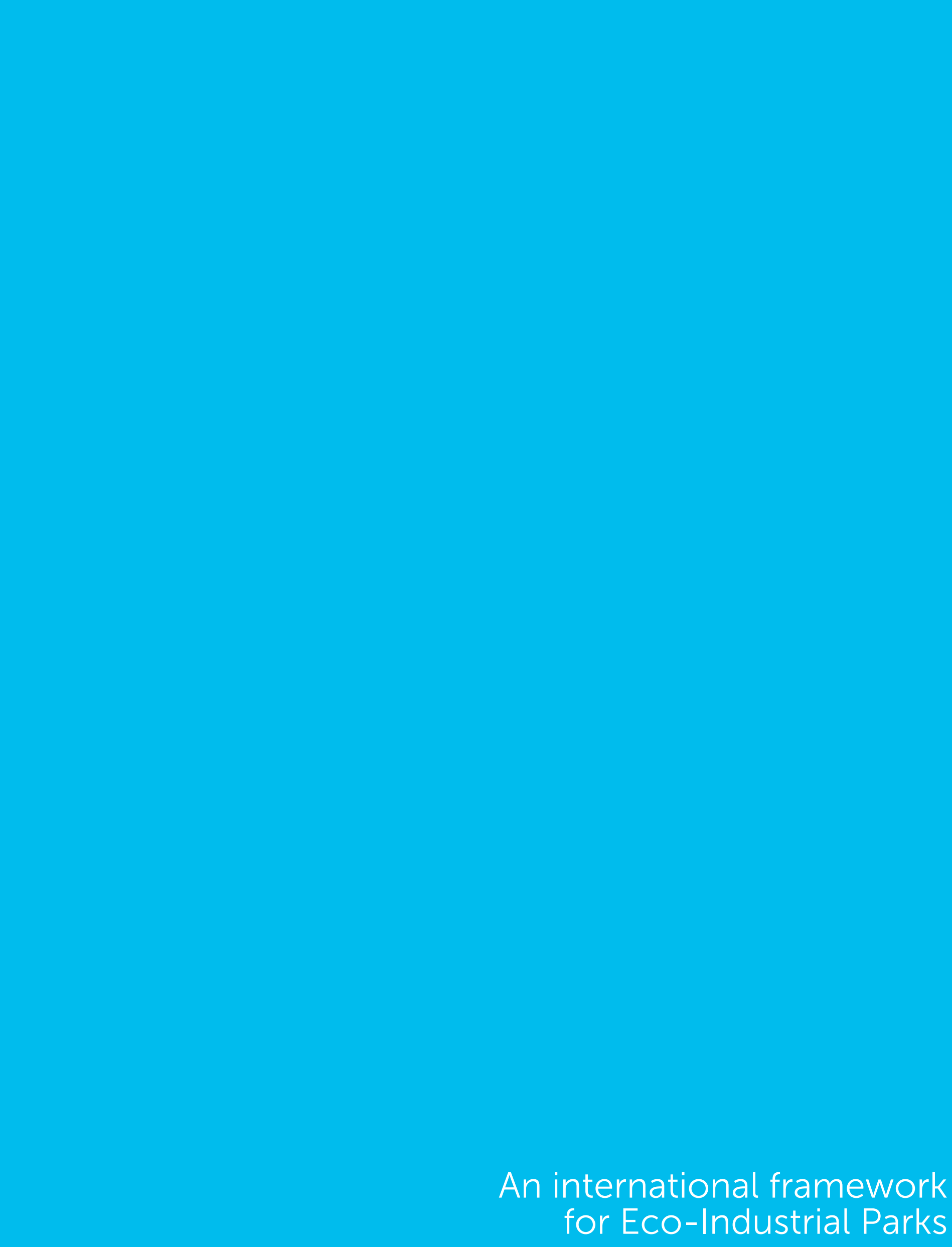


(C2017 The World Bank Group

1818 H Street NW

Washington, DC 20433

Telephone: 202-473-1000

Internet: www.worldbank.org

All rights reserved.

This volume is a product of the staff of the World Bank Group. The World Bank Group refers to the member institutions of the World Bank Group: The World Bank (International Bank for Reconstruction and Development): International Finance Corporation (IFC - the largest global development institution focused on the private sector in emerging markets); and Multilateral Investment Guarantee Agency (MIGA), which are separate and distinct legal entities each organized under its respective Articles of Agreement. We encourage use for educational and non-commercial purposes.

The findings, interpretations, and conclusions expressed in this volume do not necessarily reflect the views of the Directors or Executive Directors of the respective institutions of the World Bank Group or the governments they represent. The World Bank Group does not guarantee the accuracy of the data included in this work.

\section{Rights and Permissions}

The material in this publication is copyrighted. Copying and/or transmitting portions or all of this work without permission may be a violation of applicable law. The World Bank Group encourages dissemination of its work and will normally grant permission to reproduce portions of the work promptly.

For permission to photocopy or reprint any part of this work, please send a request with complete information to the Copyright Clearance Center Inc., 222 Rosewood Drive, Danvers, MA 01923, USA; telephone: 978-7508400; fax: 978-750-4470; Internet: www.copyright.com.

All other queries on rights and licenses, including subsidiary rights, should be addressed to the Office of the Publisher, The World Bank Group, 1818 H Street NW, Washington, DC 20433, USA; fax: 202-522-2422;

e-mail: pubrights@aworldbank.org. 


\section{Acknowledgements}

This publication is a product of collaboration between the United Nations Industrial Development Organization (UNIDO), the World Bank Group, and Deutsche Gesellschaft für Internationale Zusammenarbeit (German Development Cooperation) (GIZ) GmbH.

The following contributors to this publication are acknowledged:

UNIDO Nilguen Tas, Smail Alhilali, Elisabeth Mueller, Dick Van Beers

World Bank Group Etienne Kechichian, Sinem Demir

GIZ Karina Nikov, Anna Schaetzlein, Raghu Babu Nukala, Johanna Jagnow, Mareike Boll

Carbon Trust Guy Henley, David Aitken

The publication has also benefited greatly from continuous contributions from David Tobin (Carbon Trust) and Michael Weber (Weber Sites Consulting).

We are also grateful to the following people for their peer review of the draft publication: Dr. Anna Braune and Dr. Stephan Anders from the German Sustainable Building Council (DGNB e.V., Stuttgart); Thomas Kraubitz (Buro Happold, Berlin); Gokhan Akinci, Soren Heitmann, Mohan Seneviratne and Eskender Alemayehu Zeleke (WBG); and Patrick Nussbaumer, Adnan Seric and Rene Van Berkel (UNIDO). The report was carried out under the guidance and direction of Ernesto Lopez-Cordova (WBG) and Stephan Sicars (UNIDO).

We would also like to thank Barbara Balaj for the editing, Naz Beykan for design coordination, and Linker Creative for the graphic design of this report. 


\section{Foreword}

Over the past few decades, the creation of industrial parks has been recognized as an efficient way of bringing together industrial activities with commercial, infrastructure and services. However, it is now largely understood that the nature of industrial parks can potentially have both positive and negative impacts. While they contribute to economic growth, they also have the potential to concentrate negative environmental and social impacts, including: greenhouse gas (GHG) emissions, pollution, resource depletion, poor labor standards, and attendant local community grievances.

As developing and emerging economies seek to increase industrial output, there is also a pressing need to decouple economic growth from environmental and resource inefficiency to meet wider social objectives. There is a real opportunity now to strategically plan and effectively manage industrial parks to help achieve the desired economic, social, and environmental targets.

As a result, the concept of Eco-Industrial Parks (EIPS) has increasingly been recognized as an effective tool to overcoming challenges related to inclusive and sustainable industrial development within the scope of Sustainable Development Goals (SDGs). Countries such as Denmark, France, Japan and the Republic of Korea, among many others, have leveraged key elements of the EIP concept to promote more inclusive and sustainable action to improve industrial competitiveness in line with climate change goals.

The concept has been further developed, and this publication outlines a common framework for EIP implementation. In this context, the United Nations Industrial Development Organization (UNIDO), the World Bank Group and the Deutsche Gesellschaft für Internationale Zusammenarbeit GmbH (German Development Cooperation) (GIZ) intend to use this framework as a baseline across all of their initiatives in partner countries.

The International Framework for Eco-Industrial Parks will guide policymakers and practitioners on the critical elements that will help both governments and the private sector work together in establishing economically, socially and environmentally sustainable eco-industrial parks.

An important element of the EIP approach is to create a more sustainable operating environment for firms, and to ensure that they are able to improve their competitiveness and create jobs. These eco-industrial parks would be designed to use resources more efficiently, and improve productivity. They would provide investors with an environment specifically adapted to support the achievement of their social responsibility goals. They would also increase market access to sustainable products, and lower exposure to climate change risks. Additionally, eco-industrial parks will contribute to the attainment of the Paris Climate Change Accord's NationallyDetermined Contributions at the country level.

By coming together, our three organizations aim to pave the way for creating a common vision for ecoindustrial parks, which countries can use and modify according to their own specificities. The International Framework is a unifying structure for further efforts on country projects. It leverages a wide range of tools and strengths that each organization brings to the effort. We hope that this common framework fills the current void in understanding of eco-industrial parks and encourages their development on a global scale.



\section{Stephan Sicars}

Director of the Department of Environment

Programme Development and Technical Cooperation

United Nations Industrial Development Organization (UNIDO)

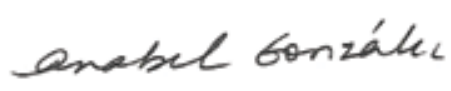

\section{Anabel Gonzalez}

Senior Director

Trade and Competitiveness Global

Practice

World Bank Group

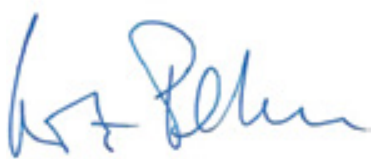

\section{Lorenz Petersen}

Director of Division

Climate Change, Rural

Development Infrastructure

Deutsche Gesellschaft für

Internationale Zusammenarbeit (GIZ) GmbH 


\section{Table of contents}

Acknowledgements $\quad 3$

\begin{tabular}{lr} 
Foreword & 5 \\
\hline
\end{tabular}

Acronyms $\quad 9$

Executive Summary $\quad 11$

1 Introduction $r$

$\begin{array}{lr}1.1 \text { Context } & 13\end{array}$

$\begin{array}{llr}1.2 & \text { Aims and objectives } & 14\end{array}$

1.3 Scope of the EIP framework 15

1.4 Rationale for a consolidated eco-industrial park framework 16

1.5 Framework application and target audience 18

$\begin{array}{llr}1.6 & \text { Publication structure } & 19\end{array}$

2 A common understanding of Eco-Industrial Parks 21

2.1 Defining Eco-Industrial Parks 21

2.2 Drivers and benefits of Eco-Industrial Parks 21

2.3 Barriers to the implementation of Eco-Industrial Parks 24

3 Approach to defining performance requirements for Eco-Industrial Parks 27



3.2 Defining performance requirements for Eco-Industrial Parks 29

4 Requirements for Eco-Industrial Parks

4.1 Introduction

4.2 Compliance requirements with national and local regulations 31

4.3 Park management: Performance requirements 35

4.4 Environment: Performance requirements 40

4.5 Social performance requirements 46

4.6 Economic performance requirements $\quad 51$

5 Concluding remarks and future prospects $\quad 55$

References $\quad 57$

Annex 1: Going beyond the EIP performance requirements $\quad 60$

Annex 2: Eco-Industrial Park Case Studies $\quad 65$

Industrial Zone NÖ-Süd, Austria $\quad 66$

Ulsan Mipo and Onsan Industrial Park, South Korea 68

Hoa Khanh Industrial Zone, Vietnam

Izmir Ataturk Organized Industrial Zone, Turkey 73

ALEAP Green Industrial Park in Telangana, India 


\section{List of boxes}

Box 1: EIP Conformance with International Standards and Protocols 33

Box 2: Climate Change Adaptation (CCA) and Disaster Risk Management in Eco-Industrial Parks 37

Box 3: An Example of Performance and Continuous Improvement based on the Framework 61

\section{List of figures}

Figure 1: Publication Structure $\quad 19$

Figure 2: Examples of Combinations of Terminologies used Internationally in Relation to Eco-Industrial Parks 21

Figure 3: Overall Framework for Describing Eco-Industrial Parks 27

Figure 4: Example of Performance and Continuous Improvement-Based Framework for Assessing Eco-Industrial Parks

Figure 5: Park Management and Governance Structure of Ulsan Mipo and Onsan Industrial Park 68

Figure 6: Main Stages of A-GRIP Site Master Planning

\section{List of tables}

Table 1: Key Barriers for EIPs and Potential Solutions 25

Table 2: Park Management: Performance Requirements for Eco-Industrial Parks 38

Table 3: Environment: Performance requirements for Eco-Industrial Parks 42

Table 4: Social: Performance Requirements for Eco-Industrial Parks 48

Table 5: Economic: Performance Requirements for Eco-Industrial Parks 53

Table 6: Suggestions for Exceeding Eco-Industrial Park Performance Requirements 62

Table 7: Governance structure of Izmir Ataturk OIZ 



\section{Acronyms}

CCA Climate change adaptation

DGNB German Sustainable Building Council

EIA Environmental Impact Assessment

EIP Eco-Industrial Park

EMS Environmental Management System

EnMS Energy Management System

GHG Greenhouse Gas

GIZ Deutsche Gesellschaft für Internationale Zusammenarbeit (GIZ) GmbH (German Development Cooperation)

IFC International Finance Corporation (part of World Bank Group)

ISO International Organization for Standardization

NDC Nationally-Determined Contributions

NGO Non-Governmental Organization

OECD Organisation for Economic Co-operation and Development

OH\&S Occupational Health and Safety

RECP Resource Efficient and Cleaner Production

SDG Sustainable Development Goal

SEZ Special Economic Zone

SIA Sustainable Industrial Area

SME Small and Medium-sized Enterprise

UNCED United Nations Conference on Environment and Development

UNEP United Nations Environment Programme

UNIDO United Nations Industrial Development Organization 


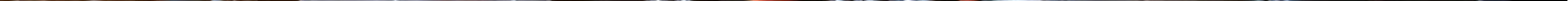




\section{Executive Summary}

The aim of this publication is to provide an international framework (the "Framework") with the performance requirements as to how an industrial park can become an Eco-Industrial Park (EIP). It summarizes the key areas in which the three international organizations that have driven the development of this framework - including the United Nations Industrial Development Organisation (UNIDO), the World Bank Group, and Deutsche Gesellschaft für Internationale Zusammenarbeit GmbH (GIZ) (German Development Cooperation) - have aligned regarding what constitutes an Eco-Industrial Park (EIP).

The purpose of this publication is three-fold, namely: (i) to assist relevant stakeholders in developing and transitioning to EIPS; (ii) to consistently approach, encourage, and recognize EIPs; and (iii) to improve the performance, sustainability and inclusiveness of the industrial sector and move toward an international standard on EIPS.

UNIDO, the World Bank Group, and GIZ are currently supporting governments and industrial park practitioners with the development of EIPs in a range of countries and contexts. EIPs can be defined as dedicated areas for industrial use at a suitable site that ensures sustainability through the integration of social, economic, and environmental quality aspects. These aspects are incorporated into the siting, planning, management, and operations of EIPS.

Industrial parks are known by different names including: industrial areas, industrial zones, industrial investment regions, special economic zones, and industrial corridors that are planned and developed for the purposes of industrial activities and associated commercial, infrastructure, and service activities. Industrial parks have potentially positive and negative impacts. While they serve to contribute to the socio-economic growth of a country or a region, they also have the potential to cause negative environmental and social impacts including: climate change, pollution, resource depletion, health and labor issues, and attendant community disruption.

There are currently a number of complementary tools and processes to assist governments and industrial park stakeholders to progress in the implementation of inclusive and sustainable industrial development. However, a consolidated and targeted framework for EIPs is largely lacking at the international level. Countries and industrial park stakeholders are increasingly requesting 'standards' or benchmarks for ensuring that envisioned industrial developments are sustainable and meet the spirit of an EIP. An innovative approach is to set "minimum requirements" or "sustainability performance standards" for industrial parks, covering legal compliance as well as socio-economic, environmental, and management aspects. Such standards provide benchmarks for assessing existing industrial parks, planning retrofitting measures for existing parks, or better planning new industrial parks with the end goal of driving inclusive and sustainable industrialization.

The EIP framework presented here contains prerequisites and performance requirements, which are outlined in separate tables in Section 4. These are international and inclusive in scope, and are aimed at all industrial parks (including Special Economic Zones, Investment Zones, Industrial Estates, Industrial Parks, Manufacturing Zones, and so on). They also pertain to stakeholders in the private and public sectors wherever these industrial parks are located.

They can inform stakeholder frameworks and be used by UNIDO, the World Bank Group and GIZ in their development cooperation projects and in promoting EIPS across the world. The activities and regulatory environments that define national governance legislation, regulations and structures for industrial parks vary considerably across the world. Therefore, the framework also recognizes the need to consider local contexts and sensitivities when applying these requirements. The EIP framework starts from the position that relevant policies and regulations must be complied with. It then sets specific additional performance requirements across management, environmental, social, and economic topics.

UNIDO, the World Bank Group, and GIZ are committed to using this EIP framework in their future projects and programs. The three organizations also encourage partners and stakeholders to apply the requirements outlined in this publication throughout the process of industrial park planning, development, management, operations and monitoring. By applying a common international EIP framework, the development community can move toward more inclusive and sustainable industrialization.

1. The Sustainable Development Goals (SDGs), particularly SDG 9, makes reference to inclusive and sustainable industrialization. For the sake of brevity, references to sustainability of industrial parks are meant to also cover inclusivity in this publication. 


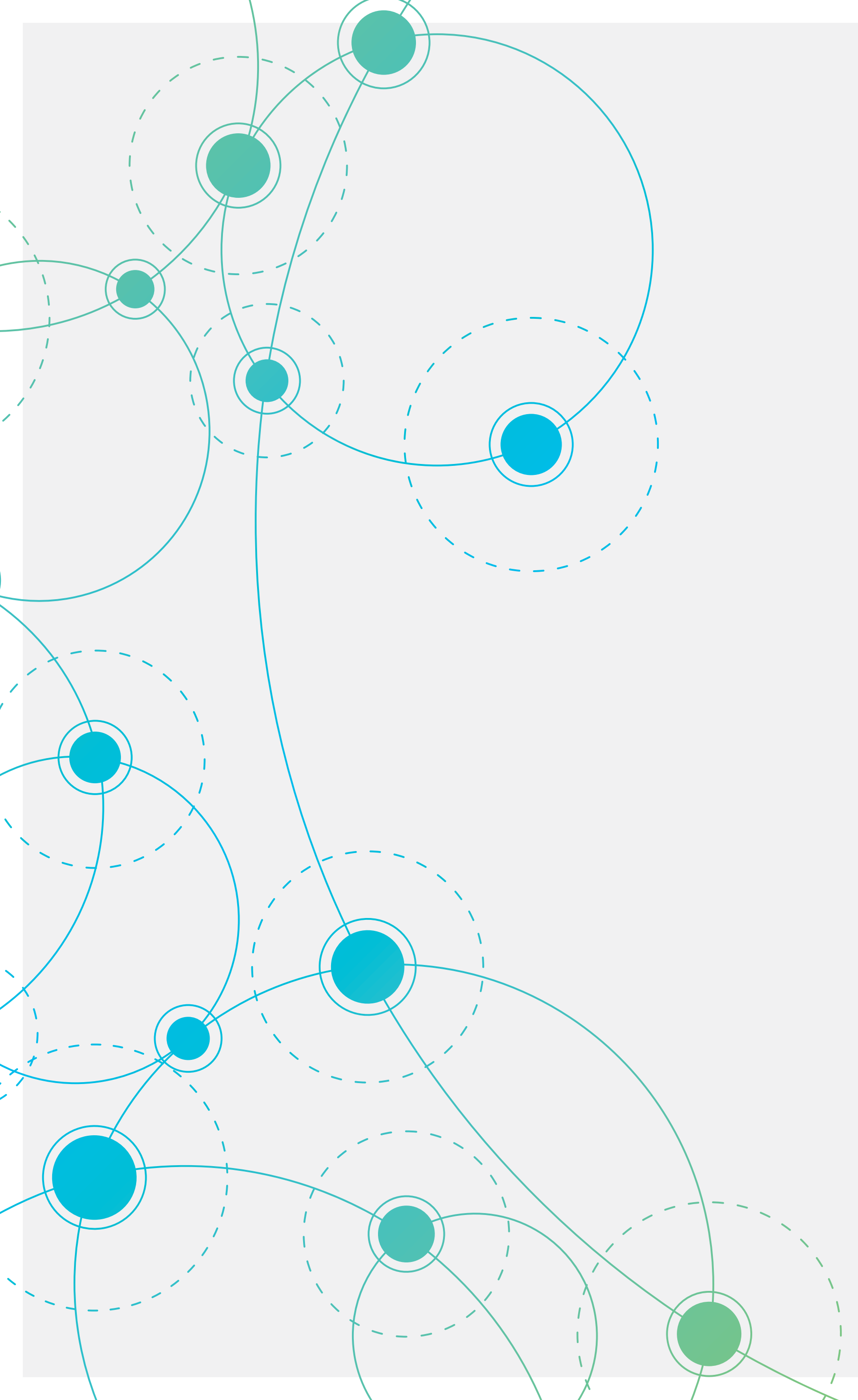




\subsection{Context}

Industrial parks are known by different names and cover industrial areas, industrial zones, industrial investment regions, special economic zones, industrial corridors, and so on. They are planned and developed for the purpose of industrial and associated commercial, infrastructure, and service activities.

Industrial parks have both potentially positive and negative impacts. While they serve in contributing to economic growth and social development of a country or a region, they also have the potential to cause negative environmental and social impacts including: climate change, pollution, resource depletion, labor issues, and attendant community disruption. Strategic planning and effective management of industrial parks will help achieve economic, social, and environmental goals.

Interest in industrial parks has grown substantially in recent decades ${ }^{1}$. Through the grouping of industrial firms in a defined location, industrial parks offer important potential collaborative and efficiency gains. As developing and emerging economies seek increased industrial output, there is a pressing need to balance economic growth with environmental and social objectives.

International efforts strive to make industrial development inclusive and sustainable: The idea of EcoIndustrial Parks (EIPs) was first described during a presentation at the United Nations Conference on Environment and Development (UNCED) in Rio de Janeiro 1992. By early 2005, communities in the Africa, Asia, Europe, South America, and the United States had initiated EIP or other eco-industrial development planning processes. For many, EIPs were viewed as an appropriate and effective framework to transition to sustainable production. As a result, Eco-Industrial Parks became commonly used as a reference term.

The EIP concept and approach have evolved over time to address additional, interrelated aspects, including, for example: resource efficient and cleaner production; industrial symbiosis; climate change; pollution; social standards; shared infrastructure; improved spatial zoning; and management. It has become clear that an interdisciplinary approach is required to circumvent barriers and ensure the successful implementation and operation of EIPS.

The United Nations Industrial Development Organisation (UNIDO), the World Bank Group, and the German Development Cooperation (GIZ) are supporting governments and industrial park practitioners with the development of EIPs. GIZ is providing technical cooperation based on the concept of "Sustainable Industrial Areas" to countries across the globe. Similarly, UNIDO has been promoting EIPs, green industry, resource efficiency and cleaner production through its projects and technical assistance program. The World Bank Group is financing and providing technical assistance to climate competitive industries projects, including EIPs and low-carbon zones, in a range of countries around the world.

Countries and industrial park stakeholders are increasingly requesting 'standards' or benchmarks to ensure that envisioned industrial development is sustainable and inclusive. The partners in this effort have come together to work on performance requirements that can inform an EIP stakeholders framework. The framework could then be used to guide development cooperation projects and the promotion of EIPs around the world.

Eco-Industrial Parks: There are a number of definitions for EIPs. Broadly, EIPs can be defined as a dedicated area for industrial use at a suitable site that ensures sustainability through the integration of social, economic, and environmental quality aspects into its siting, planning, management and operations. The EIP definition by Lowe (1997) is referenced by many international organizations working on this topic (as quoted also in Section 2.1 of this publication). Since then, definitions have evolved to reflect the importance given to the three pillars of sustainable development, namely environment, social, and economic.

Preliminary World Bank Group research in 2016 identified over 250 operating or planned EIPs globally, although these vary widely in quality. This represents significant growth over 1990 levels (World Bank Group, 2016) 
Setting international benchmarks and performance requirements for EIPs: There are a host of individual tools and processes to assist governments and industrial park stakeholders in moving toward sustainable industrial development. However, consolidated and targeted guidelines for EIPs are largely lacking at the international level. An innovative approach is to set "performance requirements" for industrial parks, which cover legal compliance as well as socio-economic, environmental, and management aspects. Such standards provide benchmarks for assessing existing industrial parks, planning retrofitting measures, or better planning new industrial parks.

Sustainable Development Goals (SDGs) are a driver for sustainable industry: The 2030 SDGs include relevant targets and actions for industry, innovation and infrastructure, as well as measures for decent work, economic growth, gender equality, and climate action. For instance, SDG 9 aims to significantly raise industry's share in employment and gross domestic product by 2030. The means for achieving this can include retrofitting industries to make them sustainable, increasing resource-use efficiency, and the greater adoption of clean and environmentally sound technologies and industrial processes. SDG 7 aims, among other things, at doubling the rate of energy efficiency improvement and significantly increasing the share of renewable energy by 2030. SDG 8 targets sustained per capita economic growth at 7 percent per year, and SDG 13 focuses on climate actions. SDG 5 addresses issues of gender equality. These SDGs are applicable to EIPs and the development of an international framework for their use.

\subsection{Aims and objectives}

The aim of this publication is to provide an international framework with guidance on performance requirements on how an industrial park can work towards becoming an Eco-Industrial Park (EIP).

With the provision of an international framework for EIPs, this publication aims to:

(i) Assist relevant stakeholders in developing and transitioning to EIPs;

(ii) Consistently approach, encourage, and recognize EIPs; and

(iii) Improve the performance, sustainability and inclusiveness of the industrial sector, and move toward an international standard for EIPs.

Interest in ensuring sustainability of industrial parks, by addressing economic, social and environmental aspects, has grown substantially in recent decades. However, with this growth in interest, there has been a divergence in the understanding of what constitutes an EIP. The international performance requirements for EIP outlined in this publication aim to complement, rather than replace, existing tools and standards. They seek to give guidance on good international industrial park policy and practice, as well as performance requirements. Stakeholders can use the Framework provided as a reference point when working with industrial park stakeholders to establish expectations and improve performance.

Specific objectives of the performance requirements for Eco-Industrial Parks include attaining ambitious, but achievable performance requirements, as follows:

- Increase the park management and governance performance, specifically with regard to proper management and monitoring of the industrial park. This includes investing in associated infrastructure; applying national/international standards; organizing and managing services (including industrial park disaster preparedness and risk management), and marketing of the park.

- Enhance the environmental performance of the industrial park by minimizing the footprint of the industrial park, which can be achieved by providing sustainable means to manage water, wastewater, waste, and resources. It also involves addressing climate change issues and effects on the local and global environment.

- Improve the social performance of the industrial park by addressing the needs of the community and employees, including in relation to labor, gender, community dialogue, and appropriate social infrastructure. 
- Increase the economic performance of the industrial park by the adoption of, or transition to, an EIP approach that maximizes possible returns for businesses and park managers. Economic benefits from an industrial park range include revenue and profit generation, job creation, and competitiveness - as well as access to additional investment resources for resident industries.

\subsection{Scope of the EIP framework}

This framework adopts an inclusive approach, and provides a common understanding of EIPs to assist stakeholders. Given the diversity of industrial parks, and the regulatory regimes in which they operate, sensitivity in the application of this framework is required.

This framework is intended to apply to the following:

- Industrial parks in developed, transition, and developing countries;

- Existing industrial parks (brownfield) and planned industrial parks (greenfield):

- All types of industrial parks with different characteristics (for example, size/area, level of technological development, and intensity of existing collaborations); and

- All industrial sectors, such as leather processing, textile production, manufacturing, chemical production, and so on (which will each have their specific, national compliance requirements).

The focus of this framework is to encourage industrial parks to exceed compliance with local and national regulations with respect to environmental and social issues ("Compliance Plus"). An EIP must comply with all applicable local and national legislation ${ }^{1}$. In situations where national requirements fall short of international good practices, an EIP will be expected to align with good international industry practice, coinciding with the performance requirements set out in this publication. In exceptional situations where local or national regulations exceed these performance requirements, then it is expected that relevant local and national regulations would take precedence.

The framework for EIPs centers on four key categories: park management performance, environmental performance, social performance, and economic performance. The requirements within each category are divided into "prerequisites" and "performance indicators," that can be verified and measured in qualitative and/or quantitative terms. To be deemed an EIP, a park is expected to be compliant with all relevant prerequisites and performance expectations.

The present framework's reference to "industrial park management" is limited to expectations from park managers, sometimes called park operators, regarding the planning, development, management and operations of the park - and not to higher-level park governance structures and institutions. The park manager is defined as the entity that deals with management and day-to-day operations, resident services, park infrastructure and facilities, promotion and marketing, and interactions with authorities and the community on behalf of residents. This is to be performed in line with existing higher-level park governance structures, institutions, and regulating bodies. By focusing on the park management level, the framework aims to allow for comparisons between defined areas within countries and economies. This demarcated system consists of the industrial park and facilities contained on its premises, the park management entity, resident park firms, and the community and relevant authorities.

The framework focuses on aspects that can be controlled or influenced by the industrial park's management. These aspects will naturally cover the aggregated impacts from the firms operating in the industrial park, as well as those of the park management entity and all facilities it manages within the park. The park management structure and operating approach are crucial to achieving the objectives of EIPs in tandem with resident businesses and the wider community. 
This framework, including specific EIP performance expectations, focuses comprehensively on the environmental, social, economic aspects of industrial park management. Common EIP components include: a sustainable park management structure; park- and where applicable, firm-level resource efficiency and cleaner production; industrial symbiosis and synergies; interactions with the local community and natural environment; spatial planning and zoning; socially acceptable working and living conditions; and collective use of park-level infrastructure, such as utility services and facility management.

\subsection{Rationale for a consolidated eco-industrial park framework}

International experience demonstrates that the EIP concept is a valid and sustainable approach to increasing resource efficiency, and cleaner production, as well as to ensure environmental protection and socially fair and responsible business practices in existing and new industrial parks. However, to date, different parties and principles have defined EIPs. As a result, industrial park stakeholders are uncertain of what is globally expected to achieve EIP status. The following issues (UNIDO 2016) require clarification:

- Divergence in name and understanding: The EIP concept can mean different things to different parties. While similarities exist across the breadth of literature, stakeholders require a clear and consistent designation from the international community;

- Practice does not yet match ambition: Some parks describe themselves as an EIP, but fall short in performance. For instance, they may not be continuously implementing environmental and social improvements;

- There is potential to leverage best-in-class examples: Many good practice elements exist, but these need to be brought together and implemented routinely in the planning, development, and management of industrial parks; and

- Barriers and market failures still exist: Lack of experience, awareness, and supporting regulations, as well as enforcement, slow the development and implementation of EIPs.

Having a consolidated EIP assessment framework and performance criteria are important because they can assist stakeholders with the following decisions and actions:

- Private sector decision making: Businesses often require assistance in determining whether to locate within an industrial park, as well as help with their decisions about whether to invest in clean production technologies and processes. The framework can complement existing tools and implementation approaches to support the sustainable development of industrial parks and their resident firms.

- Public-sector decision making: The framework presented here can also provide guidance and incentives for stakeholders to encourage the transition toward EIPS. Governments could use the framework to prioritize industrial areas for support based on a common set of qualifications and understanding of what constitutes an EIP. In addition, the framework can further facilitate the creation of a joint vision for a specific park, or the mandate for a regional industrial program.

- Performance improvement: The framework can assist stakeholders in assessing performance levels of industrial parks by highlighting priority topics and indicators, which can be used to review whether an industrial park meets EIP requirements. In addition, having a clear and commonly agreed understanding of EIPs and their characteristics can assist in bringing together park operators, park owners, and stakeholders as they seek to improve their processes and operations.

- Allocating funding: The framework can help the financial sector, funding agencies and donors to allocate financial support to industrial parks that meet minimum thresholds. In addition, with the growing interest in green bonds, steps toward the standardization and verification of EIPs have the potential to unlock new funding streams and products necessary for inclusive and sustainable industrial development.

- Reputational benefits: Consolidating criteria in an assessment framework can help stakeholders to compare EIPs. It could also provide reputational benefits to industrial parks that meet performance requirements - and help incentivize other industrial areas to move toward meeting those criteria. This could, in turn, increase demand among firms wishing to locate/relocate in an EIP.

- Awareness raising: A common framework can help raise awareness of the benefits and added value of EIPs, including alignment with international priorities such as the SDGs, climate change, inclusive and sustainable industrial development, and corporate social responsibility. 
- Marketing advantages: Industrial areas are competing for investors worldwide. The high eco-industrial performance and corporate social responsibility of EIPs can provide marketing benefits.

- Better allocation and use of resources: A well-designed park will also consider the most efficient use of resources such as land, water, and/or energy by creating synergies (for example, by the use of waste heat), or by achieving better economies of scale (for example, through joint usage of infrastructure).

- Retrofitting of existing industrial areas: This framework will help assess the performance of an existing industrial park, identify gaps, and plan additional development in the park.

This framework constitutes a natural progression, and builds on the work carried out by UNIDO, the World Bank Group, GIZ and the wider international community. Over the past two decades, a number of local and national initiatives, best practices, and certification programs have been established to formulate standards and benchmarks, which are directly and indirectly related to the concept of EIPs. These include:

- United Nations' indicators for sustainable development (United Nations Department of Economic and Social Affairs 2007);

- Green Growth Indicators (Organisation for Economic Co-operation and Development [OECD]);

- Guidelines for Sustainable Industrial Areas (GIZ, Version 1.0, 2015)1;

- Chinese Eco-Industrial Park Standards and Certifications²;

- Indicators of Kaiserslautern University of Technology;

- Certification System of the German Sustainable Building Council (DGNB);

- Green Special Economic Zone (SEZ) Rating System of the Indian Green Building Council (IGBC);

- Guidelines for Multinational Enterprises: Responsible Business Conduct Matters (OECD 2013);

- The Implementation of Industrial Parks: Some Lessons Learned in India (World Bank 2014);

- Low-carbon Zones: A Practitioner's Handbook (World Bank 2014);

- Global Assessment of Eco-Industrial Parks in Developing and Emerging Economies (UNIDO 2016);

- Implementation Handbook for Eco-Industrial Parks (UNIDO 2017);

- Mainstreaming Eco-Industrial Parks (World Bank 2016);

- Greening Industrial Parks: A Case Study on South Korea's Eco-Industrial Park Programme (Global Green Growth Institute [GGGI] 2017); and

- Guide to Corporate Sustainability (United Nations Global Compact 2017).

These initiatives provide valuable insights both at the national and global levels. Key features of EIPs are highlighted, and cover environmental management, industrial symbiosis, resource efficiency, energy savings, inclusive development, and economic competitiveness. However, despite these important initiatives, there is still no consolidated and internationally accepted criteria or performance indicators for what constitutes an EIP. UNIDO, the World Bank Group, and GIZ established a joint initiative to address this gap. 


\subsection{Framework application and target audience}

This international EIP framework has been developed to provide guidance to governments, industrial park operators, resident businesses, and associated stakeholders. A diverse range of stakeholders are involved in the development and operation of industrial parks. The performance requirements can serve to inform EIP stakeholders about their respective frameworks, auditing procedures, and certification systems where applicable.

This publication aims to serve as a reference for a broad group of stakeholders involved in the development and implementation of EIPs. It will serve to help them report on EIP status and achievements in a comprehensive and transparent manner. It should be noted that this publication does not provide actual implementation advice, as this responsibility rests with national governments and EIP decision makers.

UNIDO, the World Bank Group, and GIZ will ensure application of the performance requirements in their respective projects and programs. They will also encourage partners and stakeholders beyond the boundaries of their projects to apply these requirements in industrial park planning, development, management and monitoring.

The target audience for the framework includes a broad range of industrial park stakeholders. This comprises both governmental institutions looking to inform industrial park-related policy to incentivize green manufacturing activities, as well as private sector stakeholders who are involved in the development and operation of EIPs. It also includes, but is not limited to the following stakeholders:

- Industrial park planners and developers;

- Industrial park operators and management;

- Firms located in industrial parks;

- Industrial associations and chambers of commerce;

- Governments at the national, provincial and local levels, as well as regulators;

- Financial sector, funding agencies and donors;

- International development agencies and non-governmental organizations (NGOs); and

- Scientific research institutions.

Limitations of the framework: It should be noted that this framework in its current format aims to provide strategic and operational direction regarding performance requirements for EIPs. It does not translate these expectations into a formal international EIP labelling and certification scheme. 


\subsection{Publication structure}

This publication is divided into five sections (see figure 1). This first section details the context, aims and objectives of the EIP performance requirements framework, along with the scope and intended audience. Section 2 provides a common understanding of EIPs, and highlights the associated benefits, drivers and barriers. Section 3 outlines the approach followed to develop the framework for EIP requirements. Section 4 provides the EIP performance requirements across park management, as well as environmental, social, and economic categories. Finally, Section 5 provides closing remarks from the three authoring organizations of this EIP framework and its application.

Figure 1: Publication Structure

\begin{tabular}{|c|c|c|c|c|c|}
\hline \multicolumn{2}{|c|}{ Introductory sections } & \multicolumn{2}{|c|}{$\begin{array}{c}\text { Core of this publication: } \\
\text { EIP requirements }\end{array}$} & Application & $\begin{array}{l}\text { Supporting } \\
\text { information }\end{array}$ \\
\hline $\begin{array}{l}\text { Section 1: } \\
\text { Introduction } \\
\text { to the EIP } \\
\text { performance } \\
\text { requirements } \\
\text { framework } \\
\text { including, } \\
\text { context, } \\
\text { objectives, } \\
\text { scope, } \\
\text { rationale and }\end{array}$ & $\begin{array}{l}\text { Section 2: } \\
\text { Common } \\
\text { understanding } \\
\text { of EIPs, } \\
\text { including } \\
\text { definitions, } \\
\text { benefits, drivers } \\
\text { and barriers. }\end{array}$ & $\begin{array}{l}\text { Section 3: } \\
\text { Approach } \\
\text { to define } \\
\text { requirements } \\
\text { for EIPs, } \\
\text { covering } \\
\text { assessment } \\
\text { framework } \\
\text { and process to } \\
\text { define the EIP } \\
\text { performance }\end{array}$ & $\begin{array}{l}\text { Section 4: } \\
\text { Performance } \\
\text { requirements } \\
\text { for EIPs, } \\
\text { including legal } \\
\text { compliance } \\
\text { and detailed } \\
\text { tables with } \\
\text { performance } \\
\text { requirements } \\
\text { on park }\end{array}$ & $\begin{array}{l}\text { Section 5: } \\
\text { Moving } \\
\text { forward } \\
\text { and closing } \\
\text { remarks from } \\
\text { authoring } \\
\text { organisations. }\end{array}$ & $\begin{array}{l}\text { Annex 1: } \\
\text { Going beyond } \\
\text { performance } \\
\text { requirements, } \\
\text { recognising } \\
\text { that EIPs are } \\
\text { based on } \\
\text { continuous } \\
\text { improvements } \\
\text { processes. }\end{array}$ \\
\hline $\begin{array}{l}\text { application } \\
\text { and target } \\
\text { audience. }\end{array}$ & & requirements. & $\begin{array}{l}\text { management, } \\
\text { environmental, } \\
\text { social, and } \\
\text { economic } \\
\text { topics. }\end{array}$ & & $\begin{array}{l}\text { Annex 2: } \\
\text { EIP good } \\
\text { practice } \\
\text { case studies, } \\
\text { addressing } \\
\text { the EIP } \\
\text { framework. }\end{array}$ \\
\hline
\end{tabular}




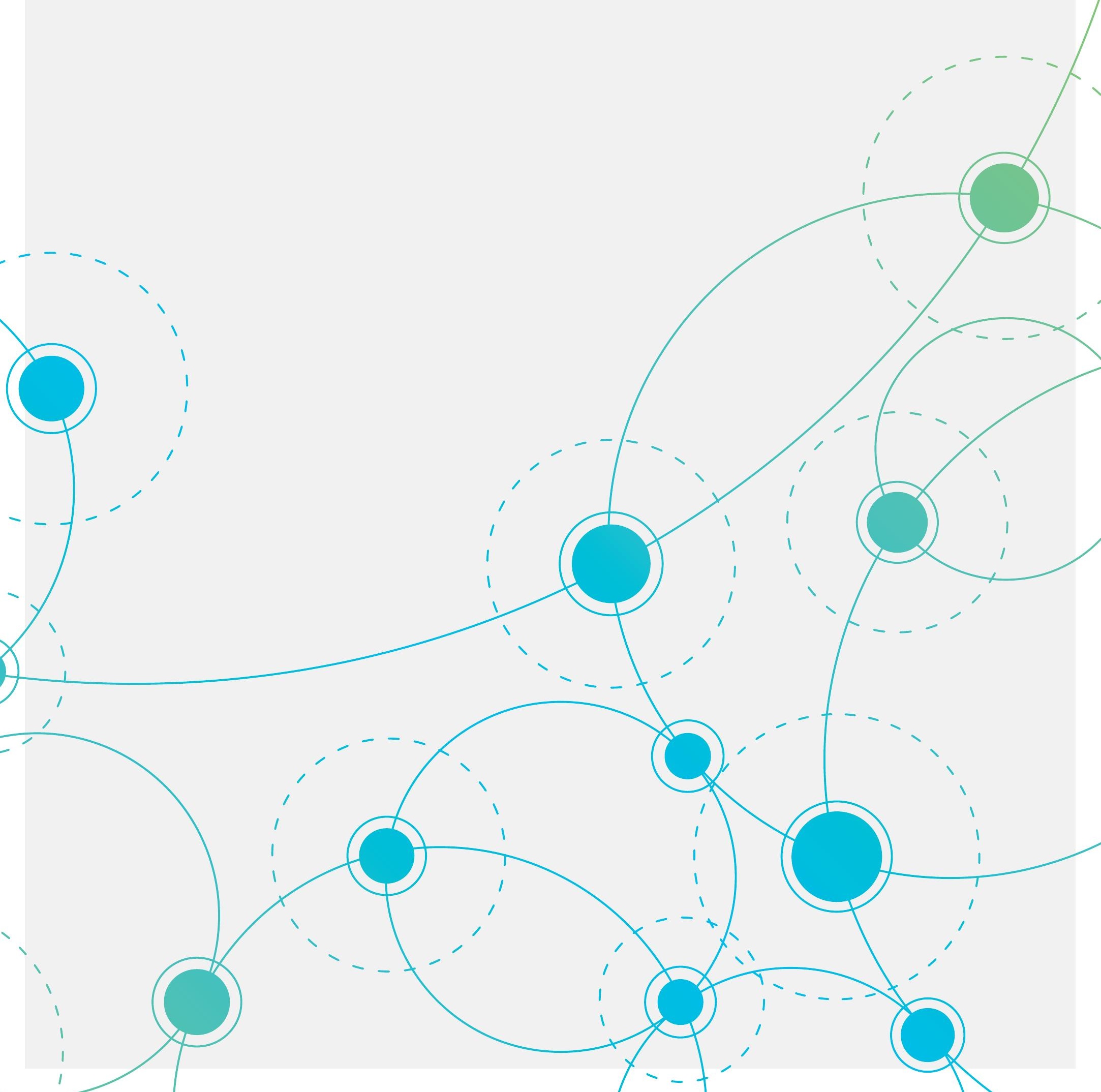




\subsection{Defining Eco-Industrial Parks}

Different terminologies and definitions are used by various organizations around the world to refer to EIPs, or to relatively similar concepts. Figure 2 presents the various combinations of commonly-used terminologies that directly or indirectly relate to the concept and practice of EIPS. This publication does not aim to dictate a particular terminology. Rather, it highlights areas of alignment that provide a practical way to move forwardwhichever terminology is used.

Figure 2: Examples of Combinations of Terminologies used Internationally in Relation to Eco-Industrial Parks

\section{Combinations of related EIP terminology used internationally}

\begin{tabular}{|c|c|c|}
\hline $\begin{array}{c}\text { Eco } \\
\text { Sustainable } \\
\text { Low Carbon } \\
\text { Green } \\
\text { Circular }\end{array}$ & $\begin{array}{c}\text { Industrial } \\
\text { (Special) Economic } \\
\text { Technological } \\
\text { Investment } \\
\text { Manufacturing }\end{array}$ & $\begin{array}{l}\text { Park } \\
\text { Zone } \\
\text { Area } \\
\text { Cluster } \\
\text { Estate }\end{array}$ \\
\hline
\end{tabular}

Various definitions are used in relation to EIPs. The EIP definition by Lowe (1997) is referenced by many international organizations active in this area:

"A community of manufacturing and service businesses located together on a common property. Member businesses seek enhanced environmental, economic, and social performance through collaboration in managing environmental and resource issues. By working together, the community of businesses seeks a collective benefit that is greater than the sum of individual benefits each company would realize by only optimizing its individual performance."

Since the EIP definition provided by Lowe was developed, the definition has evolved to reflect the importance given to the three pillars of sustainable development: environment, social, and economic.

\subsection{Drivers and benefits of Eco-Industrial Parks}

Industrial parks are an important driver of industrialization. By grouping businesses in a dedicated colocation, they can offer important efficiency and collaborative opportunities. However, they can also potentially negatively affect the physical and social environment in which they operate. Industrial parks generally involve a collection of businesses undertaking a combination of heavy and light manufacturing and processing, whose aims are to maximize output. Industrial activities in an EIP area can produce significant negative environmental externalities, which can come from point sources or dispersed sources. These are principally in the form of air emissions, water pollution, land contamination, and over-exploitation of resources. Furthermore, industrial parks which are not properly managed can negatively impact the workforce and communities in which they operate.

An EIP framework allows associated risks to be appropriately managed and sustainable development opportunities to be maximized. With the growth of industrial output in developing and emerging economies alike, there is significant scope for EIPs to drive efficiency and contribute positively to socio-economic development at the local and national levels. Mitigating and managing the potentially adverse impacts of industrial parks is crucial. Indeed, it is increasingly important, particularly in those economies where legislation and approaches to managing risks may not be sufficient to maximize sustainable development opportunities. 
Key drivers for Eco-Industrial Parks include: reducing an industrial park's environmental footprint; promoting efficiency gains; enabling community cohesion; providing better access to finance and technical support; and enhancing business competitiveness. Good international industry practice demonstrates a wide range of economic, environmental, and social benefits from EIPs. Indeed, these can go well beyond the conventional business case benefits. In this context, EIP benefits are not just commercial. They are also strategic in nature because they lead to reduced exposure to resource and licensing risks. They also increase competitiveness, promote business development, and build a better reputation with key stakeholders. Drivers such as access to finance, technical support, and policy, economic and community benefits were frequently noted by most of the cases analyzed in the comparative study undertaken by UNIDO (2016).

One of the most significant drivers of EIPs is the opportunity to increase business, industrial competitiveness and sustainable growth. For an EIP to be economically successful, the overall park concept must be attractive for investors and industries, including access to the appropriate resources and human capital. A key motivation for developers of EIPs is the desire to attract strategic investors and incentivize local and foreign direct investment. Support can be offered through the provision of economically-, environmentally-, and sociallyaligned services and a plan to meet the sustainability agenda for an industrial area.

The clustering of businesses at the park-level also enables added-value services to be offered at reasonable prices. Also, an efficient management structure minimizes the administrative overhead costs. Industries operating in well-designed and well-managed EIPs are in a better position to take advantage of resource efficiency, value-adding and risk-mitigating measures, and services available at both the firm and park levels.

From an industrial competitiveness perspective, the main drivers for EIPs are:

- Providing an improved and dynamic business environment;

- Minimizing operating costs and improving process efficiency and productivity;

- Increasing demand to improve efficiency and growth:

- Minimizing risks of exposure to natural resource scarcity;

- Providing assurance to stakeholders regarding environmental and social concerns relevant to consumers, local communities, governments and investors;

- Utilizing corporate social responsibility advantages; and

- Providing access to high-quality infrastructure and collective representation of business interests.

Environmental protection, climate change and resource efficiency are making the imperative for EIPs stronger. Industry accounts for a significant portion of global emissions, and has wide-reaching environmental and local community impacts. EIPs can make a significant contribution to reducing carbon dioxide $\left(\mathrm{CO}_{2}\right)$ emissions, thereby contributing toward the implementation of the Paris Climate Change Agreement (2015) and Nationally-Determined Contributions (NDCs) ${ }^{1}$. Reaching these targets will require deep and long-lasting changes in energy and industrial greenhouse gas emissions. In this context, EIPs have the potential to play an important role.

Key environmental drivers of EIPs include:

- Climate change commitments at the global and national levels;

- The presence of relevant policy mechanisms (for example, taxes and market mechanisms, such as carbon pricing);

- Greening the supply chain and alleviating resource constraints², which can lead to improved resource management and resource conservation;

- Ensuring infrastructure is resilient to higher resource costs and adapts to climate change risks;

- Responding to environmental and social concerns from consumers; and

- Increased demand to improve efficiency and growth.

1 The Paris Agreement's central aim is to strengthen the global response to the threat of climate change by keeping a global temperature rise in this century well to below 2 degrees Celsius above pre-industrial levels. In addition, the Agreement calls for efforts to limit the temperature increase even further to 1.5 degrees to below 2 degrees Celsius above pre-industrial levels. In addition, the Agreement calls for efforts to limit the temperature increase even further to 1.5 degrees Celsius.

2 Water shortages are becoming more common and, in some cases, raw material inputs are becoming increasingly scarce as well. Such shortages and scarcities can affect the development and operation of industrial parks. 
With increasing industrial output in developing and emerging economies alike, an EIP framework can help to ensure social standards are maintained - and employees and the wider community are appropriately protected. Integrating social quality standards within industrial parks is becoming increasingly important. Evidence suggests frictions between communities and industrial parks can occur due to poor preparedness for dealing with emergencies, concerns about operational standards, and increasing encroachment between residential and industrial developments. In addition, industrial parks often depend on intensive labor, the supply of resources from the surrounding local communities, appropriate social infrastructure, and in some cases housing and wider social services. This requires a carefully planned and appropriate framework and processes for addressing social concerns.

\section{Key social drivers of EIPs include:}

- Better working and labor conditions;

- Creation of local jobs;

- Improvement of gender equality;

- Better security and crime prevention:

- Provision of social infrastructure to workers and community;

- Support to local community well-being and community outreach;

- Provision of vocational training;

- Improved occupational health and safety; and

- Transition to more sustainable land use.

EIPs can provide a wide range of socio-economic benefits, in particular, employment creation. EIPS often involve the creation of an enhanced social infrastructure, which is particularly important for developing countries. Examples include medical facilities, vocational training opportunities, and broader community services. Indirect benefits are often difficult to quantify, but are increasingly important for the long-term economic sustainability of the park and resident firms.

\section{Key economic drivers of EIPs include:}

- Direct and indirect employment creation;

- Skills-upgrading of the labor force;

- Linkages between industrial park firms and small and medium sized enterprises (SMEs) and communities outside the industrial park;

- Technology and knowledge transfer through foreign direct investment; and

- Demonstration effects arising from application of good international industry practices and regional development approaches.

Reputational risk is increasingly important, and can be mitigated through an EIP framework. Government authorities, industrial park developers, and industrial landowners are conscious of the potential negative reputation that industrial parks may acquire because of weakly managed operations. An EIP framework allows them to adopt a positive marketing opportunity with the introduction of more sustainable industrial operations that provide environmental protection, climate change mitigation, resource efficiency, and higher social quality standards. These factors play an important role in driving the development of EIPs (World Bank 2016). 
EIPs are subject to a range of barriers, some of which can be tackled through the provision of an EIP framework and strategic planning. Although a number of industrial parks have taken steps toward sustainability (Lambert and Boons 2002), on the global scale, few fully developed EIPs exist today. Barriers faced by park owners, operators, and resident businesses are both internal and external, and cover a range of aspects from technology to managerial deficiencies.

\section{Common perceived barriers facing successful implementation of EIPs include (IISD 2015; Sakr and others} 2011):

- Insufficient financial returns on sustainable investments;

- Lack of appropriate and enforceable regulations;

- Limited technological development and cost-efficient solutions;

- Lack of awareness and information sharing;

- Complexity in organizational structure; and

- Limited customer awareness of, and demand for, sustainable products.

International examples demonstrate that the success of an EIP is dependent on its ability to compete and offer cost-effective and non-disruptive solutions to resident firms. For example, the lack of access to competitively priced water, energy, and raw materials - as well as the risk of disrupting operations to accommodate innovative low carbon technologies and process improvements - can be potential barriers to firms establishing and operating in EIPS.

In addition, although crucial to a sustainable operation, the cost of 'eco-efficient' industrial processes can be prohibitive for parks in developing countries. For example, wastewater treatment plants capable of treating complex chemicals - such as dyes, pharmaceutical by-products and waste heat recovery processes - require significant investment and have long financial return periods. Depreciating these and recovering costs through EIP management fees can be difficult to negotiate with resident businesses. In addition, the realization of efficiency gains is dependent on the appropriate management of process improvements, which often requires additional capacity building. This highlights the need for effective planning and strong internal support. External assistance for the implementation of an EIP framework may also be required.

Barriers exist in designing and building new EIPs, as well as in retrofitting existing parks. The type and severity of barriers will differ across different industrial parks. It is often argued that transitioning operations and processes to sustainable pathways for existing parks is especially difficult. For example, those tasked with retrofitting parks are faced with integrating complex process into existing infrastructure, which can present technical design, installation, and operational challenges. Stakeholders need to look to tailored or phased solutions within each park to ensure the barriers they face can be successfully overcome. Creating new EIPS requires time allocation and expenditure in planning, designing, and acquiring the required licenses. However, these can be controlled from the outset through detailed front-end engineering design phases, which can allow for the integration of the most efficient and cost-effective design, as well as the adoption of eco-efficient processes.

The lack of clear guidance, indicators and international benchmarks presents a challenge in directing prospective developers in the right direction - as well as in quantifying and communicating the benefits to firms. As a result, differentiating true EIP leaders from laggard industrial parks is difficult (Zhang 2012). A commonly agreed framework and set of indicators are needed to design and measure management and governance practices, social benefits, knowledge sharing efforts/results, and collaboration that lead to greater resilience and competitiveness (Geng and others 2009; Lombardi and Laybourn 2012).

Table 1 provides an overview of some of the key barriers faced by industrial parks as they seek to make their operations more sustainable. It also contains some high-level solutions to overcome these barriers. 


\section{Key barriers for EIPs and potential solutions}

Regulatory barriers

Description: The lack of sufficient, appropriate and enforcement of regulations limits the push for traditional industrial parks and their resident businesses to transform their operations into sustainable production centers.

\section{Barriers:}

Potential regulatory barriers include:

- Lack of suitable policies to encourage EIP development (both command and control, and fiscal incentives)

- Lack of policies to encourage clean technology development and adoption.

- Lack of transparency surrounding industrial regulations and enforcement.

- Regulations are not universally applied, leading to competitive disadvantages

- Limited ability of stakeholders to transpose privileged regulatory frameworks into industrial parks.

\section{Sample Solutions:}

Policy makers can:

- Seek to understand the key national and local barriers to the adoption of environmental and social standards in industrial operations

- Set hard and soft targets for the development of EIPs.

- Develop command and control, and fiscal incentives that encourage EIPs

- Develop regulations that are conducive to the development of an enabling environment for EIPs.

- Engage in national, regional, and international dialogue to source best practices, rather than duplicate existing practices.

Technological and socio-economic barriers

Description: Certain high impact and innovative technological solutions are not advanced enough, and/or are cost prohibitive to implement - especially in low margin environments and developing contexts. Competitive concerns can arise for firms in parks having to bear higher costs (due to higher environmental and social performance requirements) relative to those that do not, when both compete in the same markets.

\section{Barriers:}

- Park management entity and enterprises lack financing to implement pollution prevention mechanisms.

- High upfront capital costs with long returns on investment prospects limit implementation.

- Limited financial support for innovative processes and environmental measures from the park to resident enterprises

- Park management is not entrusted with clear and appropriate mandates and budgets

- Long lead times and disruptions in installing new technologies.

- Limited understanding of the benefits of socially responsible business practices

- Lack of research funding.

\section{Sample Solutions:}

Policy makers can:

- Provide capital subsidies and technical assistance to assist with the implementation of new technologies.

- Encourage technological cooperation programs.

- Promote mechanisms to encourage standardization

- Promote socially responsible business practices.

EIPs can:

- Engage in park-level dialogue and enterprise training to improve awareness of the most cost effective and advanced technology solutions and socially responsible business practices and associated benefits

- Deploy outsourced, technically sound infrastructure and services through viable business models.

Institutional and organizational capacity

Description: There are potentially a large number of internal barriers, one of the most important being technical capacity.

\section{Barriers:}

- Lack of internal resources and technical workforce.

- Lack of motivation across resident businesses for continuous improvements in moving toward an EIP.

- Lack of experience and awareness of developers and authorities.

- Lack of capabilities for energy conservation and pollution prevention.

- Lack of stakeholder communication channels

- Lack of management resources.

- Lack of indicators and guidelines.

- More pressing priorities than environment, safety, and social cohesiveness

- Lack of external support from owners, value chains, communities and international organizations.

\section{Example Solutions:}

Policy makers can:

- Prepare national guidelines and standards for EIPs. The standards suggested here can help inform frameworks and serve as a benchmark.

- Fund training programs.

EIPs can

- Examine sector-specific international best practices and replicate them across the parks.

- Develop internal training programs to build human resource capacities, which in turn can provide a competitive advantage.

- Engage with national and regional stakeholders to build external capacity and confidence in EIPs.

- Engage competent professionals and/or qualified companies in undertaking EIP assessments, site master planning, and so on. 



\section{Approach to defining performance requirements for Eco-Industrial Parks}

\subsection{Framework for Eco-Industrial Parks}

The EIP framework describes the performance requirements for EIP centers according to four key categories: park management performance, environmental performance, social performance, and economic performance. Figure 3 presents the overarching framework. This framework provides the basis for defining and setting prerequisites and performance requirements for EIPs (see Section 4). As a baseline, EIPs must comply with all applicable local and national regulations. They must also meet the broader performance requirements set out within this framework. The performance requirements for EIPs are defined so that environmental and social impacts go beyond regulatory requirements.

Figure 3: Overall Framework for Describing Eco-Industrial Parks

Process of Continuous Improvement:

Going Beyond the EIP Performance Requirements

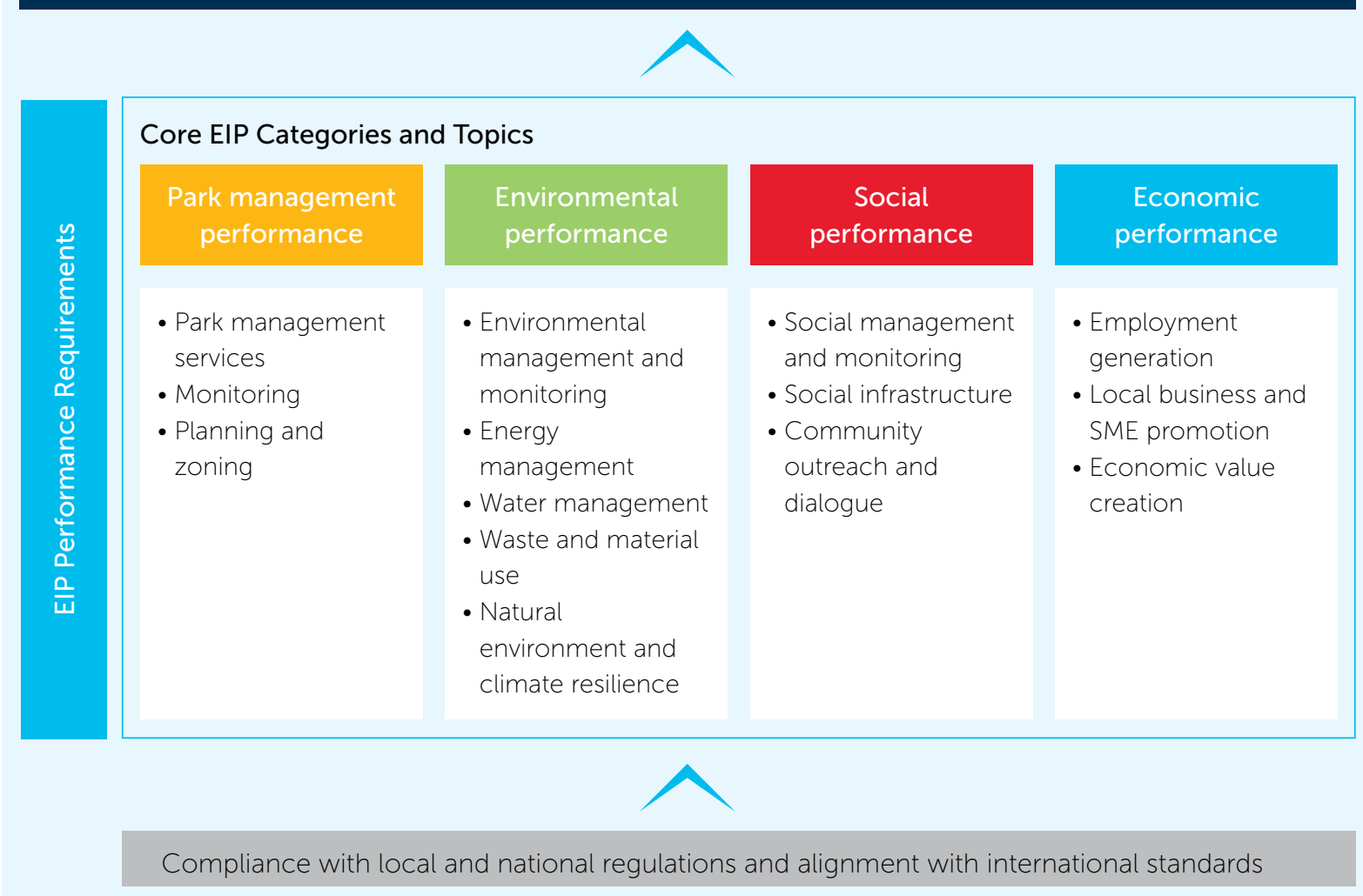


Regulatory compliance at the park and firm levels

Compliance with national and local regulations is an absolute requirement for all industrial parks, regardless of their specific geographic location and characteristics. An EIP, as a collective entity of residing firms, must comply with all applicable national and local laws, regulations, and standards. When applying this framework to a specific park, stakeholders (typically local authorities and, where relevant, the EIP management team and investors) will be required to check for, and ensure, regulatory compliance.

When national regulations fall short of expected international compliance requirements, EIPs would be expected to align with relevant common standards based on international obligations. It is recognized that the stringency of national and local regulations will differ from country to country and, in some cases, from sector to sector. Therefore, in countries where regulatory frameworks have not yet fully matured, compliance can also refer to fundamental international standards applicable to the park and its resident firms. Compliance with local/national regulations and the spirit of good international business practice applies to both the industrial park level (for example, the park management entity, property owners) and the firm level (for example, individual small-, medium-, and large-sized enterprises operating in the park).

\section{EIP performance requirements (compliance plus)}

The EIP framework provides performance prerequisites and performance requirements for EIPs. The international requirements regarding environmental, social, economic and park management performance have been primarily developed to inform EIP stakeholders about sustainable industrial development. The specified requirements in the framework are not a prescriptive or an absolute list. Given differences in the type, function, and regulatory setting of parks globally - and wide range of industrial sectors covered - sensitivity to local norms and standards will ultimately be required to make decisions about how to implement this EIP framework in a given context.

\section{Going beyond EIP performance requirements (see annex 1)}

Good industry practice for EIPs will recognize the importance of a continuous system and process of improvement at the park and firm levels - one that should seek to go beyond the requirements. Meeting the EIP requirements is a primary step in integrating sustainability criteria within industrial parks. Where technically, socially, and economically possible, EIPs must strive to go beyond the expectations set out within this publication. Industrial parks differ in context and stage of development ${ }^{1}$. This presents unique opportunities for an EIP to assume the lead in performance within a given area, such as environmental sustainability. Annex 1 of this framework highlights the opportunities that can be found by adhering to more ambitious criteria for industrial parks - going beyond the requirements, and ultimately leading to more inclusive and sustainable industrial production. 


\subsection{Defining performance requirements for Eco-Industrial Parks}

This section outlines the considerations necessary to develop performance requirements for EIPS.

Achieving a balance between meaningful and achievable EIP performance requirements is important for implementation in developing countries and transition economies. The requirements outlined in this framework aim to achieve a balance between developing a meaningful requirement level ${ }^{1}$, and not setting the requirements so high that parks with some successful and impactful initiatives do not qualify as EIPs. The requirements are classified by category, topics, and sub-topics. The relevance of (sub-) topics may depend on the geographical location and type of EIP. As such, sensitivity is required when applying these standards to an industrial park. However, all (sub-) topics are important and should be considered when determining whether a park can be considered an EIP.

The EIP framework requirements include both prerequisites and performance requirements. The prerequisites highlight the basic requirements for EIPS, and the performance requirements provide indicators about expected performance levels that an EIP must meet. These requirements should cover both qualitative and quantitative indicators. The approach helps in providing flexibility, and allows for different types of industrial parks to be assessed through these requirements.

In setting the topics necessary to constitute an Eco-Industrial Park, careful consideration was given to the following:

- Going beyond national compliance standards: The performance topics have been chosen for industrial parks that typically go beyond compliance with local and national regulations pertaining to environmental and social requirements ("compliance plus") in developing and transition economies.

- Addressing key environmental and social requirements: The framework aims to focus on key environmental, social, and economic impacts - rather than focusing on very detailed requirements, which may differ by industrial park. It also aims to achieve a balance of qualitative and quantitative indicators.

- Focus on impact areas that can be controlled or influenced by the park's management: The topics need to address a significant environmental, social, or economic impact or benefit, which can be influenced at the park and/or firm level. It needs to include indicators that can be monitored, managed or influenced by the park management entity or resident firms in the industrial park.

- Practicality of topics and feasibility of implementation: It is important to align with real-life practices and not necessarily with what is theoretically desirable. In some countries, it is already a challenging and complex process for firms to comply with local and national regulations. Data availability, measurability, and confidentiality are also all-important considerations. In addition, the indicators should not extensively burden the park management/operator entity or firms. Preferably, indicators would be easily monitored, measured, and reported. As such, they would leverage existing or available metrics and data, where possible.

- Globally applicable: Indicators should be relevant to both new ("greenfield") and existing ("brownfield") industrial parks. When a topic is so unique or limited to specific situations, then it is not included in this international framework. The indicators aim to be applicable to all countries.

- Align with competitive requirements: There are many measures that can assist park management and firms to be more competitive, and to have a better designed and managed industrial park. Such measures may include: increasing resource efficiency (and thereby reducing costs); encouraging collaborative business opportunities (for example, through supply, utility, by-product, and service synergies); reducing risks (for example, environmental and social risks or business risks); ensuring the long-term, license-tooperate and viability of the park; and collectively addressing government and community requirements. 



\section{Requirements for Eco-Industrial Parks}

\subsection{Introduction}

This section outlines the performance requirements for an industrial park to be classified as an EIP; it also details what would be globally expected from its performance. The requirements are based on the framework outlined in Section 3. The requirements focus on the key components and management of EIPs. Specifically, they focus on environmental, social and economic performance. As such, the framework flows from a common understanding of EIPs (Section 2) to a higher-level criteria and assessment approach (Section 3) to specific requirements within this Section.

When applying this framework to a current or prospective industrial development the following should be noted:

- The EIP framework and corresponding performance requirements provide a useful guideline toward the mainstreaming of EIPs. Additionally, it serves as a tool to build capacity and sound institutional frameworks. On an operational level, the EIP framework assists practitioners and park managers in assessing opportunities where further strengthening is required in line with international good practices.

- The EIP performance requirements set the baseline expectations of EIPs globally. Performance requirements are provided as international expectations. Sensitivity to local norms and standards is required in their application (for example, when setting thresholds for fuel and industry mix, energy intensity, waste disposal, as well as requirements of the higher-level governance structures, institutions, regulating bodies, and so on).

- The requirements within each category are divided into prerequisites and performance indicators. To be deemed an EIP, a park is expected to be compliant with all relevant prerequisites and performance expectations.

- Where currency values are specified, these should be converted to the local currency. Quantitative performance targets should be aligned against ambitious, but feasible national industry norms and standards.

- Compliance with applicable national and local regulations is a requirement for all industrial parks, whatever the geographical location and specific characteristics of the park.

- The performance requirements for EIPs in this framework aim to go beyond compliance with environmental and social regulations and requirements ("Compliance Plus").

- EIPs are encouraged to go beyond these requirements and performance expectations where it is technically, socially, and financially feasible and cost effective to do so.

\subsection{Compliance requirements with national and local regulations}

EIPs and resident firms need to comply with all applicable national and local laws, regulations, and standards. This includes, but is not limited to, compliance with: national employment regulations; discharge limits; national air emission limits; waste disposal techniques; waste transportation requirements; hazardous waste handling restrictions; and noise limits during operations. In this context, the park management should have a monitoring system in place to report on the performance of the firms (for instance, International Organization for Standardization [ISO] 19600, which is designed to provide guidance on establishing, developing, implementing, evaluating, maintaining, and improving a compliance management program). ${ }^{1}$

In applying these requirements to a specific park, stakeholders, particularly governments and competent authorities and park management/operator entities, will be required to ensure national and local compliance. EIPs should seek to align with relevant good international industry practice when national requirements fall short of international expectations. 
The following regulatory compliance topics are considered most relevant to EIPs based on the experiences of UNIDO, the World Bank Group, and GIZ in their Eco and Sustainable Industrial Park projects worldwide. They aim to inform stakeholders of the relevant regulatory considerations. The following listing is not an all-inclusive record because regulations vary by country, and their relevance to specific industrial parks will differ as well.

Park Management Compliance: The park management should instil a culture of high regulatory performance in its own functions and activities. In addition, it should promote and maintain a strong compliance culture across its resident businesses. A regulatory framework can ensure a clear separation between park management and a park regulatory entity. At a minimum, the park management should ensure compliance with:

- National regulations on Occupational Health and Safety (OHS) and emergency requirements (for example, protective clothing and equipment, safety features of machines and work posts, regular medical inspections, and preventative measures);

- National regulations on anti-corruption (for example, access to information, accountability, bribery, and conflict of interest);

- National regulations on violence and crime prevention (such as cybercrimes, theft, violence against women, and protection of children and the elderly):

- National regulations on land use planning, zoning and permitting;

- National regulations on intellectual property, trade and fiscal measures:

- National regulations on emergency awareness and preparedness (including disaster risk and management);

- National regulations on environmental and social aspects (as listed below); and

- Local by-laws related to national regulations.

Environmental Compliance: EIPs and associated businesses are expected to comply with all local and national environmental regulations. These include but are not limited to the following:

- National regulations on air emission limits (for example, sulfur oxides (SOX), nitrogen dioxide (NOx), particulate matter, greenhouse gases (GHG), and chemical odors)

- National regulations on water extraction, watershed management and water discharge limits;

- National regulations on waste disposal techniques (including contaminants, and treatment requirements) and waste transportation (including labelling, maximum volumes, storage, and recycling);

- National regulations on hazardous waste handling restrictions (including labelling, containment, and use of qualified contractors);

- National regulations on noise limits during operations (for example, maximum and ambient noise levels as measured in decibels);

- National regulations on energy and resource efficiency, as well as other regulations related to efficiency (for example, the "3Rs: reduce, reuse, and recycle");

- National regulations on soil and ground water contamination (including effluent/waste discharges):

- National regulations on protection of the natural environment and biodiversity (for example, sensitive marine environments, inland water bodies, native forests, and protective flora and fauna);

- National regulations related to climate change mitigation and adaptation; and

- Local by-laws related to the national regulations listed above.

Social Compliance: EIPs and the associated businesses are expected to comply with all local and national regulations. These include, but are not limited to the following:

- National regulations on human rights (for example, gender equality and women's and children's rights);

- National regulations on protection of indigenous people (including traditional, tribal and other landconnected peoples);

- National regulations on addressing discrimination (for example, discrimination based on color, race, religion, sex, age, and disability);

- National labor laws/regulations (including working hours, OHES, child labor, and maternity leave);

- Local by-laws related to the national regulations listed above. 
Economic Compliance: EIPs and the associated businesses are expected to comply with all local and national financial and economic regulations. These include but are not limited to the following:

- National regulations on the reporting of financial performance and disclosure;

- Regulations on employment creation and local skills development;

- Regulations on the promotion of SMEs and local business development;

- Regulations on technology transfer and protection of intellectual property;

- Regulations on skills development and vocational training; and

- Business regulations, including financial, trade and fiscal regulations.

EIPs also need to conform with international standards and protocols, as outlined in Box 1.

\section{Box 1: EIP Conformance with International Standards and Protocols}

When local and national requirements are not well developed, or where the impact of the park has an exceptionally important international transboundary impact, it is expected that an EIP would align with the spirit of applicable international standards, conventions, and protocols. These could include, among others, the following

\section{Environmental:}

- Stockholm Convention on Persistent Organic Pollutants;

- Basel Convention on the Control of Transboundary Movements of Hazardous Wastes;

- Vienna Convention for the Protection of the Ozone Layer;

- Emission Thresholds from the World Health Organisation;

- International Convention for the Prevention of Pollution from Ships;

- IFC Environmental, Health and Safety (EHS) Guidelines and Performance Standards;

- Montreal Protocol on Substances that Deplete the Ozone Layer;

- Economic Commission for Europe (ECE) Water Convention on the Protection and Use of Transboundary Water Courses and Internal Lakes;

- Ramsar Convention of Wetlands:

- Food and Agriculture Organization (FAO) International Code of Conduct on the Distribution and Use of Pesticides;

- World Health Organization (WHO) Recommended Classifications of Pesticides by Hazard Class la/lb; and

- Espoo Convention on Environmental Impact Assessment in the Transboundary Context.

Social:

- United Nations Guiding Principles for Business and Human Rights;

- The International Bill of Human Rights;

- International Covenant on Economic, Social and Cultural Rights;

- Declaration on Social Progress and Development;

- Freedom of Association and Protection of the Right to Organize Convention:

- Convention on the Rights of the Child;

- Declaration on Fundamental Principles and Rights at Work (International Labour Organization):

- International Labour Standards on Child labour (International Labour Organization):

- Standard Rules on the Equalization of Opportunities for Persons with Disabilities;

- Declaration on the Rights of Indigenous Peoples;

- International Convention on the Elimination of all Forms of Racial Discrimination:

- Convention on the Elimination of All Forms of Discrimination against Women; and

- International Convention on the Protection of the Rights of All Migrant Workers and Members of Their Families. 


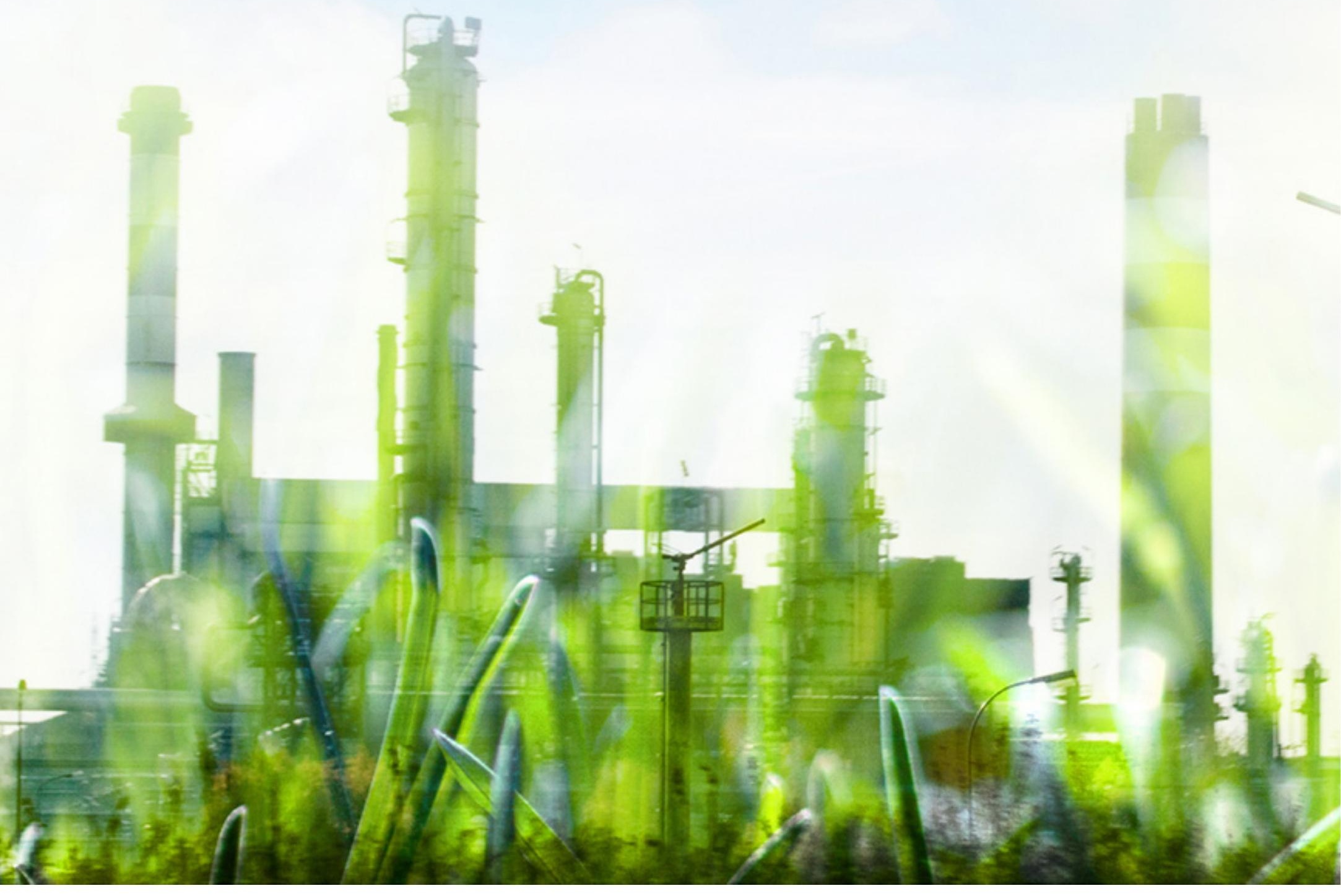




\subsection{Park management: Performance requirements}

\section{Introduction}

The management of an industrial park plays a pivotal role in the daily operations of the industrial park property, ensuring the continuous implementation of an EIP framework, and engaging with the park's stakeholders, including resident firms, communities, and regulating bodies. The overarching aim of the performance requirements for park management is to ensure there is a distinct and empowered park management unit. This unit then manages a range of issues required to develop and operate an industrial park in a sustainable manner, attract investments, and provide socially acceptable and attractive working conditions.

The park management needs to have the appropriate measures in place to manage risks and accidents at the park level, catalyze stakeholder dialogue, provide platforms for knowledge sharing, and operate and maintain park-level infrastructure. Furthermore, it is expected to formulate environmental- and social sustainability-related strategies in relation to the overall industrial park, including collaboration with regulators, resident firms and surrounding communities. It should also set targets at the industrial park level. In addition, the park management needs to be knowledgeable about resident firm operations (for instance, resource demands, labor requirements, waste and wastewater generation and management, administration, and so on).With this knowledge, it can appropriately guide the EIP strategy and adequately supply the required shared services.

Although park management is instrumental in driving sustainability, the scope of influence of the management entity should not be overestimated. Park management can influence industrial operations in the park, yet in most cases it does not have control over such operations. A park charter or code of conduct signed by all resident firms can assist in driving expected sustainable business practices across resident businesses. In addition, careful attention should be given to potential conflicts of interest with regard to the different roles and functions of the regulators, inspectors and the park management entity. Typically, these are not aggregated into one entity, and appropriate checks and balances should be ensured.

Having a formalized, well-functioning and economically sustainable park management structure can deliver a range of benefits, including the following:

- Having a single entity in charge of managing the industrial park property and act as the interface between resident firms, provide customer-oriented services, and engage with relevant stakeholders will result in efficiency gains;

- Ensuring a single entity drives the overall strategy for clean production and social standards within the park will help to meet national and international expectations in attracting local and international investments;

- Having an environmentally- and socially-orientated management team in place can assist in identifying synergies and opportunities for collaborative approaches among park firms, as well as in achieving mutual environmental and social goals and targets; and

- A dedicated entity is better able to disseminate knowledge and inform stakeholders about new technologies and successful interventions available to EIP firms.

Beyond regulatory compliance, there are some important considerations and performance requirements that the EIP park management entity must fulfill. Key considerations for ensuring a high performance and effective management structure in an EIP including the following: 
Park management services: The park management should have a dedicated functioning entity to manage infrastructure and provide a range of services. These include:

- An empowered park management entity is in place: A dedicated entity exists and acts as the park manager ${ }^{1}$. A park management entity is required for all industrial parks, including EIPs. The entity's role is to manage and maintain infrastructure and utilities, and organize and implement collective measures and services for resident firms and their employees. It will also manage risks, accidents and incidents at the park. In addition, it markets the park for new residents, preferably by firms with synergetic operations with existing residents.

- All resident firms have signed a residency contract with the park management entity: The park management entity needs to have a clear mandate, and be able to generate and/or secure sufficient financial resources to undertake its responsibilities and tasks. The residency contract should specify the responsibilities and tasks of the park management entity with respect to all park operations and services It should also outline the responsibilities and tasks of resident firms in detail, including provisions for payments and the collection of user fees.

- Park management facilitates continuous and uninterrupted provision of collective park infrastructure and utility services: EIPs provide integrated and collective infrastructure and utilities to avoid isolated, inefficient, and ineffective systems. The park management needs to ensure essential infrastructure is in place, along with appropriate risk, accident, and incident management at the park. It also needs to appropriately maintain the facilities and infrastructure in the industrial park, and ensure adequate financing for these services is secured through the collection of user fees.

- Engagement with the park's stakeholders and business representation: The park management within an EIP is expected to carry out periodic stakeholder consultations with relevant parties (for example, local citizens, governmental officials, workers and company representatives). It also promotes, supports, and facilitates knowledge sharing and collaboration between companies in the industrial park. Where appropriate, it explores and promotes opportunities for company-level resource efficiency and sharing of wider benefits. Park management and engagement should also involve the creation of a forum for tenants to cooperate and collaborate to identify common interests, synergies, and funding opportunities. The park management should also represent the interests and objectives of the park in handling local or regional disputes and in holding stakeholder meetings

Monitoring: Monitoring is an important mechanism to track progress against EIP environmental, social and economic performance targets in a transparent and accountable manner. Residency contracts of park firms should include provisions for sharing information with the park management entity regarding compliance declarations made to regulators and inspection bodies to comply with prevailing regulations. Of course, this should be done with due respect for issues of confidentiality and intellectual property rights.

In both brownfield and greenfield industrial parks, park firms should seek to reach a documented agreement regarding the implementation and enforcement of additional measures (compliance plus) related to EIP performance targets at the firm level and collectively - but without imposing disproportionate burdens on firms. Upon such agreement, the park management entity should undertake EIP performance monitoring on a regular basis. In some cases, the park management entity may also engage in enforcement of selected regulatory compliance issues. The entity would monitor compliance to the extent of the delegation powers given to it by park regulatory and other relevant inspection entities, including requisite financial resources for related monitoring and enforcement activities. If some statutory compliance monitoring and enforcement is delegated to a park management entity, regulators and relevant inspection bodies and the park management entity must ensure that processes and procedures will - transparently and objectively - eliminate any potential and/or real conflicts of interest. 
Planning and zoning: A thorough spatial planning and zoning process is a key component of an EIP, particularly for Greenfield EIPs and in the case of retrofitting existing ones. This includes the consideration of economic, environmental, and social aspects through multi-stakeholder processes with relevant stakeholders (for instance, government agencies, the private sector and the local community). As part of the planning and designing process of greenfield industrial parks, the location of the park needs to be carefully considered by relevant stakeholders. In addition, a comprehensive master plan needs to be developed that encompasses environmental and social considerations. In regards to climate change adaptation and disaster risk management, the design and planning can have significant implications for risks to firms in the EIP, as outlined in Box 2.

\section{Box 2: Climate Change Adaptation (CCA) and Disaster Risk Management in Eco-Industrial Parks}

Climate change is a growing threat to industrial development. Some industrial parks are located in vulnerable areas, which may pose long-term risks to their economic activities and generate negative effects for the operability of the industrial park. Impacts of a changing climate - particularly due to increasing temperatures, heat waves, droughts, excessive or reduced rainfall, flooding, and so on - are becoming a significant concern for vulnerable industrial parks. Indeed, climate change can lead to infrastructure damage, environmental degradation, risks to human health, and considerable economic losses. In some developing countries, there is an insufficient awareness about the necessity of adapting to climate change, as well as a lack of technical expertise in park management to provide climate-resilient measures in industrial areas.

Climate change requires anticipating local and international impacts, and acting to prevent or minimize any possible damage. Those EIPs that are vulnerable to climate change should seek to reduce environmental, social and economic damages caused by heat waves, droughts, heavy rainfall and cyclones, and floods. In this context, they should look to offer consequential adaptation measures for infrastructure and services. For example, this can be achieved through the integration of CCA measures into site selection, planning, implementation, and risk management within new parks, as well as in the retrofitting of existing industrial parks.

To successfully integrate climate change adaption measures, the park management should create awareness through capacity development and sensitization. This enables resident firms to analyze and prioritize their climate change-related risks, and develop suitable adaptation strategies - which could ultimately lead to investment in climate-resilient development of industrial areas. Adaptation measures and disaster preparedness for industrial parks and their companies could increase their resilience. Therefore, the costs of losses and damages, as well as negative socio-economic impacts, caused by extreme weather events can be reduced.

\section{Park Management: EIP Performance Requirements}

The park management requirements for EIPS are outlined in table 2, which details EIP prerequisites and performance indicators. These can help to set international EIP expectations, but may require adaptation to local norms and industry benchmarks. 
Table 2: Park Management: Performance Requirements for Eco-Industrial Parks

\section{EIP prerequisites for Park Management}

Topic

Park management services

Park property, common

infrastructure and services

Monitoring and risk management

\section{Description/Requirement}

A park management entity (or alternative agency, where applicable) exists to handle park planning, operations and management, and monitoring.

The park management entity provides and facilitates common services and infrastructure to resident firms to ensure smooth operations
Monitoring performance

The park management entity has establishes and maintains a system for monitoring achievement of threshold EIP performance targets and management of critical risk factors within the park.

The park management establishes measures to deal with climate change adaptation and disaster preparedness

Information on applicable regulations and standards
Park management has a good understanding of regulations and international standards applicable to industrial park compliance.

A master plan for the EIP should be developed by relevant authorities (for example by governments, land owners, and planning agencies); it should applicable for both planning and operations.

\section{Performance indicators for Park Management}

\begin{tabular}{l|l|l|l}
\hline \multirow{2}{*}{ Topic } & Sub-topic & Description/Requirement \\
Park management services & $\begin{array}{l}\text { Park management } \\
\text { empowerment }\end{array}$ & $\begin{array}{l}\text { Distinct park management entity is empowered to provide and charge fees for } \\
\text { common services through the use of a legally binding instrument. }\end{array}$ \\
\cline { 2 - 4 } & $\begin{array}{l}\text { Park management entity } \\
\text { property and common } \\
\text { infrastructure }\end{array}$ & $\begin{array}{l}\text { The park management entity provides and facilitates efficient common services } \\
\text { and infrastructure to resident firms. }\end{array}$ & \\
\hline $\begin{array}{l}\text { Monitoring and risk } \\
\text { management }\end{array}$ & $\begin{array}{l}\text { ElP performance and } \\
\text { critical risk management }\end{array}$ & $\begin{array}{l}\text { Park management entity regularly monitors and reports on EIP performance } \\
\text { targets and critical risks. }\end{array}$ & \\
\hline
\end{tabular}


Prerequisites/Evidence

A distinct park management entity (or alternative agency, where applicable) exits to handle park planning, operations and management, and monitoring

Park management entity to manage and maintain the industrial park property, common infrastructure, and services as prescribed in the tenant contract and the park's Master Plan. This should include, but is not limited to the following:

- Property management, including plot allotments, re-allotments, development, land use monitoring, and so on

- Utilities, roads, and technical units such as waste and wastewater treatment plants and operations, power and

energy systems.

- Waste collection areas and services.

- Maintenance and repair workshops.

- Security and emergency response services and facilities

- Common landscaping, buffer zones, street lighting, security surveillance and street cleaning

- Common employee and tenant facilities.

- Provide facilitating services to and between tenant firms (for example, networking, collaboration and training opportunities)

- Engagement with the park's stakeholders and business representatives.

Park management entity maintains an EIP framework monitoring system in place, tracking:

- Progress on environmental, social and economic performance at the park level.

- Critical risk factors and related responses, at least for:

o Risk points where the accidental release of poisonous solid, liquid and gaseous effluents, including during transportation and disposal when fire hazards are possible; and

o Applicable natural disaster risks (for example, earthquakes)

Where required, Park management has a plan in place to react to possible negative impacts due to climate change risks (heat waves and droughts, storms and floodwater events). All adaption needs for infrastructure and services are identified and in place for the industrial estate to protect against climate change risks and potential damages.

Park management entity has a functioning system in place to comply with local/national regulations and international standards applicable to the industrial park. Park management informs compliance by resident firms including compliance information that firms share with the park management entity.

A Master Plan (or equivalent planning document) for any new and existing industrial park has been developed and is reviewed periodically (and updated if required), including the following core elements:

- Site selection study based on various risk analyses; essential and efficient infrastructure, utilities, and transportation network; environmental and social issues; internal park land zoning; buffer zone around the park; procedure to safely locate high risk industries; and cluster synergistic industries.

- Integration into Master Plan of relevant requirements specified in this EIP framework that have spatial implications.$$
\text { implications. }
$$

\section{Performance indicator}

Proportion of firms in the industrial park to have signed a residency contract/park charter/code of conduct (depending on what is legally binding on park firms according to the existing legislation in the country ${ }^{1}$ ); and additional legally binding arrangements that empower the park management entity to perform its responsibilities and tasks and charge fees (sometimes absorbed in rental fees) for common services. This may include transparent fees for s services pertaining to the achievement of EIP performance targets.

The resident firms indicate satisfaction with regard to the provision of services and common infrastructure by the park management's entity (or alternative agency, where applicable).

Available

[Yes/No]

Available

[Yes/No]

Available

[Yes/No]

Park management entity regularly monitors and prepares consolidated reports regarding the achievement of target values as documented in this framework) to encompass the following:

- Environmental performance;

- Social performance;

- Economic performance; and

- Critical risk management at the level of the park.
Unit [Target value]

Percentage of firms [100\%]

Percentage of firms [75\%]

Frequency of reports

[Every 6 months]

1 In most developing countries, a park's charter orcode of conduct may not be a legally binding instrument. Therefore, it would not provide the park management entity with the necessary powers. 


\subsection{Environment: Performance requirements}

\section{Introduction}

If not managed well, industrial parks can potentially have a significant adverse impact on the environment. Avoiding, minimizing, and mitigating detrimental environmental impacts are essential if industrial parks are to be considered EIPs. The overarching aim of the environmental performance requirements is to ensure that EIPs meet performance expectations with respect to environmental management. Environmental performance encompasses both the management and mitigation of potential adverse environmental impacts. In addition, it entails the introduction of low/zero carbon energy generation and resource-efficient production processes.

Typically, key environmental themes in the context of Eco-Industrial Parks include pollution prevention, resource efficiency and clean production, industrial symbiosis and synergies, and water, waste and energy management.

Pollution prevention systems must be introduced to mitigate the toxic nature of any industrial production and operation. Indeed, pollution prevention is an important consideration for all eco-industrial parks. If technically possible, pollution should be avoided in the first place. When process emissions and by-products cannot be avoided, they should be mitigated at the source.

Resource Efficiency and Cleaner Production (RECP) refers to the integrated and continued application of preventive environmental practices and total productivity techniques. These practices and techniques are aimed at increasing the efficiency of industrial processes, products and services, while reducing risks to people and the environment (UNIDO and UNEP 2010). Cleaner production also includes the implementation of low carbon inputs (resources and energy) to avoid negative environmental externalities.

The concepts of industrial cooperation and synergies are attracting increasing interest as an approach to fostering greater environmental, social, and economic benefits. Industrial symbiosis entails the exchange of by-products, energy, and process wastes among closely situated firms. The keys to industrial symbiosis are collaboration and taking advantage of the synergistic possibilities offered by firms situated in geographic proximity to one another (Chertow 2000).

Waste, water and energy management are key factors in working toward the development of a circular economy at the industrial park level. Circularity involves utilizing water resources as efficiently as possible. It could also entail adding large waste streams into material exchanges to make industrial parks greener. Combining energy and heat networks enables the exchange of waste energy and heat, thereby providing potentially lower-cost energy to resident firms. Circularity can also help enterprises to minimize operational expenses by designing or reducing the quantity of waste and effluents to be treated and discharged. In addition, renewable energy and energy efficiency measures can help to displace the use of fossil fuels across key park infrastructure and tenant businesses.

The strategic tackling of environmental considerations within EIPs can deliver a range of benefits including:

- Ensuring EIPs avoid or minimize any adverse impact on climate change, human health, and the natural environment. Promoting the sustainable use of resources within EIP physical boundaries and surrounding areas;

- Assisting industrial parks to reduce costs, increase competitiveness, and enhance investor attractiveness; and

- Enabling EIPs to show environmental leadership with a view to promoting and improving environmental performance in their respective sectors, countries, and neighboring nations.

Beyond regulatory compliance, there are a number of important environmental considerations and requirements that an EIP must fulfill. Important considerations for increasing environmental performance are summarized as follows: 
Management and monitoring: An EIP needs to have dedicated personnel within the park management entity for operating both environmental management systems (EMS) and energy management systems (EnMS). These systems should be in line with internationally certified standards. In addition, they should be capable of monitoring park performance, and supporting resident firms in the maintenance of their own firm level management systems. Where appropriate, firm level data should be aggregated and reported confidentially at the park level.

Energy: An EIP supports resident firms in actively identifying and implementing opportunities to improve the efficiency of industrial processes and buildings. It ensures a high level of energy efficiency in all shared and common services under the control of the park management entity. Where technically possible and cost effective, EIPs must seek to displace fossil fuels through the integration of low-zero carbon/renewable energy generation across key park infrastructure - and promote its implementation to resident businesses. ElPs should also take stock of their carbon footprint (greenhouse gas emissions). In addition, reduction targets should be annually set and monitored for achievement. The park management also needs to have in place a strategy to avoid or minimize GHG emissions though extended energy efficiency measures, industrial symbiosis, as well as the utilization of renewable energy sources.

Water: An EIP should ensure sustainable water use, efficiency and treatment. EIPs are expected to responsibly source water, taking into account local water scarcity issues and sensitive water reservoirs. An EIP should also plan to increase water efficiency for resident firms and the park as a whole. Wastewater must be appropriately treated, and water circularity promoted.

Waste and material use: An EIP needs to have a Waste Management Plan to ensure effective waste management, and reduction and reuse activities at the park and firm levels. These should cover the different types of waste resulting from construction through departure from the park. The park management entity monitors and accounts for all waste disposal and ensures environmentally sound disposal. All hazardous and toxic materials need to be appropriately stored and disposed of, which can be facilitated through a recording and monitoring system for hazardous waste.

Climate change and the natural environment: The park management entity needs to be aware of the main environmental impacts, and undertake appropriate actions to mitigate any potential risks. Climate change requires anticipating local and international effects of climate impacts, and preventing or minimizing any potential damage. In this context, the EIP should seek to mitigate GHG gases, as well as air and point-source pollution.

\section{EIP Environmental Performance Requirements}

The environmental performance requirements for EIPs are outlined in table 3 in the form of EIP prerequisites and performance indicators. These can help to set international EIP expectations, but may require adaptation to local norms and industry benchmarks. 
Table 3: Environment: Performance requirements for Eco-Industrial Parks

\begin{tabular}{|c|c|c|}
\hline \multicolumn{3}{|l|}{ EIP prerequisites } \\
\hline Topic & Sub-topic & Description/Requirement \\
\hline $\begin{array}{l}\text { Management and } \\
\text { monitoring }\end{array}$ & $\begin{array}{l}\text { Environmental/Energy } \\
\text { Management Systems (EMS } \\
\text { and EnMS, respectively) }\end{array}$ & $\begin{array}{l}\text { The park has an appropriate, functioning EMS and EnEMS systems (for example, } \\
\text { ISO } 14001 \text { Environmental Management Standard and ISO } 50001 \text { Energy } \\
\text { Management Standard) in place to set and achieve targets, and covering } \\
\text { key issues (for example, energy waste and material use; water; point-source } \\
\text { emissions; and the natural environment). }\end{array}$ \\
\hline \multirow[b]{2}{*}{ Energy } & Energy efficiency & $\begin{array}{l}\text { Energy efficiency strategies are in place for the park management infrastructure } \\
\text { and major energy-consuming resident firms. }\end{array}$ \\
\hline & $\begin{array}{l}\text { Exchange of waste heat } \\
\text { energy }\end{array}$ & $\begin{array}{l}\text { A program/mechanism is in place to identify opportunities for common energy } \\
\text { and heat exchange networks to be established, including support programs to } \\
\text { assist resident firms with implementation. }\end{array}$ \\
\hline Water & $\begin{array}{l}\text { Water efficiency, reuse and } \\
\text { recycling }\end{array}$ & $\begin{array}{l}\text { Water-saving and re-use plans are important to reducing total water } \\
\text { consumption. The park and businesses should have systems in place to increase } \\
\text { water savings and reuse. }\end{array}$ \\
\hline \multirow{2}{*}{$\begin{array}{l}\text { Climate change and the } \\
\text { natural environment }\end{array}$} & $\begin{array}{l}\text { Air, GHG emissions and } \\
\text { pollution prevention }\end{array}$ & $\begin{array}{l}\text { The park seeks to limit and mitigate all point-source pollution and GHG } \\
\text { emissions, including air, waterway, and ground pollution. A set of measures } \\
\text { at the park level is introduced (for instance, low-carbon technologies, energy } \\
\text { efficiency measures, waste heat) to reduce GHG emissions. }\end{array}$ \\
\hline & $\begin{array}{l}\text { Environmental assessment } \\
\text { and ecosystem services }\end{array}$ & $\begin{array}{l}\text { Protection of the sensitive natural environment is key to environmental and } \\
\text { community well-being. The industrial park demonstrates an understanding } \\
\text { of the potential impact of park activities on priority ecosystem services in and } \\
\text { around the vicinity of the park. }\end{array}$ \\
\hline
\end{tabular}


- Park management entity operates an environmental/energy management system in line with internationally certified standards, monitoring park performance and supporting resident firms in the maintenance of their own firm-level management systems.

Available

[Yes/No]

- Supporting programs and documents are in place to improve the energy efficiency of resident firms, especially for the top 50 percent of major energy-consuming businesses in the park.

- An industrial heat recovery strategy is in place to investigate opportunities for heat and energy recovery for the major energy-consuming firms in the park. (Typically, these are firms that individually consume at least 10-20 percent of total firm level energy consumption).

- Park management entity has demonstrable plans and (preferably) prior documented evidence to increase water reuse in the short and medium term. This would be achieved by either reuse of industrial effluents, or by rainwater/storm water collection.

- A program is established to monitor, mitigate and/or minimize GHG emissions, such as carbon dioxide $\left(\mathrm{CO}_{2}\right)$, methane $\left(\mathrm{CH}_{4}\right)$, nitrogen oxide $(\mathrm{NOx})$, and so on. There is clear evidence of steps taken to introduce mitigation activities.

The park management entity has a plan in place to assess operational environmental impacts, and aims to

Available limit the impact on prioritized local ecosystem services.

Available [Yes/No] 
Table 3: Environment: Performance requirements for Eco-Industrial Parks

\begin{tabular}{|c|c|c|}
\hline \multicolumn{3}{|l|}{ Performance indicators } \\
\hline Topic & Sub-topic & Description/Requirement \\
\hline $\begin{array}{l}\text { Management and } \\
\text { monitoring }\end{array}$ & $\begin{array}{l}\text { Environmental/Energy } \\
\text { Management Systems (EMS } \\
\text { and EnMS, respectively) }\end{array}$ & $\begin{array}{l}\text { Firms have functioning and fit-for-purpose EMS/EnMS systems. Summary } \\
\text { information from these management systems is provided to park management, } \\
\text { who will aggregate and report on data at the park level. }\end{array}$ \\
\hline \multirow{3}{*}{ Energy } & Energy consumption & $\begin{array}{l}\text { The industrial park has adequate metering and monitoring systems in place to } \\
\text { measure energy consumption at both the park and firm levels. }\end{array}$ \\
\hline & $\begin{array}{l}\text { Renewable and clean } \\
\text { energy }\end{array}$ & $\begin{array}{l}\text { The industrial park leverages available renewable generation sources, with plans } \\
\text { to increase contribution for shared services (for example, solar street lamps, } \\
\text { biomass, hydro, natural gas, and so on). }\end{array}$ \\
\hline & Energy efficiency & $\begin{array}{l}\text { Energy efficiency opportunities should be actively identified at the park and firm } \\
\text { levels to reduce energy use and associated greenhouse gas emissions. EIPs } \\
\text { should identify and promote technological and process-related interventions in } \\
\text { their own and resident business operations. }\end{array}$ \\
\hline \multirow{3}{*}{ Water } & Water consumption & $\begin{array}{l}\text { A mechanism is in place to appropriately monitor water consumption across the } \\
\text { park, and ensure demand management practices are in place in case of water } \\
\text { stress. Extraction from water sources (such as rivers, and groundwater sources) } \\
\text { occurs at sustainable levels. }\end{array}$ \\
\hline & Water treatment & $\begin{array}{l}\text { The industrial park has provisions in place to appropriately treat, recycle and } \\
\text { reuse treated wastewater. No effluents significantly impact potable water } \\
\text { resources and the health of local communities or nearby ecosystems }\end{array}$ \\
\hline & $\begin{array}{l}\text { Water efficiency, reuse and } \\
\text { recycling }\end{array}$ & $\begin{array}{l}\text { The park and businesses have systems in place to increase water savings and } \\
\text { reuse. }\end{array}$ \\
\hline \multirow{3}{*}{ Waste and material use } & $\begin{array}{l}\text { Waste/by-products re-use } \\
\text { and recycling }\end{array}$ & $\begin{array}{l}\text { A program/mechanism is in place to promote and encourage reuse and } \\
\text { recycling of materials by firms in the park (for example, raw materials for process } \\
\text { and non-process applications) }\end{array}$ \\
\hline & $\begin{array}{l}\text { Dangerous and toxic } \\
\text { materials }\end{array}$ & $\begin{array}{l}\text { Program/mechanism in place with clear targets to reduce and avoid the use of } \\
\text { dangerous and hazardous materials by firms in the park. }\end{array}$ \\
\hline & Waste disposal & $\begin{array}{l}\text { A functioning waste collection, treatment and disposal system is in place } \\
\text { to ensure that unused waste materials are treated and disposed of in proper } \\
\text { landfills. }\end{array}$ \\
\hline \multirow[b]{2}{*}{$\begin{array}{l}\text { Climate change and the } \\
\text { natural environment }\end{array}$} & Flora and fauna & $\begin{array}{l}\text { Native flora and fauna are important to maintain the proportion of natural areas. } \\
\text { They are integrated within the industrial park and natural ecosystem where } \\
\text { possible. }\end{array}$ \\
\hline & $\begin{array}{l}\text { Air, GHG emissions and } \\
\text { pollution prevention }\end{array}$ & $\begin{array}{l}\text { A mechanism is in place to avoid, minimize, and/or mitigate significant point- } \\
\text { source pollution and } \mathrm{GHG} \text { emissions. This should cover gases }\left(\mathrm{CO}_{2} \text {, methane }\right. \\
\left(\mathrm{CH}_{4}\right) \text {, nitrous oxide }\left[\mathrm{N}_{2} \mathrm{O}\right] \text {, Chlorofluorocarbons }[\mathrm{CFCS}] \text {, and hydrofluorocarbons } \\
{[\mathrm{HFCs}] \text { ), local particulate and air pollution emissions (for example, sulfur oxides }} \\
{[\mathrm{SO}] \text {, nitrogen dioxide }\{\mathrm{NOx}) \text {, as well as chemicals and pesticides use and }} \\
\text { management. }\end{array}$ \\
\hline
\end{tabular}


- Proportion of resident firms, with more than 250 employees, which have an environmental/energy management system in place that is in line with internationally certified standards.

Percentage of firms [40\%]

- Proportion of combined park facilities and firm-level energy consumption, for which metering and monitoring systems are in place.

- Total renewable energy use in the industrial park is equal to or greater than the annual national average energy mix.

- Park management entity sets and works toward ambitious (beyond industry norms) maximum carbon intensity targets (maximum kilograms of carbon dioxide equivalent $\left(\mathrm{kg} \mathrm{CO}_{2} \mathrm{e}\right) /$ kilowatt hour ( $\mathrm{kWh}$ ) for the park and its residents. Targets should be established for the short, medium, and long term.

- Park management entity sets and works toward ambitious maximum energy intensity targets per production unit (kWh/\$ turnover) for the park and its residents. Targets should be established for the short, medium, and long term.

- Total water demand from firms in industrial park which do not have significant negative impacts on local water sources or local communities.

- Proportion of industrial wastewater generated by industrial park and resident firms, which is treated to appropriate environmental standards.

- Proportion of total industrial wastewater from firms in the park are reused responsibly within or outside the industrial park.

- Proportion of solid waste generated by firms, which is reused by other firms, neighboring communities, or municipalities.

- Proportion of firms in park, which appropriately handle, store, transport and dispose of toxic and hazardous materials.

- Maximum proportion of wastes generated by firms in the industrial park which go to landfills.

- Minimum proportion of open space in the park used for native flora and fauna

- Proportion of firms in park which have pollution prevention and emission reduction strategies to reduce the intensity and mass flow of pollution/emission release beyond national regulations.

- Proportion of largest polluters in industrial park which have a risk management framework in place that: (a) identifies the aspects which have an impact on the environment and; (b) assign a level of significance to each environmental aspect.
Percentage of combined park \& firm level energy consumption [90\%]

Percentage of renewable energy use in park relative

to national average \% $[\geq]$

$\mathrm{kg} \mathrm{CO}$ e/ $\mathrm{kWh}$ [in line with local norms and industry sector benchmarks]

$\mathrm{kWh} / \$$ turnover

[in line with local norms and industry sector benchmarks]

Percentage of water demand [100\%]

Percentage of waste water treated/total waste water [95\%]

Percentage of water reused/total water consumed [50\%]

Percentage of solid waste reused/total waste [20\%]

Percentage of firms [100\%]

Percentage of waste to landfill [<50\%]

Percentage of open space [5\%]

Percentage of firms [50\%]

Percentage of largest emitters [30\%] 


\subsection{Social performance requirements}

\section{Introduction}

Eco-Industrial Parks should ensure implementation of good social management practices, including decent work, social and community infrastructure, and maintaining good relationships with the local community. The overarching aim of social performance requirements is to adopt good international practice across the park and resident firms. The social performance of the EIP is an indicator of its inclusiveness, local employee/ community welfare, and equal opportunities.

Historically, industrial parks have been faced with a number of social challenges, including labor conditions, child labor, migrant workers, land rights (such as land grabbing), community cohesion, and associated compensation mechanisms - including employment contracts, and adequate employee facilities (for example, restrooms, cafeterias, child care provision, and medical facilities). The severity of these issues differs by country, the nature of the industrial activity, as well as the stringency and enforcement of local regulations. For example, often consumer goods-related economic activity, such as garment manufacturing, receives greater supply chain pressures on labor conditions than heavy manufacturing activities, such as steel mills, basic chemicals production and food processing, which typically receive less consumer scrutiny.

The park management must ensure that the EIP appropriately reflects good international practice with regard to social management practices across its resident firms and activities. In addition, it should seek to comply with all client and investor requests. Finally, it should apply social safeguards to both its upstream and downstream value chains.

Meeting these social performance requirements can deliver a wide range of benefits, including:

- Ensuring the EIP minimizes any adverse social impact on its work force and local community;

- Better integration of social conditions for workers and community will contribute to a more resilient and efficient industrial park; and

- Integrating a proactive approach to tackling social risks can enhance reputation and relations with the community, investors and customers.

Apart from national regulatory compliance, there are a number of important considerations and social requirements that an EIP must fulfill. Important considerations for improving the social performance in an EIP include:

Social management systems: Customized and fit-for-purpose management systems are required at the park and firm levels to address relevant social, Occupational Health and Safety (OHES) and grievance procedures and impacts. This should be based on a continuous improvement process approach. The improvement of working and labor conditions for workers in the industrial parks is also an important concern to address as part of the OHES management system. Working hours, working conditions, compensation, and rest days must be, at a minimum, in line with national and sectoral norms.

Social infrastructure: Essential social infrastructure should be provided in industrial parks or its surroundings for its workers and local community to function properly. This infrastructure could include local shops, restaurants/ cafeterias, recreation areas, medical facilities, banks, postal offices, and emergency fire facilities.

- Gender equality is a fundamental human right. While the world has achieved progress towards gender equality and women's empowerment, women continue to suffer discrimination and violence in every part of the world. Gender issues need to be addressed by creating equal employment and capacitybuilding opportunities, as well as social infrastructure and safe working conditions responding to the specific needs of women.

- Security and crime in industrial parks are often issues of concern, particularly in developing and transition countries. A security concept is crucial for both the personal security of the employees and the security of the firms in the park. 
- Human resource development, vocational training and capacity building should be offered ensure the continued supply of a skilled labor force that can respond to new market developments.

Local community dialogue and outreach: International experience shows that the engagement of firms in community activities can lead to significant positive contributions. Likewise, it can strengthen the trust and relationships between industries and local communities.

\section{EIP Social Performance Requirements}

The social performance requirements for EIPs are outlined in table 4 in the form of EIP prerequisites and performance indicators. These can help to set international EIP expectations, but may require adaptation to local norms and industry benchmarks.

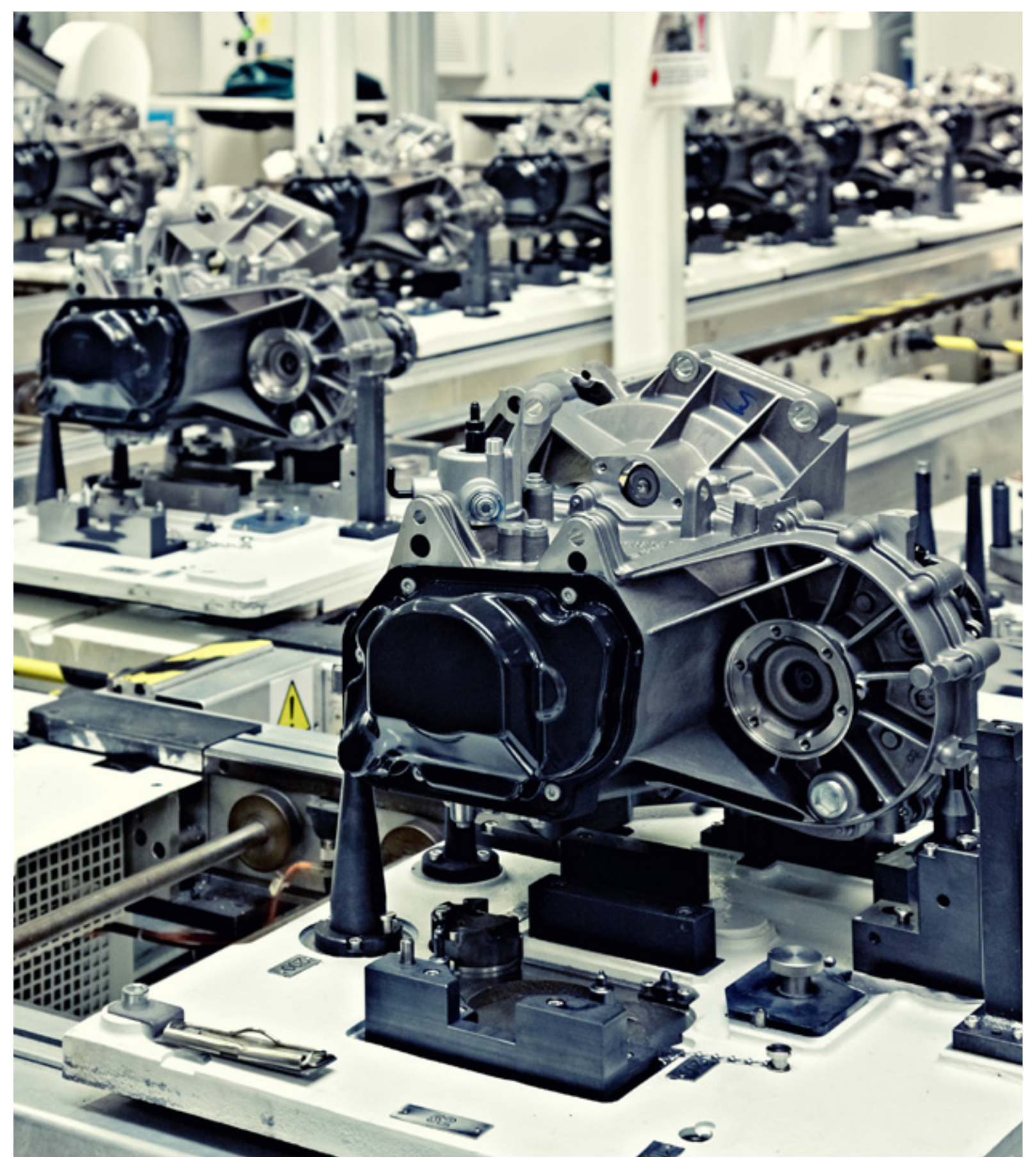


Table 4: Social: Performance Requirements for Eco-Industrial Parks

\section{EIP prerequisites}

\begin{tabular}{l|l|l|l} 
Topic & Sub-topic & $\begin{array}{l}\text { Description/Requirement } \\
\text { systems }\end{array}$ & Management team \\
\hline Social infrastructure & $\begin{array}{l}\text { Functioning system(s) are in place for ensuring social infrastructure provisioning, } \\
\text { operations and performance, as well as collecting, monitoring, and managing } \\
\text { key social information and impacts relevant to the industrial park. }\end{array}$ \\
\hline Primary social & $\begin{array}{l}\text { Provision of fundamental social infrastructure in the industrial park or its } \\
\text { proximity also facilitate and encourage women's employment, for example, } \\
\text { lavatories and public toilets (for men and women), drinking water fountains, } \\
\text { provision of cafeterias within reach of the employees, recreational areas, } \\
\text { and childcare programs. This infrastructure needs to be fully operational to } \\
\text { encourage women's employment. }\end{array}$ \\
\hline
\end{tabular}

\section{Performance indicators}

\begin{tabular}{|c|c|c|}
\hline Topic & Sub-topic & Description/Requirement \\
\hline \multirow{3}{*}{$\begin{array}{l}\text { Social management } \\
\text { systems }\end{array}$} & $\begin{array}{l}\text { OH\&S management } \\
\text { system }\end{array}$ & $\begin{array}{l}\text { Firms in the industrial park should have an OH\&S management system in place } \\
\text { (based on ISO } 18001 \text { standard), keep records about rates of injury, occupational } \\
\text { diseases, absenteeism, as well as total numbers of work-related fatalities. }\end{array}$ \\
\hline & Grievance management & $\begin{array}{l}\text { A grievance mechanism should be in place and accessible to receive and } \\
\text { address grievances from within the industrial park, as well as outside the park } \\
\text { from external stakeholders. Examples include help desks, complaint boxes, and } \\
\text { hotlines (phone booths) located inside and outside of the industrial park. }\end{array}$ \\
\hline & Harassment response & $\begin{array}{l}\text { A harassment prevention and response system with clear complaint and } \\
\text { response procedures should be in place. }\end{array}$ \\
\hline \multirow{3}{*}{ Social infrastructure } & $\begin{array}{l}\text { Primary social } \\
\text { infrastructure }\end{array}$ & $\begin{array}{l}\text { Social infrastructure should meet the norms and requirements of the workforce } \\
\text { and client expectations. }\end{array}$ \\
\hline & Industrial park security & $\begin{array}{l}\text { The industrial park has security systems and services that are fully operational } \\
\text { and fit-for-purpose operation. Examples include, among others: appropriate } \\
\text { lighting systems in and around the park, closed circuit television (CCTV) } \\
\text { systems, a centralized security office, and night transportation provisioning. }\end{array}$ \\
\hline & Capacity building & $\begin{array}{l}\text { Programs for skills training and development by employee category are in place, } \\
\text { with a particular emphasis on equal opportunity. Examples include training } \\
\text { and skills development programs, and women entrepreneurship development } \\
\text { programs. }\end{array}$ \\
\hline \multirow[b]{2}{*}{ Local community outreach } & Community dialogue & $\begin{array}{l}\text { Provision of established accessible communication platforms or other means } \\
\text { to maintain regular dialogue with the community and relevant civil society } \\
\text { organizations. Examples include news bulletins, regular media releases, and } \\
\text { information display boards. }\end{array}$ \\
\hline & Community outreach & $\begin{array}{l}\text { The park management entity and resident firms engage in community outreach } \\
\text { activities and maintain documentation. These activities could include: an } \\
\text { annual day with celebrations inside the park; clean-up drives or public service } \\
\text { activities that are organized in the community areas by the park management; } \\
\text { infrastructure for community areas (for instance, drinking water supply, } \\
\text { sanitation). }\end{array}$ \\
\hline
\end{tabular}




\begin{tabular}{|c|c|}
\hline Prerequisites/Evidence & Checklist \\
\hline $\begin{array}{l}\text { - Dedicated personnel exist (as part of the park management entity) to plan and manage social quality } \\
\text { standards. }\end{array}$ & $\begin{array}{l}\text { Available } \\
\text { [Yes/No] }\end{array}$ \\
\hline $\begin{array}{l}\text { - Essential primary social infrastructure has been adequately provided in the site master plan, and is fully } \\
\text { operational in the park. }\end{array}$ & $\begin{array}{l}\text { Available } \\
\text { [Yes/No] }\end{array}$ \\
\hline
\end{tabular}

\section{Performance indicator}

- Percentage of all firms in the industrial park with more than 250 employees that have a well-functioning OH\&S management system in place.

Unit [Target value]

- Percentage of grievances received by the park management entity which are addressed within 90 days.

- Percentage of grievances received by the park management entity, which were brought to conclusion.

- Percentage of all firms in the industrial park with more than 250 employees that have a code of conduct system in place to deal with grievances.

- Percentage of all firms in the industrial park with more than 250 employees that have a harassment prevention and response system in place.

- Percentage of the surveyed employees' reporting satisfaction with social infrastructure.

Percentage of firms [75\%]

Percentage of grievances [100\%]

Percentage of grievances $(60 \%)$

Percentage of firms [75\%]

Percentage of firms [75\%]

mploye reporting satisfaction with social infrastructure.

- Percentage of reported security and safety issues that are adequately addressed within 30 days.

Percentage of surveyed employees [80\%]

Percentage of reported security and safety issues $[100 \%]$

- Percentage of all firms in the industrial park with more than 250 employees with a program for skills/ vocational training and development.

Percentage of firms [75\%]

- Percentage of female workforce who benefit from available supporting infrastructure/programs for skills development.

Percentage of female workforce $[\geq 20 \%]$

- Over 80 percent of the surveyed community members are satisfied with the community dialogue.

Percentage of surveyed community members [80\%]

- Number of outreach activities implemented by the park management entity annually that are regarded as positive by over 80 percent of the surveyed community members.

Number of outreach activities per year [2] 


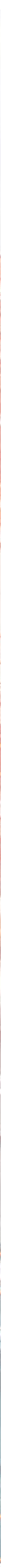




\subsection{Economic performance requirements}

\section{Introduction}

Industrial parks are an important vehicle used by governments to boost their manufacturing sector and to add value to the economy. In the planning phase, the proposed park infrastructure needs to be designed to respond to market demand. It should seek to attract investors and businesses interested in establishing operations within the park. In addition, strategic EIP interventions can improve park and firm level competitiveness when they are included in the EIP design and operational procedures. Interventions should be designed with a view to keeping up with changing markets that require continual economic transformation.

EIPs offer important synergies between resource and energy efficiency processes, and socially compliant practices. As such, EIPs can provide economic gains and competitive advantages. For example, international good practice demonstrates that cleaner production and the implementation of energy efficiency interventions with low capital costs, minimal operational disruption, and strong payback periods can offer important economic gains. EIPs can also offer important employment generation opportunities, industrial added value, and linkages with local businesses. The industrial parks may use green incentive structures to attract high-quality investors, thereby making it easier to comply with EIP targets during operations.

Adhering to these economic performance requirements can deliver a wide range of benefits, including:

- Meeting the government's targets regarding investments, revenues and employment;

- Attracting local, national and international financing and investments;

- Increasing demand from prospective businesses and high retention rates for current businesses; and

- Improving political licenses and social licenses to operate and expand operations.

Apart from national regulatory compliance, there are a number of important considerations and economic requirements that an EIP must fulfill. Important economic considerations for EIP are as follows:

Employment generation: Industrial parks can drive significant employment generation. However, employment should be managed and driven in a sustainable manner to ensure: economic linkages are maximized; employees and surrounding communities duly benefit; and diversity and inclusiveness of employment are maintained. An EIP should seek to maximize local revenue linkages, employee growth potential, and community satisfaction. This can be done through local employment targets, providing employee skill development opportunities, and longer-term employment security through the provision of long-term or permanent contracts.

Local businesses, SME promotion and linkages: SMEs are the backbone of the economy and employment in many countries. An EIP provides opportunities for the establishment of SMEs in parks that can, in turn, provide services and add value to other (larger) industries operating in the park. EIPs can also provide strong economic development benefits through the promotion of linkages with local businesses as suppliers to the industrial park and its resident firms.

Economic value creation: International experience demonstrates that some industrial parks are planned or designed without a good understanding of the types and levels of market demand for its services, or for green infrastructure. For example, integrating cost-effective, energy-efficient technologies and management processes can provide competitive advantages. "Investment-ready" industrial parks are more attractive as these parks present lower risks and investment costs to firms (for example, through the existence and provision of essential infrastructure, utilities, and services).

\section{EIP Economic Performance Requirements}

The economic performance requirements for EIPs are outlined in table 5 in the form of EIP prerequisites and performance indicators. These can help to set international EIP expectations, but may require adaptation to local norms and industry benchmarks. 
Table 5: Economic: Performance Requirements for Eco-Industrial Parks

\begin{tabular}{|c|c|c|}
\hline EIP prerequisites & & \\
\hline Topic & Sub-topic & Description/Requirement \\
\hline Employment generation & Type of employment & $\begin{array}{l}\text { An EIP has employment generation plans in place to provide opportunities for } \\
\text { long-term employment. }\end{array}$ \\
\hline $\begin{array}{l}\text { Local business and SME } \\
\text { promotion }\end{array}$ & SME development & $\begin{array}{l}\text { An EIP provides opportunities for local, regional, and national SMEs, enabling } \\
\text { them to benefit from EIP activities. }\end{array}$ \\
\hline & $\begin{array}{l}\text { Market demand for EIP } \\
\text { services and infrastructure }\end{array}$ & $\begin{array}{l}\text { The development of an EIP, including green infrastructure and services, must be } \\
\text { based on realistic market and industry demands to ensure economic feasibility. }\end{array}$ \\
\hline Economic value creation & $\begin{array}{l}\text { EIP meets economic } \\
\text { interests of the } \\
\text { government }\end{array}$ & $\begin{array}{l}\text { The site is economically efficient in terms of achieving government targets, } \\
\text { including investment, foreign direct investment, and tax revenue targets. }\end{array}$ \\
\hline
\end{tabular}

\begin{tabular}{l|l|l|l}
$\begin{array}{l}\text { Performance indicators } \\
\text { Topic }\end{array}$ & $\begin{array}{l}\text { Sub-topic } \\
\text { Local employment } \\
\text { generation }\end{array}$ & $\begin{array}{l}\text { Description/Requirement } \\
\text { An EIP must generate local employment opportunities in the areas in which it } \\
\text { operates to ensure revenue linkages and development opportunities. }\end{array}$ \\
\cline { 2 - 4 } $\begin{array}{l}\text { Local business and SME } \\
\text { promotion }\end{array}$ & Type of employment & The EIP provides longer term employment contracts to employees. \\
\hline Economic value creation & $\begin{array}{l}\text { Investment-ready park for } \\
\text { firms }\end{array}$ & $\begin{array}{l}\text { An EIP must look to local suppliers when appropriate and cost-effective to do } \\
\text { so. EIPs provide local businesses with the opportunity to grow. } \\
\text { economic risks and better investment opportunities to firms. Essential } \\
\text { infrastructure services should be offered by the industrial park, including access } \\
\text { to water, energy, roads, service corridors, and so. }\end{array}$ & \multicolumn{2}{|l}{} \\
\hline
\end{tabular}




\section{Prerequisites/Evidence}

- Park management entity has plans to generate specific numbers and types of jobs (including diversity and inclusiveness) in line with government targets.

- Park management entity allows and promotes the establishment of SMEs that provide services and add value to park residents.

- A market demand and feasibility study, supported by a business plan, for specific "green" infrastructure and service offerings has been undertaken to justify planning and implementation in the industrial park.

- Tracked by the park management entity, the industrial park fulfils relevant government targets, including domestic, foreign direct investment, and tax revenues.

- Percentage of total workers employed in industrial park who live within daily commuting distance.

- Percentage of total firm workers in industrial park employed through direct employment (that is, not employed on a fee-for-output basis or provided through a labor supply firm) and permanent contracts.

- Percentage of resident firms using local suppliers or service providers for at least 80 percent of their total procurement value.

Percentage of employees [60\%]

Percentage of total procurement value of park management entity supplied by local firms or service providers.

Percentage of employees [25\%]

Percentage of firms [25\%]

Percentage of total procurement value of park management entity [90\%]

- The ratio of rented or used space by resident firms compared to the total amount of available space earmarked for resident firms within IPS.

Average percent occupancy rate over 5 years [50\%] 



\section{$5 \quad$ Concluding remarks and future prospects}

The concept and practice of Eco-Industrial Parks offers an important and integrated approach to drive and scale up efforts by the private and public sectors for inclusive and sustainable industrial development.

This publication has highlighted many ways in which industrial parks and their stakeholders can leverage the performance requirements for EIPS - from creating a common understanding of EIPs, to determining the baseline performance of EIPs, identifying improvement opportunities, and monitoring operational performance.

There are opportunities to learn and build on available supporting tools and approaches to assist public and private sector organizations in developing and implementing EIPs. Support and advice about the development and implementation of EIPs are available from multiple commercial entities (for example, engineering consultancies, and strategy consultancies) and non-commercial organizations (for instance, international development agencies). The type and intensity of support will depend on the specific local needs and context of the industrial park.

UNIDO, the World Bank Group, and GIZ welcome the opportunity to discuss options and available support on EIPs with interested stakeholders. They are committed to using performance requirements in their projects and programs. The three organizations also encourage partners and stakeholders outside of their projects to apply these performance requirements in industrial park planning, development, management, and monitoring.

The development of internationally-accepted standards for EIPs is a long-term, multi-stakeholder process. The authoring organizations of this publication hope that the framework provided here can serve as an important step in developing an international standard for EIPs. They also hope that this publication will provide a common understanding of EIP concepts, benefits, performance requirements, as well as the means to monitor performance.

Given the importance and complexity of this topic, these three organizations intend to refine this framework based on further pilot testing and on-going stakeholder consultations.

Organizations interested or involved in the development and implementation of EIPs are invited to send their suggestions and feedback about this framework to the following individuals and organizations:

UNIDO Smail Alhilali

Email: s.alhilali@unido.org

Website: http://www.unido.org/

World Bank Group Etienne Raffi Kechichian Email: ekechichian@ifc.org Website: http://www.worldbank.org/

\section{GIZ}

Roger Wolf

Email: roger.wolf@giz.de

Website: https://www.giz.de/en/ 



\section{References}

- Chertow, M. 2000. "Industrial Symbiosis: Literature and Taxonomy." Annual Review of Energy and Environment Vol. 25: 313-337.

- Côté, R.P., and E. Cohen-Rosenthal. 1998. "Designing Eco-Industrial Parks: A Synthesis of Some Experience." Journal of Cleaner Production 6:3-4: 181-188.

- Ellen MacArthur Foundation. 2012. Towards the circular economy 1: Economic and business rationale for an accelerated transition. Cowes, Isle of Wight.

- Geng, Y., P. Zhang, R.P. Côté, and T. Fujita. 2009. "Assessment of the National Eco-Industrial Park Standard for Promoting Industrial Symbiosis in China." Journal of Industrial Ecology 13: 15-26.

- $\quad$ GIZ. 2017. Prefeasibility Study on Green Rating System for Industrial Districts in India. Prepared by Happold Ingenieurbüro GmbH and German Sustainable Building Council (DGNB). Eschborn, Germany: Deutsche Gesellschaft für Internationale Zusammenarbeit (GIZ) GmbH.

- _ _-_-_-_. 2015. Guidelines for Sustainable Industrial Areas - Version 1.0. Eschborn, Germany: Deutsche Gesellschaft für Internationale Zusammenarbeit (GIZ) GmbH.

- IISD. 2015. China's Low-Carbon Competitiveness and National Technical and Economic Zones Development of Eco-Efficient Industrial Parks in China: A Review. International Institute for Sustainable Development.

- Indigo Development. 2005. "An Eco-Industrial Park Definition for the Circular Economy."

- $\quad$ http://www.indigodev.com/Defining_EIP.html.

- Lambert, A.J.D. and F.A. Boons. 2002. "Eco-Industrial Parks: Stimulating Sustainable Development in Mixed Industrial Parks." Technovation 22(8): 471-484.

- Lombardi, D.R., and P. Laybourn. 2012. "Redefining Industrial Symbiosis - Crossing Academic-Practitioner Boundaries." Journal of Industrial Ecology 16(1): 28-37.

- Lowe, E.A. 1997. Eco-Industrial Parks: A Handbook. Manila, Philippines: Asian Development Bank.

- Lowe, E.A., S.R. Moran, and D.B. Holmes. 1998. Eco-Industrial Parks - A Handbook for Local Development Teams. Oakland, USA: Indigo Development, RPP International.

- Sakr, D, L Baas, S. El-Haggar, D. Huisingh. 2011. "Critical Success and Limiting Factors for Eco-Industrial Parks: Global Trends and Egyptian Context." Journal of Cleaner Production 19 (2011): 1158-1169.

- UNEP. 2009. "Responsible Production - A Framework for Chemical Hazard Management for Small and Medium-Sized Enterprises." United Nations Environment Programme.

- _ _-_-_._2001. "Environmental Management of Industrial Estates in China." China: Environmental Planning Institute for UNEP and SEPA.

- UNEP/SEPA. 2002. "Environmental Management of Industrial Estates and Zones. Workshop Report, UNEP/ SEPA, May 11-13, 2002, China.

- $\quad$ UNIDO and UNEP. 2010. PRE-SME - Promoting Resource Efficiency in Small and Medium-Sized Enterprises - Industrial Training Handbook.

- UNIDO. 2017. Implementation Handbook for Eco-Industrial Parks. Vienna, Austria: United Nations Industrial Development Organization.

- _ _ _-_-_-_.16. Global Assessment of Eco-Industrial Parks in Developing and Emerging Countries Achievements, Good Practices and Lessons Learned from Thirty-three Industrial Parks in Twelve Selected Emerging and Developing Countries. Vienna, Austria: United Nations Industrial Development Organization.

- _ _ _-____.2012. "Europe and Central Asia Regional Conference on Industrial Parks as a Tool to Foster Local Industrial Development." UNIDO, Governments of Azerbaijan and Slovenia. Conference report. April. Baku, Azerbaijan.

- World Bank. 2016. Mainstreaming Eco-Industrial Parks. Washington, USA: World Bank Group.

- _ __-__-_2014. Low-carbon Zones - A Practitioner's Handbook. Washington, DC: World Bank Group, Investment Climate Department.

- Zheng, H.M., Y. Zhang, and N.J. Yang. 2012., "Evaluation of an Eco-Industrial Park Based on a Social Network Analysis." Procedia Environmental Sciences (13): 1624-1629.https://doi.org/10.1016/j.proenv.2012.01.155. 


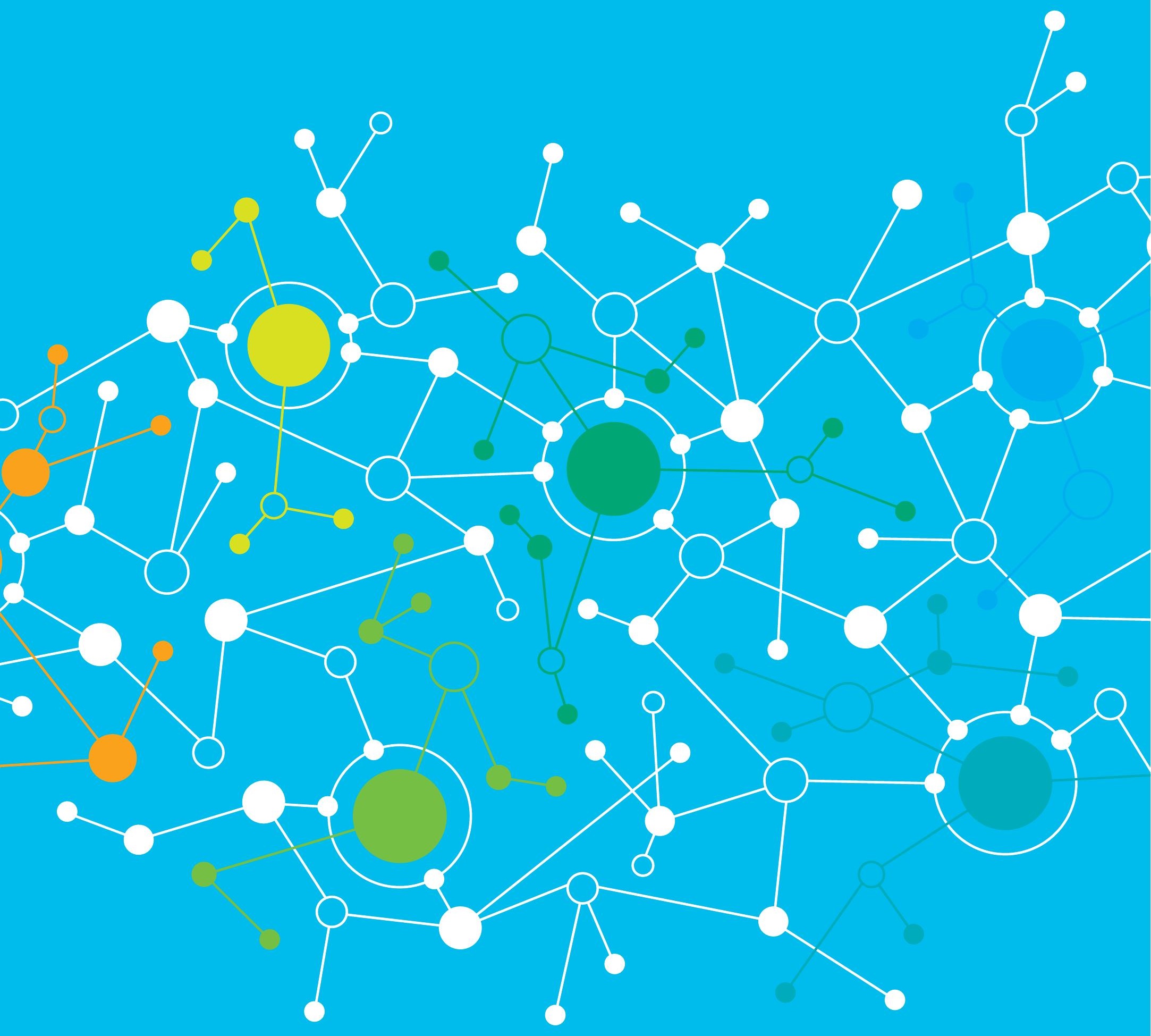




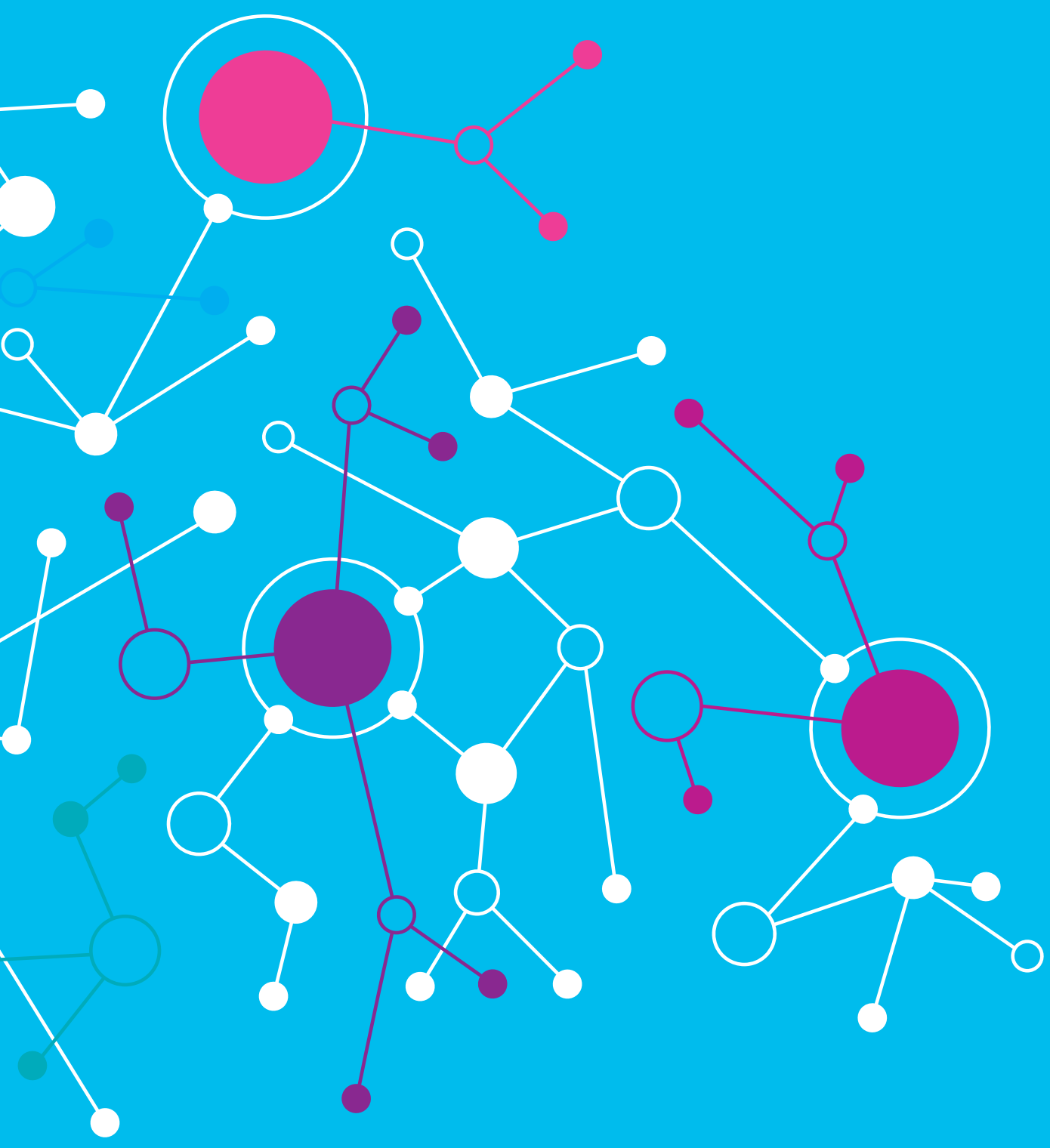

Annexes 


\section{Annex 1: Going beyond the EIP performance requirements}

Approach

Going beyond the performance requirements and instilling a culture of continuous improvement is crucial to achieving a lasting and significant impact for EIPs. Meeting the performance requirements is an important and meaningful step for an industrial park to achieve. However, achieving the performance requirements is not meant to be an end goal. Instead, instilling a culture of continuous improvement in park- and firm-level efforts and systems is fundamental to protecting the environment, ensuring high social standards, while at the same time achieving economic competitiveness.

There are several in which an EIP could go beyond the performance requirements. It is recognized that various approaches exist to evaluate the performance of EIPs. This framework and guidance on performance requirements is based on the principle that individual countries and international development organizations establish their own frameworks, and build on the requirements set out in this publication. Flexibility and sensitivity is required for countries, regions, and stakeholders to design their EIP programs, which should be customized to their specific needs and local contexts. Some may prefer a standard endorsement approach that is updated on a regular basis, whereas others may prefer a formal certification system based on different performance levels.

The examples and suggestions presented here highlight the potential ways in which EIPs could move beyond the performance requirements. (See box 3). The intention for including these examples is also to stimulate the thinking within EIPs about how to continue with improvements. Discussions should take place more broadly among EIP stakeholders about ways of exceeding performance expectations. 


\section{Box 3: An Example of Continuous Improvement based on the Framework}

Figure 4 presents an illustrative example of an approach for assessing the performance level of (Eco-) Industrial Parks through a classification system (that is, bronze, silver, and gold levels). Performance assessment can be applied both to support the planning and development of new Eco-Industrial Parks (greenfield), as well as to the conversion and optimization of existing industrial parks into Eco-Industrial Parks (brownfield).

Starting from the notion that compliance with national and local regulations should be the minimum requirement for all industrial parks - whatever the geographical location and specific characteristics of the park, this example applies three different performance levels. The bronze performance level is the minimum set of requirements for an Eco-Industrial Park under the international framework, whereas the silver and gold levels represent more stringent requirements.

Figure 4: Example of Performance and Continuous Improvement-Based Framework for Assessing Eco-Industrial Parks

Gold EIP

Silver EIP

Bronze EIP

Traditional industrial parks



Opportunities to exceed the EIP performance requirements

Given the diversity of industrial parks, their activities, geographic location and policy environments, it is expected that some parks and firms may excel in a particular sustainability area. Table 6 highlights examples of international benchmarks for EIPs to go beyond the performance requirements outlined in this framework. This provides illustrative suggestions to help steer EIP stakeholders, the park management entity and resident firms looking to exceed the performance requirements for Eco-Industrial Parks.

One way for industrial parks to exceed the EIP requirements is by increasing the target value of the performance indicators outlined in this framework. Another way is by addressing additional performance requirements in selected (sub-)topics most relevant to the industrial park. 
Table 6: Suggestions for Exceeding Eco-Industrial Park Performance Requirements

\begin{tabular}{|c|c|c|c|}
\hline Category & Topic & Sub-topic & $\begin{array}{l}\text { Illustrative suggestions for exceeding the EIP } \\
\text { performance requirements }\end{array}$ \\
\hline \multirow{7}{*}{$\begin{array}{l}\text { Park } \\
\text { management }\end{array}$} & \multirow[b]{2}{*}{$\begin{array}{l}\text { Park } \\
\text { management } \\
\text { services }\end{array}$} & $\begin{array}{l}\text { Technical training } \\
\text { services }\end{array}$ & $\begin{array}{l}\text { The park management entity provides regular fit-for- } \\
\text { purpose technical training services to resident firms (for } \\
\text { example, waste management, cleaner production, OH\&S } \\
\text { procedures, and apprenticeship training). }\end{array}$ \\
\hline & & $\begin{array}{l}\text { Building } \\
\text { standards }\end{array}$ & $\begin{array}{l}\text { Ecologically sustainable building design is incorporated } \\
\text { in park management and facility buildings, and uses } \\
\text { principles such as: } \\
\text { - Natural lighting and ventilation; } \\
\text { - Roof-type solar photovoltaic system; } \\
\text { - Rainwater harvesting for domestic water supply to park } \\
\text { management entity's facility building; and } \\
\text { - Electricity use (kWh) in park management's } \\
\text { administrative buildings to exceed local standards (kWh } \\
\text { unit per employee per year). } \\
\text { In the case of existing national green building standards, } \\
\text { building upgrades could be accredited against such } \\
\text { standards. }\end{array}$ \\
\hline & \multirow{3}{*}{$\begin{array}{l}\text { Monitoring } \\
\text { and risk } \\
\text { management }\end{array}$} & $\begin{array}{l}\text { Advanced } \\
\text { information } \\
\text { systems }\end{array}$ & $\begin{array}{l}\text { Cloud-based information systems with geographic } \\
\text { information systems (GIS)-based spatial and attribute } \\
\text { data are used by the park management entity to monitor } \\
\text { and manage the industrial park, including infrastructure, } \\
\text { services, plot-wise details, biodiversity register, and so on. }\end{array}$ \\
\hline & & \multirow{2}{*}{$\begin{array}{l}\text { Climate change } \\
\text { adaptation and } \\
\text { disaster risk } \\
\text { management }\end{array}$} & $\begin{array}{l}\text { The park management has a program in place to prepare } \\
\text { for potentially negative impacts of climate change, such } \\
\text { as heat waves and droughts, storm and floodwater } \\
\text { events, and rising sea levels. }\end{array}$ \\
\hline & & & $\begin{array}{l}\text { Thirty percent of companies in the park have carried out } \\
\text { a vulnerability analyses and risk assessments regarding } \\
\text { climate-related impacts, and developed a strategy for } \\
\text { increasing their preparedness. }\end{array}$ \\
\hline & \multirow[t]{2}{*}{$\begin{array}{l}\text { Planning and } \\
\text { zoning }\end{array}$} & $\begin{array}{l}\text { Integration of } \\
\text { collective utilities } \\
\text { within spatial } \\
\text { planning and } \\
\text { zoning }\end{array}$ & $\begin{array}{l}\text { A level of park land, beyond national norms, is allocated } \\
\text { in the industrial park to meet demand for integrated } \\
\text { and collective utilities (including cogeneration, waste, } \\
\text { and off-gas processing). Park land planning allows for } \\
\text { development of on-site renewable energy facilities } \\
\text { (for instance, wind, biomass, geothermal, solar, and } \\
\text { hydropower) over time to meet a proportion of energy } \\
\text { demand for firms operating in the park. }\end{array}$ \\
\hline & & $\begin{array}{l}\text { Service and utility } \\
\text { corridors }\end{array}$ & $\begin{array}{l}\text { The industrial park master plan optimizes a percentage } \\
\text { of lots of industrial land with direct access to service and } \\
\text { utility corridors. }\end{array}$ \\
\hline \multirow{3}{*}{$\begin{array}{l}\text { Environmental } \\
\text { performance }\end{array}$} & $\begin{array}{l}\text { Management } \\
\text { and } \\
\text { monitoring }\end{array}$ & $\begin{array}{l}\text { Energy } \\
\text { management } \\
\text { systems }\end{array}$ & $\begin{array}{l}\text { One hundred percent of resident firms whose total } \\
\text { energy consumption (thermal and electric) is more than } \\
100 \text { Tera joules (TJ) per year are certified under the ISO } \\
50001 \text { Energy Management Standard. }\end{array}$ \\
\hline & Energy & Energy efficiency & $\begin{array}{l}\text { The top } 60 \text { percent of major energy-consuming firms } \\
\text { in the industrial park are part of an industrial park Energy } \\
\text { Efficiency Network (EEN) to assist each other in achieving } \\
\text { energy savings. }\end{array}$ \\
\hline & Water & $\begin{array}{l}\text { Water efficiency, } \\
\text { reuse and } \\
\text { recycling }\end{array}$ & $\begin{array}{l}\text { Fifty percent of domestically-treated effluents are recyclec } \\
\text { for other purposes, such as cooling tower make-up water } \\
\text { moisturizing to decrease dust emissions, and so on. }\end{array}$ \\
\hline
\end{tabular}




\begin{tabular}{|c|c|c|c|}
\hline Category & Topic & Sub-topic & $\begin{array}{l}\text { Illustrative suggestions for exceeding the EIP } \\
\text { performance requirements }\end{array}$ \\
\hline \multirow{5}{*}{$\begin{array}{l}\text { Environmental } \\
\text { performance }\end{array}$} & \multirow[b]{2}{*}{$\begin{array}{l}\text { Waste and } \\
\text { material use }\end{array}$} & $\begin{array}{l}\text { Local sustainable } \\
\text { materials use }\end{array}$ & $\begin{array}{l}\text { Program/mechanism is in place by park management } \\
\text { entity to promote and encourage the use of locally and } \\
\text { responsibly produced materials by firms in the park. }\end{array}$ \\
\hline & & $\begin{array}{l}\text { Subdivision } \\
\text { works }\end{array}$ & $\begin{array}{l}\text { Program/mechanism is in place by park management } \\
\text { entity to maximize use of existing land and soils (for } \\
\text { example, overburden, topsoil), minimize earthworks, and } \\
\text { maximize } \\
\text { re-use of excavation materials. }\end{array}$ \\
\hline & $\begin{array}{l}\text { Natural } \\
\text { environment }\end{array}$ & $\begin{array}{l}\text { Native } \\
\text { biodiversity }\end{array}$ & $\begin{array}{l}\text { One hundred percent of landscaping in industrial park } \\
\text { utilizes indigenous native vegetation, and non-potable } \\
\text { water is used for irrigation. }\end{array}$ \\
\hline & \multirow{2}{*}{$\begin{array}{l}\text { Climate } \\
\text { change } \\
\text { mitigation }\end{array}$} & \multirow{2}{*}{$\begin{array}{l}\text { Air, GHG } \\
\text { emissions } \\
\text { and pollution } \\
\text { prevention }\end{array}$} & $\begin{array}{l}\text { Fifty percent of companies in the park have a GHG } \\
\text { emission cadastre; regular reports are made to the park } \\
\text { management. }\end{array}$ \\
\hline & & & $\begin{array}{l}\text { Fifty percent of companies in the park have GHG } \\
\text { prevention and reduction strategies to reduce the release } \\
\text { of GHGs beyond national reduction targets. }\end{array}$ \\
\hline \multirow{3}{*}{$\begin{array}{l}\text { Social } \\
\text { performance }\end{array}$} & \multirow{2}{*}{$\begin{array}{l}\text { Social } \\
\text { management } \\
\text { systems }\end{array}$} & $\begin{array}{l}\text { Accommodation } \\
\text { standards }\end{array}$ & $\begin{array}{l}\text { Sufficient availability (to meet demand) of quality housing/ } \\
\text { accommodation for employees working in the industrial } \\
\text { park (for example, standards related to building structure, } \\
\text { basic facilities, space, thermal environment, illumination, } \\
\text { access to electricity, water supply and effluent disposal). }\end{array}$ \\
\hline & & Cultural heritage & $\begin{array}{l}\text { In line with international good practices (IFC 2012) and, } \\
\text { where applicable, the park appropriately retains a list of } \\
\text { heritage sites and historically significant names. This helps } \\
\text { to ensure safekeeping of cultural values, and areas of } \\
\text { significant importance to indigenous populations. }\end{array}$ \\
\hline & $\begin{array}{l}\text { Social } \\
\text { infrastructure }\end{array}$ & $\begin{array}{l}\text { Gender } \\
\text { empowerment } \\
\text { and } \\
\text { entrepreneurship }\end{array}$ & $\begin{array}{l}\text { Park management entity provides or facilitates services } \\
\text { focusing on the empowerment of women (for example, } \\
\text { training focused on sustainable livelihoods, consulting on } \\
\text { domestic abuse, women's healthcare campaigns, and so } \\
\text { on). }\end{array}$ \\
\hline \multirow{3}{*}{$\begin{array}{l}\text { Economic } \\
\text { performance }\end{array}$} & \multirow{3}{*}{$\begin{array}{l}\text { Economic } \\
\text { value creation }\end{array}$} & $\begin{array}{l}\text { Competitiveness } \\
\text { strategy }\end{array}$ & $\begin{array}{l}\text { Strategy and/or system(s) is/are in place by park } \\
\text { management entity to assist industrial parks and resident } \\
\text { firms with adapting to rapidly changing markets, sectors, } \\
\text { and technologies. }\end{array}$ \\
\hline & & $\begin{array}{l}\text { Long-term, } \\
\text { diversified } \\
\text { economic } \\
\text { growth }\end{array}$ & $\begin{array}{l}\text { Functioning system(s) is/are in place by park management } \\
\text { entity to attract new industries and support existing } \\
\text { industries to industrial parks. These industries will } \\
\text { generate long-term, diversified economic benefits to the } \\
\text { region and local economy - including the pro-active } \\
\text { promotion and branding of the industrial park to facilitate } \\
\text { its successful development and operations. }\end{array}$ \\
\hline & & Financial liabilities & $\begin{array}{l}\text { Functioning system(s) is/are in place by park management } \\
\text { entity to reduce and manage financial liabilities due to } \\
\text { litigation risks related to environmental and social matters, } \\
\text { environmental regulatory risks, climate change/disaster } \\
\text { risks, local unrest, and so on. }\end{array}$ \\
\hline
\end{tabular}



Annex 2: Eco-Industrial Park Case Studies

This Annex provides a set of practical examples of existing Eco-Industrial Parks, as well as parks working toward becoming Eco-Industrial Parks. These case studies demonstrate that the EIP concept provides a practical approach toward the sustainable and inclusive development of industrial parks worldwide.

The selected case studies have been compiled based on the specific projects, collaboration and networks of UNIDO, the World Bank Group, and GIZ. They represent only a few examples of industrial parks making progress toward the sustainable agenda across the globe. It should be noted that the case studies presented here have not been independently validated against the EIP requirements set out in this publication.

\section{Existing \\ Eco-Industrial Parks}

Industrial Parks working towards becoming

Eco-Industrial Parks
- Industrial Zone NÖ-Süd, Austria

- Ulsan Mipo and Onsan Industrial Park, South Korea

- Hoa Khanh Industrial Zone, Vietnam

- Izmir Ataturk Organized Industrial Zone, Turkey

- ALEAP Green Industrial Park - Telangana, India

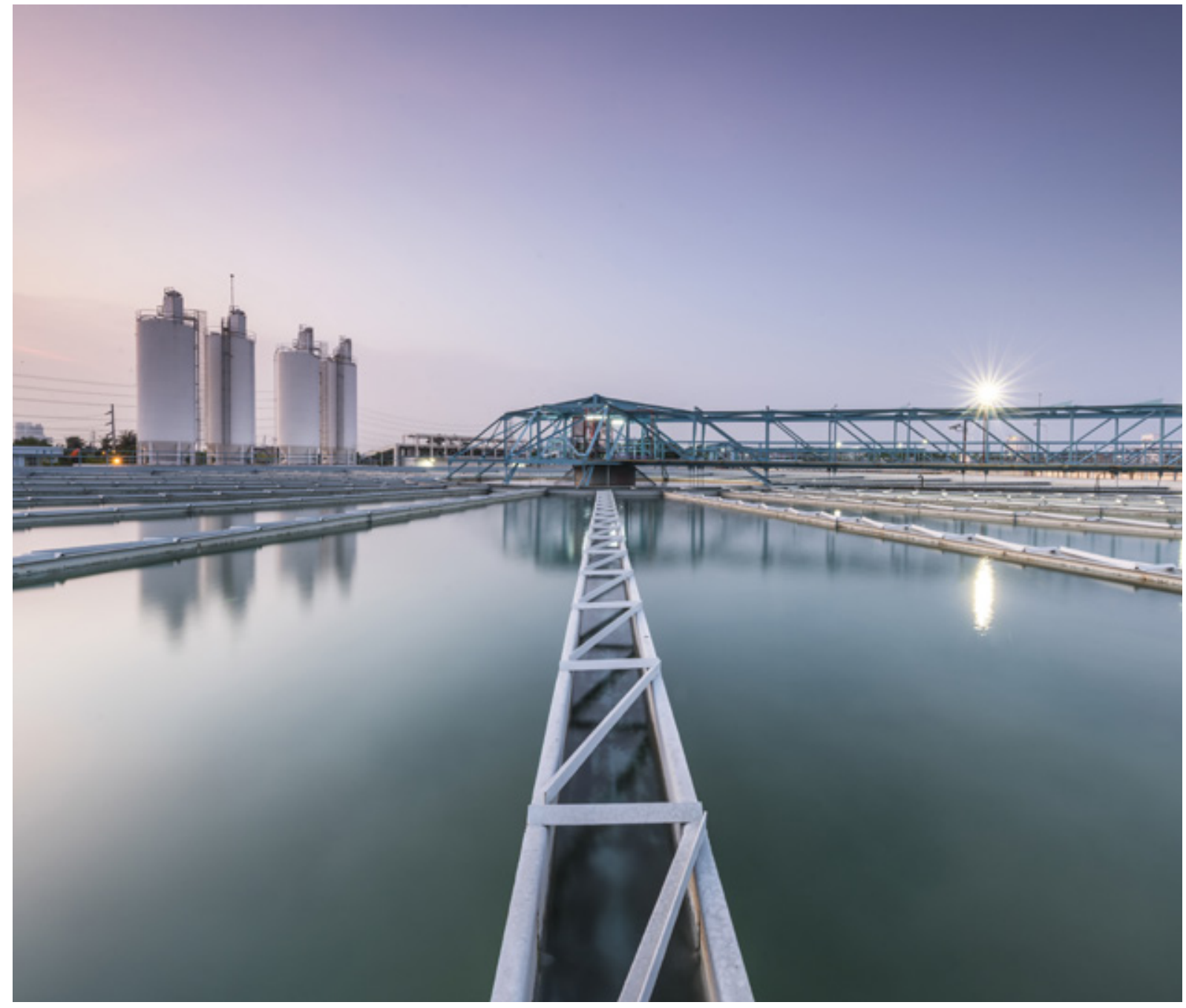




\section{Industrial Zone NÖ-Süd, Austria}



\section{Industrial park overview}

IZ NÖ-Süd was established in 1962 and is located in the Lower Austria Province, Austria. The park covers 280 hectares and comprises 370 companies. The companies located in the industrial park are mostly comprised of SMEs and international companies that mostly rent the facilities for office, storage and production space purposes. Examples of active sectors include the following: food and beverage; aluminium and steel converting; production of energy and technical components; environmental services and technologies; and logistics.

\section{Park management and governance structure}

The industrial park is managed by ecoplus, which is a private business holding company. ecoplus has a total of 55 years of experience in managing 17 industrial parks. It employs around 80 people in Lower Austria. The mandate of the industrial park realized by ecoplus is to ensure added value for the region, create local jobs, and build sustainability for regional development. The core competence of ecoplus is the development and management of customized rental properties. However, to further create and ensure a productive environment for companies located in the industrial park, ecoplus has expanded its core competence by offering a variety of services.

\section{EIP performance and impacts}

Park management: ecoplus provides a one-stop service representing a hub that connects institutions, public authorities and partners. It offers guidance from conceptualizing a business idea to its financing In this regard, ecoplus has handled 200 investment project requests, as well as the subsequent management of realized investment projects. Additionally, the park management supports tenant companies in dealing with local authorities/official channels for purposes of applying and obtaining operating permits and other issues.

Economic performance: Currently, ecoplus business park IZ NÖ-Süd employs around 11,000 people. The industrial zone has established a long- 
term collaboration with local vocational schools in the neighbouring 4 municipalities (namely, Biedermannsdorf, Guntramsdorf, Laxenburg and Wiener Neudorf). This collaboration is particularly beneficial in ensuring the recruitment and retention of highly-skilled labor.

Ecoplus offers other economic core features, include the creation of business networks, the operation of conference and event facilities, and coordinating joint media efforts for companies and the industrial park. Additionally, ecoplus is addressing the issues of industrial development and environmental and social sustainability by collaborating with academia and joining dialogue platforms with businesses.

A recent example includes the participation of ecoplus at the European Forum Alpbach in 2017, at which it participated in a dedicated break-out session bringing together high-level industrial representatives.

Environmental performance: ecoplus operates and provides a range of central infrastructure services for the park, including a central wastewater treatment plant (totally renovated in 2015-2017), $17 \mathrm{~km}$ of access roads and bus routes, and rail connections and a freight station with the Austrian railroad (OBB). Further, ecoplus maintains 100,000 square meters $\left(\mathrm{m}^{2}\right)$ of green space, shrubs and trees within the physical boundaries of the industrial parks. As such, it ensures a dedicated space for recreational areas and a positive landscaping image.

Social performance: An extensive social infrastructure provision exists in and around IZ NÖ-Süd, which has in fact grown into a small city. As such, the industrial park offers ideal access to postal offices and custom services, restaurants, a business hotel, 2 small, on-site shopping malls, and Europe's biggest shopping mall (SCS), a private child care facility, and appropriate security system (video surveillance). Due to the size of the industrial park and frequent investor and business partner visits, ecoplus has established a well-designed navigation system to guide visitors through the industrial park. Furthermore, there are a lot of recreational activities adjacent to the industrial park for employees and local communities to enjoy, including tennis courts and golf courses.

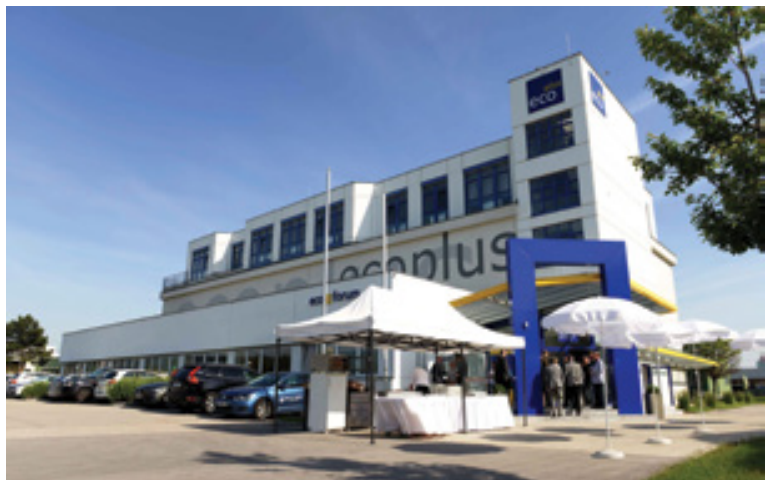

\section{Areas for continuous improvement}

IZ NÖ-Süd offers a good example of an ecoindustrial park that goes beyond the quality criteria and performance indicators established by the international framework, as defined by UNIDO, the World Bank Group and GIZ. In this regard, UNIDO and ecoplus seek to further collaborate in the future to transfer knowledge and good practice examples to international partners.

ecoplus has made efforts to speed the commissioning of building upgrades to achieve greater energy efficiency. It is also working on renewable energy generation to meet low energy standards (that is, thermal renovations, and preparation of infrastructure for charging stations for electric vehicles). This is also being implemented at the rental properties and buildings owned by ecoplus.

One outstanding example is the on-site kindergarten, which has been accredited with the gold status by klima:aktive, the Austrian Green Building Standard. Newly-built in 2015, this house offers space for 5 groups of children between the ages of 18 months and 6 years. It comprises an indoor-area of $1.200 \mathrm{~m}^{2}$ and outdoor playground of $2,500 \mathrm{~m}^{2}$. Approximately $€ 3.8$ Million has been invested in innovative architecture, environmental-friendly building materials, and cosy and wooden furniture. Investments also include a solar plant on the roof, which provides underfloor heating and controlled living space ventilation. Furthermore, the rainwater utility is used for watering the garden and the flushing of toilets.

\section{For further information:}

- http://www.ecoplus.at

- www.ecoplus.at/wp.iz

- www.ecoplus.at/izibizi 


\section{Ulsan Mipo and Onsan Industrial Park, South Korea}

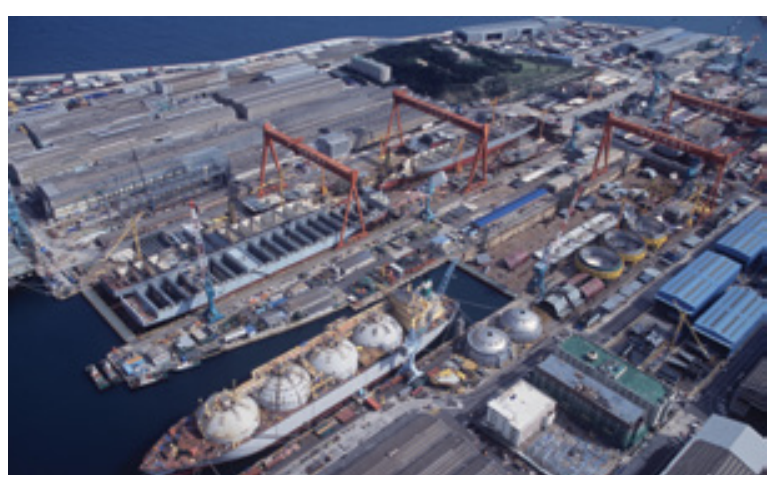

Industrial park overview

The Ulsan metropolitan city is a small fishing and agricultural town with rich historic and natural resources. It was designated as a special industrial zone in 1962 through the first 5 years of the national economic development plan that subsequently developed into the industrial capital of South Korea.

The Ulsan Mipo and Onsan industrial park is spread over an area of 6,540 hectares, at which 1,000 companies operate. The park includes a variety of industries, such as vehicle manufacturing, shipbuilding, oil refineries, machineries, non-ferrous metals, fertilizer and chemical industries. Collectively, they employ more than 100,000 people. The main objective of the Ulsan EIP initiative was to transform the Mipo-Onsan conventional national industrial complexes into sustainable eco-industrial parks (EIPS) based on the national eco-industrial park development master plan.

\section{Park management and governance structure}

The overall execution of the national EIP initiative is implemented by the Korea Industrial Complex Corporation (KICOX), a semi-governmental body that manages national industrial complexes. It handles overall planning, budget accounting, approval of project proposals, and liaison with governmental bodies and concerned organizations. The Ulsan regional EIP center is interested in the industrial symbiosis (IS) project development activities with regard to the local context. It is led by an advisory board composed of representatives from the local government, academia and industry. They also provide assistance for project development, proposal writing, providing follow-up actions for existing projects, and coordinating with local authorities and related organizations.

Figure 5: Park Management and Governance Structure of Ulsan Mipo and Onsan Industrial Park

- Establishing EIP policy

- Executing EIP policies

- Providing financial support

- Managing EIPS

- Planning

- Managing a budget

- Managing regional EIP centers

- Organizing an assessment committee

- Establishing regional master plan

- Developing projects

- Organizing a regional advisory committee and forums

- Assisting project implementation

- Monitoring

\section{MOTIE}

(Ministry of Trade, Industry \& Energy)

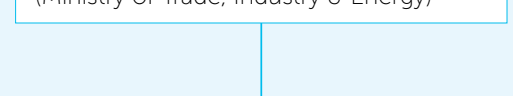

\section{KICOX}

(Korea Industrial Complex corp.)

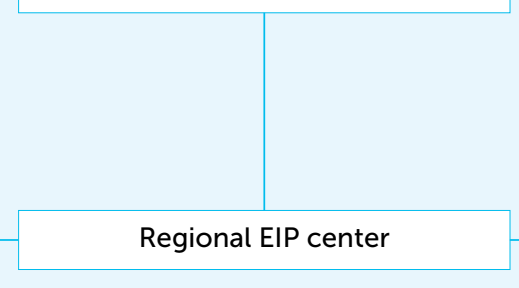

- Gyeonggi Banwol \& Sinwa

- Ulsan Mipo \& Onsan

- Gyeongbuk Pohang

- Jeonnam Yeosu

- Jeonbuk Chungju

\section{External Assessment}

- Conducting annual evaluation for EIP projects

\section{Assessment committee}

- Designating EIPS

- Evaluating EIP projects

- Evaluating Regional EIP centers

- Conducting reviews for the issues

\section{Regional advisory committee}

- Providing recommendations for projects

- Assisting forum activities

- Guiding activities of the regional offide

Source: Park et al. (2015): A review of the National Eco-Industrial Park Development Program in Korea: Progress and achievements in the first phase, 2005-2010) 


\section{Country policy environment}

The Korean National Cleaner Production Center launched the National Eco-Industrial Park program in 2003. It is in line with the efforts by the Ministry of Trade, Industry, and Economy to promote innovative industrial development, which simultaneously achieves environmental sustainability throughout the Korea Industrial Complex Corporation (KICOX) (Act on the Promotion of the Conversion into Environment-friendly Industrial Structure, Article 21 [Designation, and so on, of Ecological Industrial Complexes]).

The 3-stage EIP Program adopted a gradual approach to building national eco-industrial networks over 15 years. The first phase (November 2005-May 2010) aimed to establish the foundation of the program through an experimentation with five pilot industrial sites ( 5 regions, and 6 parks). The second phase (June 2010- December 2014) focused on expanding the network beyond its individual industrial complexes (9 regions, and 46 parks) through a hub and spoke strategy. The third phase (January 2015-December 2016) eventually aims to establish a national network to integrate industrial complexes and urban areas (12 regions, and 105 parks).

\section{EIP performance and impacts}

Park management: The Ulsan EIP Center received around 96 project proposals, of which 77 projects were funded for further research and development, and 34 for operations. Economic, environmental and social benefits are also monitored by the Ulsan EIP Center.

Economic performance: The economic benefits were calculated as the sum of cost savings (resource procurement, operations, and environmental/waste management by replacing virgin materials with by-products) and revenues (revenues generated by selling by-products) which were annually reported to KICOX since project operations began. The government investments have totalled a US\$14.8 million for the project research and development, including center operations. From this government research fund, new income of US\$ 65 million/year has been generated from selling by-products and waste for recycling purposes. An additional income of US\$ 78.1 million/year was generated from energy and material savings in 2016.



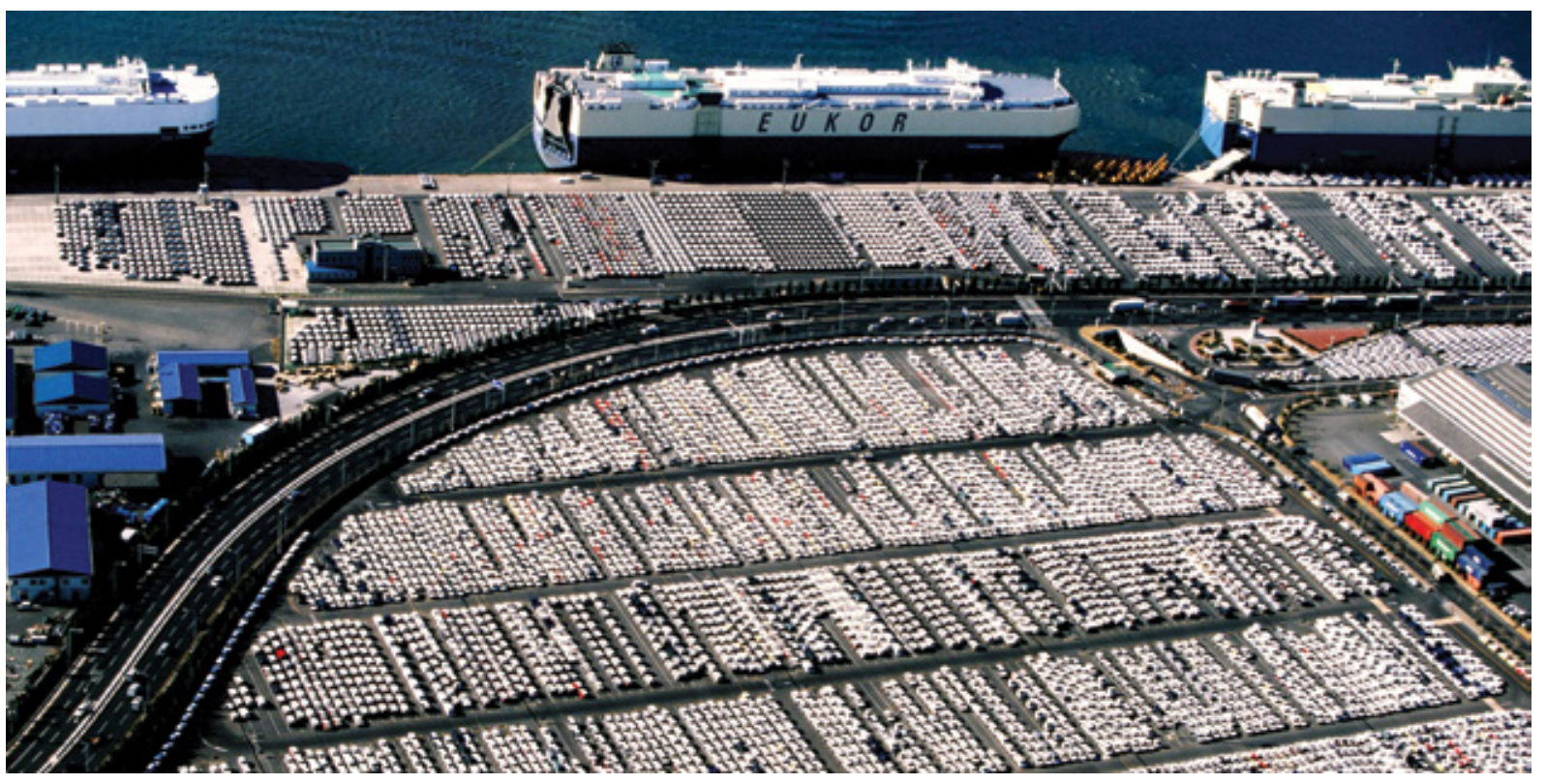

Environmental performance: The environmental benefits were evaluated in terms of the direct reduction of energy consumption, as well as a reduction in the generation of waste or byproducts, wastewater, and $\mathrm{CO}_{2}$ emissions. From an environmental perspective, the Ulsan EIP program saved 279,761 tons of oil equivalent in energy use. This resulted in a reduction of 665,712 tons of $\mathrm{CO}_{2}$ emissions and 4052 tons of toxic gases, such as SOx and NOx, during 2005-2016. In addition, a total of 79,357 tons of water was, and 40,044 tons of by-products and waste were reused. Consequently, this improved the negative image of the industrial complexes as pollution emitters, and enhanced relations with the neighboring local communities.
Social performance: A total private investment for the construction of industrial symbiosis networking facilities amounted to US\$245.8 million (as of 2016), and created 195 new jobs.

Areas for continuous improvement: The Ulsan EIP Center has led the Korean EIP initiative based on the research and development (R\&D) business model of development. As a result, the Ministry of Strategy and Finance supported the National EIP project in 2016 As such, there is now an urgent need to develop a post-EIP project to replicate and mainstream ecoindustrial development. This would help to establish a basis for self-reliance in eco-industrial development and increase business awareness and motivation as well as maintain an up-to-date resource database and increasing opportunities for industrial symbiosis.

For further information:

- Strategies for sustainable industrial development in Ulsan, South Korea: From spontaneous evolution to systematic expansion of industrial symbiosis. http://www.sciencedirect.com/science/article/pii/ S0301479707000175

- Evolution of 'designed' industrial symbiosis networks in the Ulsan Eco-Industrial Park: 'Research and development into business' as the enabling framework. http://www.sciencedirect.com/science/article/pii/ S0959652612000832

- A review of the National Eco-Industrial Park Development Program in Korea: Progress and achievements in the first phase, 2005-2010

https://ac.els-cdn.com/S0959652615012160/1-s2.0-S0959652615012160-main.pdf?_tid=087b4ea6-a28311e7-bdb5-00000aab0f27\&acdnat=1506407112_ed1da04053f9373ec5eb13a2c1753c50

- Securing a Competitive Advantage through industrial symbiosis development. http://onlinelibrary.wiley.com/ doi/10.1111/jiec.12158/pdf

- Greening Industrial Parks - A Case Study on South Korea's Eco-Industrial Park Program. www. greengrowthknowledge.org/sites/default/files/downloads/best-practices/GGGl\%20Case\%20Study_ South\%20Korea\%20Eco-Industrial\%20Park\%20Program_June\%202017.pdf 


\section{Hoa Khanh Industrial Zone, Vietnam}

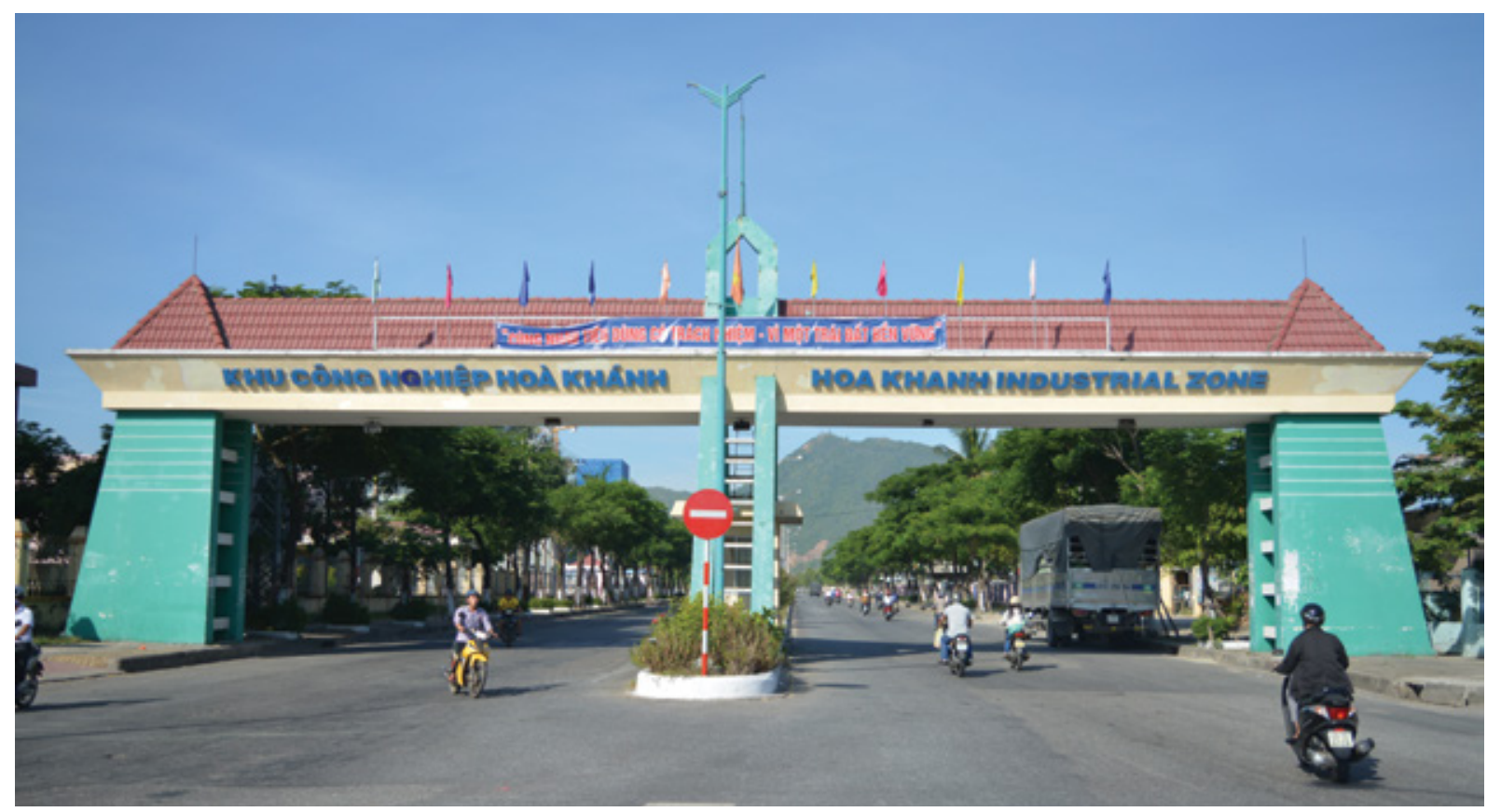

Source: UNIDO ECO-Industrial Park Initiative in Vietnam - Hoa Khanh Industrial Zone

\section{Industrial park overview}

The Hoa Khanh Industrial Zone (IZ) was established in 1996 by the Da Nang Administrative Committee. It belongs to the Lien Chieu District in Da Nang City. The park covers 396 hectares and comprises 168 companies. Resident firms operate their business through leasing contracts. Under its current investment strategy, Hoa Khanh IZ focuses on the following industries: mechanics; assembly; food and seafood processing; forest products processing; construction materials; and electronics.

\section{Park management and governance structure}

The park is managed by the Da Nang Industrial Zones and Export Processing Authority, which is an administrative organization that belongs to the Da Nang People's Committee. The authority directly monitors the planning, investment, labor, security, and environmental issues within industrial zones in Da Nang.

\section{Country policy environment}

With support provided under a current UNIDO project, a cooperation framework between the Vietnamese Ministry of Planning and Investment and the World Bank was established. The goal was to develop a technical guideline on environmental aspects with regard to eco-industrial parks. Prior to this process, the UNIDO project conducted a thorough review of the existing national legal framework, with the objective of informing the development process of a national strategy on EIPs in Vietnam.

\section{EIP performance and impacts}

Park management: The ongoing UNIDO project focuses on the scaling-up of the park management capacity through dedicated training sessions, expert group meetings and study tours. The aim of these activities is to transfer the knowledge of existing international good practice examples. Currently, the park management has a functioning monitoring system in place. However, it does not yet provide for centrally-managed services.

Economic performance: In November 2015, the Hoa Khanh IZ reported accommodating 73,215 employees, of which 99 percent were domestic SME workers. Currently better career development programs can be found in international companies rather than in domestic SMEs.

Environmental performance: The current UNIDO project is targeting companies in the park to increase their environmental performance and resource efficiencies. The Vietnam National Cleaner Production Center (VNCPC) has so far conducted 
resource efficient and cleaner production (RECP) assessments with 20 companies. The implementation of RECP options proposed under the project by the VNCPC achieved annual savings of Vietnamese dong (VND) 11.34 billion (equivalent to US\$ 500,000). Further, these assessments have saved 2,571 tons of solid waste, 1,034,300 kWh of electricity, and 6,000 kiloliters of water per year.

The main source of air pollution stems from the production activities of steel, paper and forest product processing industries. Together, they discharge a large amount of dust, $\mathrm{SO}_{2}, \mathrm{NOx}$ and heavy metals. The main source of floating dust, noise and vibration comes from transportation activities.

Since 2007, the centralized wastewater treatment plant is operating with an overall capacity of $5,000 \mathrm{~m}^{3} /$ day. It applies chemical-biological technology, and is managed by the Central Branch of Hanoi Urban Environment Company (URENCO). The biological treatment was assessed as relatively efficient, resulting in a reduced chemical consumption rate and chemical sludge generation. However, the volume of the wastewater treated is, on average, exceeding the capacity limit by 40 percent.

Every company located in the IZ must contract with the Da Nang URENCO for waste collection and treatment services. According to a study conducted under the UNIDO project, the total volume of waste amounts to 3,600 tonnes/month (94 percent is industrial waste), of which 55 percent is landfilled. Due to the absence of an IZ strategy on waste reuse and recycling, companies in the park mostly rely on the use individual contracts for their waste disposal.
Social performance: Essential social infrastructure provision exists in the immediate vicinity of the Hoa Khanh IZ, and includes local shops and banking facilities. Employees of the companies located in the $\mathrm{IZ}$ use their own private vehicles due to the lack of public or collective park transportation.

Working conditions generally follow national standards. However, SME standards do not often match the same standards as those of international companies. Although most of enterprises have equipped their workers with sufficient personal protective equipment and occupational health training, occasionally, incidents and accidents still happen.

\section{Areas for continuous improvement}

The UNIDO project has completed the social screening and solid waste assessment, company level RECP audits, and the study of the wastewater treatment plant's efficiency. In the next stage, the UNIDO project will target essential resource-efficient practices at the park level. It will also strengthen capacities for technology transfer. In this regard, the UNIDO project is collaborating with IFC and the University of Ulsan to identify industrial symbiosis options among companies located in the industrial park. The project will also scale-up service and infrastructure provisioning.
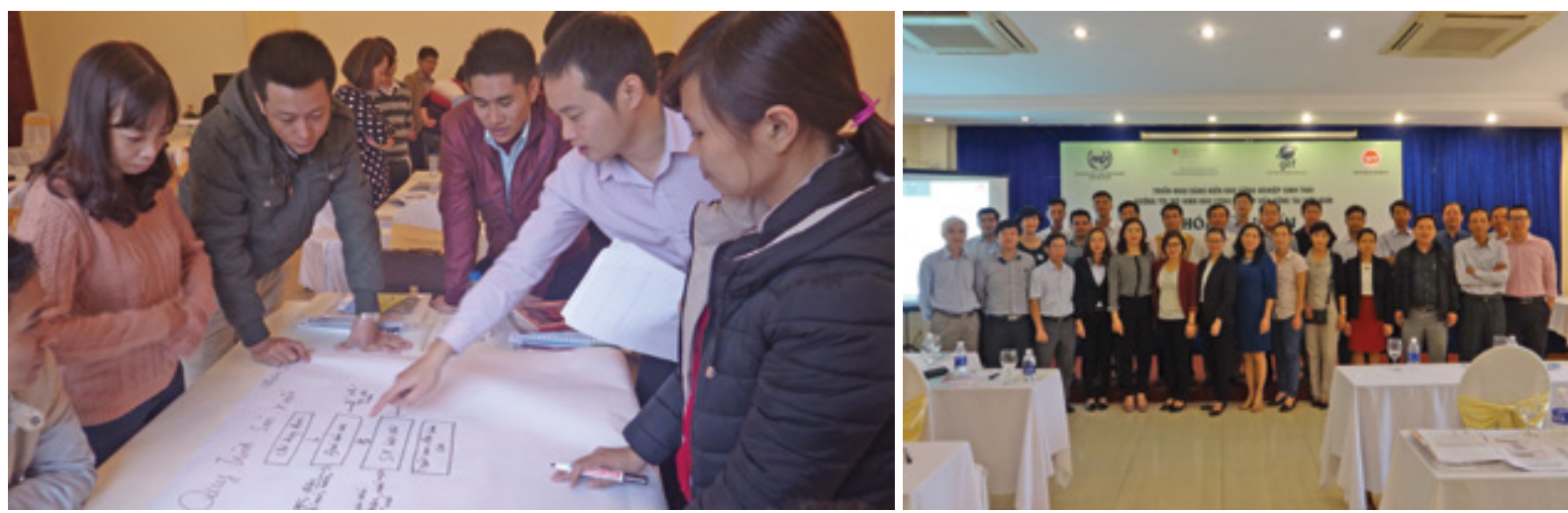

Source: UNIDO Eco-Industrial Park Initiative in Vietnam - Training Workshop

\section{For further information:}

- www.eipvn.org/ (UNIDO project website)

- www.dananginvest.com/en/industrial-zones/expanded-hoa-khanh-iz.html (Hoa Khanh Industrial Zone website) 


\section{Izmir Ataturk Organized Industrial Zone, Turkey}

\section{Context}

Established in 1990, the Izmir Ataturk Organized Industrial Zone (OIZ) is located in Western Turkey, in Ciğli County of the İzmir Province. The OIZ is currently seeking opportunities to transition to an EIP framework. The OIZ is owned and operated by the Izmir Ataturk Organized Zone Authority. It comprises 556 tenants, and operates at a 100 percent occupancy rate across an area of 6,239,756 square meters $\left(\mathrm{m}^{2}\right)$. The park is a mix of sectors, with the largest sectors (in terms of the number of firms) of machinery-metal casting; plastics; food and beverages; textiles and ready-made clothing; and chemicals.

\section{Country policy environment}

There is currently no dedicated policy governing eco- industrial parks in Turkey. However, the Organized Industrial Zones Law No. 4562 of April 15, 2000 governs the principles on the establishment, construction, and operation of organized industrial zones within Turkey. This Law also includes provisions on management and supervision, duties, authorities, and responsibilities of the persons and organizations related to such zones.

\section{ElP governance structure}

The OIZ is privately owned and established, pursuant to the OIZ Law No. 4562, and following the positive opinion of the governorship in Izmir province. The OIZ governance structure includes the following bodies:

Table 7: Governance structure of OIZ

\begin{tabular}{|c|c|}
\hline Enterprise Committee & $\begin{array}{l}\text { This is the general assembly for the operational stage, and represents the highest } \\
\text { decision maker of the OIZ. It is responsible for commitments and mortgages, and } \\
\text { the OIZ's investments and budget. }\end{array}$ \\
\hline Board of Directors & $\begin{array}{l}\text { The Board of Directors is elected by the Enterprise Committee. Their principal } \\
\text { duties are: to: determine and collect the expenses for the shared areas of the OIZ, } \\
\text { infrastructure participation shares, management dues, and so on. It also determines } \\
\text { utility prices (such as power/water), and grant licenses and permits. }\end{array}$ \\
\hline Board of Auditors & $\begin{array}{l}\text { Elected by the Enterprise Committee, the Board is responsible for auditing the } \\
\text { spending and implementation of the budget, and producing the annual general and } \\
\text { interim audit reports for the enterprising committee. }\end{array}$ \\
\hline Zone Directorate & $\begin{array}{l}\text { The Zone Directorate includes the regional director and administrative and technical } \\
\text { personnel. Its composition is subject to the approval of the Ministry of Science, } \\
\text { Industry and Technology. The zone director is responsible for the management and } \\
\text { administration of the OIZ. }\end{array}$ \\
\hline
\end{tabular}




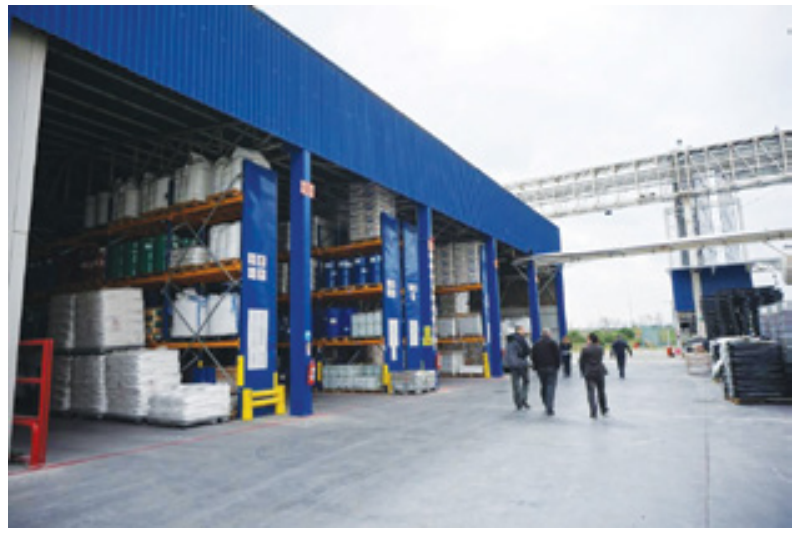

\section{EIP performance and impacts}

Park management and shared services: The zone offers $50 \mathrm{~km}$ of internal roads that are connected to the airport, bus terminal, and port and city centers. The zone authority owns a natural gas-fuelled combined cycled power plant with an installed capacity of 120 megawatts (MW). The Zone is responsible for distributing supplied municipal water. In addition, there is a $75-\mathrm{km}$ rainwater drainage system with 11 pumping stations and a fire fighting station.

Economic performance: The industrial zone supports 37,500 employees. Approximately 75 percent of the firms export their products, with the majority going to the European Union (EU). Total annual turnover of the firms is US\$ 7.8 billion and total annual exports of the firms are valued at US\$2.5 billion. The total annual imports amount to US\$ 1 billion.

Increased competitiveness can be achieved through lower operational costs at the firm level through energy and water efficiency upgrades. Across seven energy intensive sectors there is potential to save, as follows:

- 2,200 MWh/year through the upgrading of electricity motors:

- $16,100 \mathrm{~m}^{3}$ of water and $644,000 \mathrm{kWh}$ of electricity annually, with a payback period of c. 1 year. This can be achieved by employing continuous washing with counter-current water/textile flow after dying and printing operations;

- 5, MWh annual energy efficiency savings with a payback period of c. 0.2 years. This can be achieved by installing additional automated metering and monitoring of electricity, fossil fuel and/or thermal energy consumption; and
- 5,000 MWh of electricity annually within the zone with an estimated payback period of $\mathrm{c}$. 1.4 years. This can be achieved through the optimization of chilled water systems (for process support) across 5 key sectors.

Environmental performance: The OIZ is TS EN ISO 90001 and TS EN ISO 14001 certified, and has environmental and energy management units within its organizational structure, as well as a three full-time personnel/ unit.

- Management: The environmental management unit is responsible for operations, maintenance and retrofitting of wastewater, storm water, water supply networks and a wastewater treatment plant. Periodic audits are carried out by this unit, and corrective measures are put into place. The environment unit has its own laboratory measuring wastewater treatment plant inlet/outlet quality parameters. The energy management unit is responsible for monitoring the energy facilities owned by the zone authority. Upon request, 'energy walkthroughs' are conducted by the unit for the tenants. It also organizes periodic sessions to raise awareness about energy efficiency improvement interventions among tenants.

\section{- The Wastewater Treatment Plant (WWTP)} is owned and operated by the management team, and consists of two parallel facilities with the capacities of $12,000 \mathrm{~m}^{3} /$ day and 9,000 $\mathrm{m}^{3} /$ day. The OIZ goes beyond the national discharge standard, and holds the most stringent discharge parameters compared to other OlZs in Turkey. The head of the $\mathrm{OIZ}$ is directly responsible for meeting these standards. Within the WTTP, the sludge formed after treatment process is stored on site at a 
dedicated sludge drying beds unit, where the drained water from the sludge is cycled back to the WWTP. The dried sludge is eventually sent to the municipal landfill. One hundred percent of the firms are obliged to connect to the WWTP system.

- Water: The OIZ sources its water needs from the municipality water supply network. Rainwater and wastewater are collected separately through a $75 \mathrm{~km}$-long storm water drainage system and a $45 \mathrm{~km}$-long wastewater line.

- Power generation: The zone owns and operates a natural gas-fuelled $120 \mathrm{MW}$ combined cycle power plant. There is also a 500 kW Solar photovoltaic (PV) plant (owned by the OIZ management), with an average of 780,000 KWh in annual electricity generation. In addition, one firm currently has its own solar PV system.

- Recycling: A private company operates a plastic recycling facility on site. The tenants periodically report their solid waste volume to the Ministry of Environmental and Urbanization. Hazardous waste is transferred to and disposed by mutual agreements with legitimate waste management companies.

Social performance: The OIZ owns a Private Technical College, which accommodates 285 students, offering 100 percent scholarship opportunities for eligible students. The OIZ also owns and operates a vocational training center, a sports center, a dispensary, and a kindergarten. The OIZ has enhanced its security by employing a smart camera system, and works in partnership with the Izmir Police Department. The OIZ organizes sectoral workshops, R\&D competitions, informative seminars and carries out university-industry cooperative activities. OH\&S are governed by national regulations, although there is currently no obligation to be certified under Occupational Health and Safety Assessment Series (OHSAS)

\section{Partner engagement}

In November 2017, the World Bank Group initiated a project with the Turkish Ministry of Science, Industry and Technology for the transformation of conventional OIZs into EIPs. This is to be done through the development of a national EIP framework.

The project has partnered with Izmir Ataturk OIZ to investigate the technical opportunities for EIP transformation. Specifically, it has identified the areas for EIP improvement as follows

- The project team and zone authority has worked on the waste data of 45 companies and matched 83 different types of wastes (EWC codes) with 31 different sectors (NACE codes). This has resulted in the identification of 10 industrial symbiosis opportunities.

- Izmir Ataturk OIZ has decided to establish a green OIZ/EIP unit with full time personnel to mainstream an 'EIP culture' among its tenants. This will involve the development of industrial symbioses projects, and the raising of awareness about EIP interventions and their operational/monetary benefits. Once the EIP framework is rolled out by the Ministry, the Unit will take over monitoring, verification, and evaluation (MV\&E) duties.

- Until recently, İzmir OIZ received its water supply from municipal water sources. A pilot scheme has been introduced using local groundwater as a secondary source of water to supply up to 50 percent of the demand from the OIZ's top 10 water users. Collectively, these top 10 water users comprise 50 percent of the OIZ's total water usage. A reduction of 25 percent in municipal water usage is therefore being sought under this scheme.

- Opportunities have been identified to further reduce municipal water usage by wastewater recycling. This will serve to reduce the OIZ's reliance on municipal water while also reducing demand and increasing the capacity within the municipal network. Wastewater recycling offers the OIZ a potential for cost, energy and carbon savings. Potential cost savings have been estimated to be approximately US\$ 1 - 2 million per year.

\section{For further information:}

- http://www.iaosb.org.tr/

- http://www.investinizmir.com/en/28346/Ataturk-Organized-Industrial-Zone 


\section{ALEAP Green Industrial Park in Telangana, India}

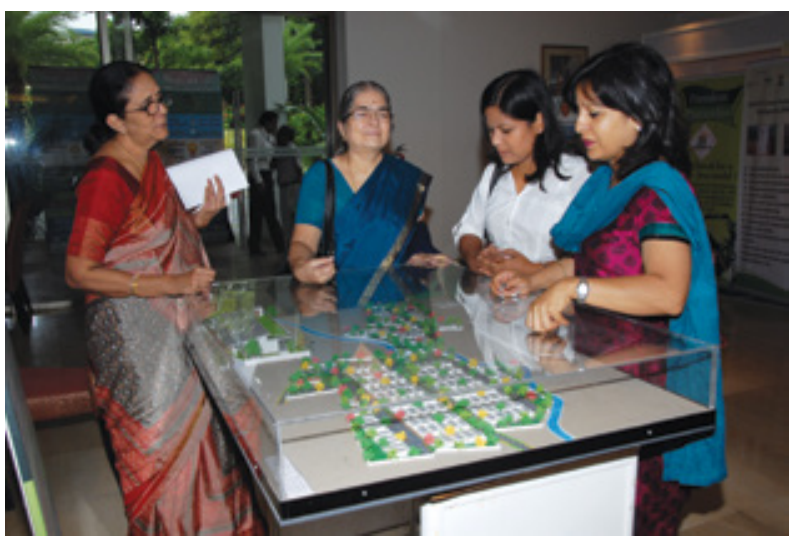

Industrial park overview

The Association of Lady Entrepreneurs of India (ALEAP) (now known as the Association of Lady Entrepreneurs of Andhra Pradesh) is a national level organization, with the objective of uplifting and empowering women through the establishment of small and medium enterprises. Given the paucity of government-funded industrial parks for women, ALEAP raised funds develops industrial parks exclusively for women entrepreneurs.

The Deutsche Gesellschaft für Internationale Zusammenarbeit (GIZ) provided technical support to ALEAP for site master planning of the ALEAPGreen Industrial Park (A-GRIP) project. It is located at Nandigama, near Hyderabad of the Telangana State, and caters to women entrepreneurs. A-GRIP extends over $334,094 \mathrm{~m}^{2}$ ( 82.55 acres) of land area outside the settlement area of the Nandigama village. It contains a total of 170 women entrepreneurs. For site master planning, many criteria were considered. These relate to economic, social, environmental, gender and resource efficiency issues. These considerations have now been integrated into the planning of the industrial park, and rely on benchmarks set by the German Sustainable Building Council (DGNB).

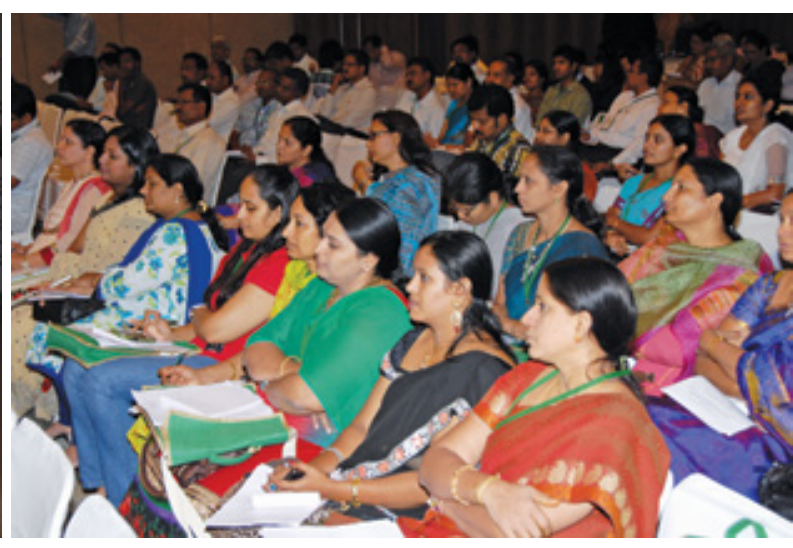

Processes

In the beginning, the special requirements for women entrepreneurs and employees, as well as overall development needs, were identified. Since most of the women entrepreneurs were unable to clearly communicate their needs, a series of workshops, meetings, and field visits were organized. In addition, case examples and international conferences were organized to gather ideas and requirements for the A-GRIP. A site master plan was developed according to the DGNB rating system. It was reviewed at various stages by the stakeholders, especially the women entrepreneurs and ALEAP.

ALEAP steered the whole process (see figure 6) with technical support from GIZ. It actively coordinated with various government agencies for land use conversions, plan approvals, and so on. In addition, it also played an important role in negotiating and decision-making. This included the gathering of different perspectives, the catalyzing political and strategic decisions, and the enhancement of cooperation among partners and stakeholders.

Figure 6: Main Stages of A-GRIP Site Master Planning

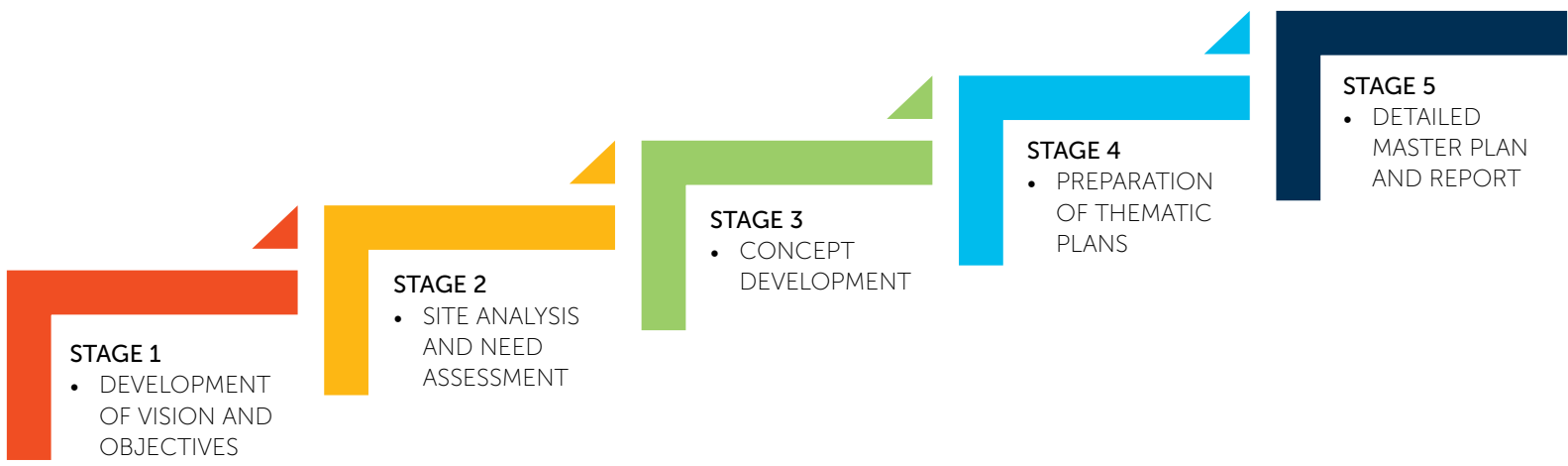

Source: GIZ Indo-German Environment Partnership Programme 


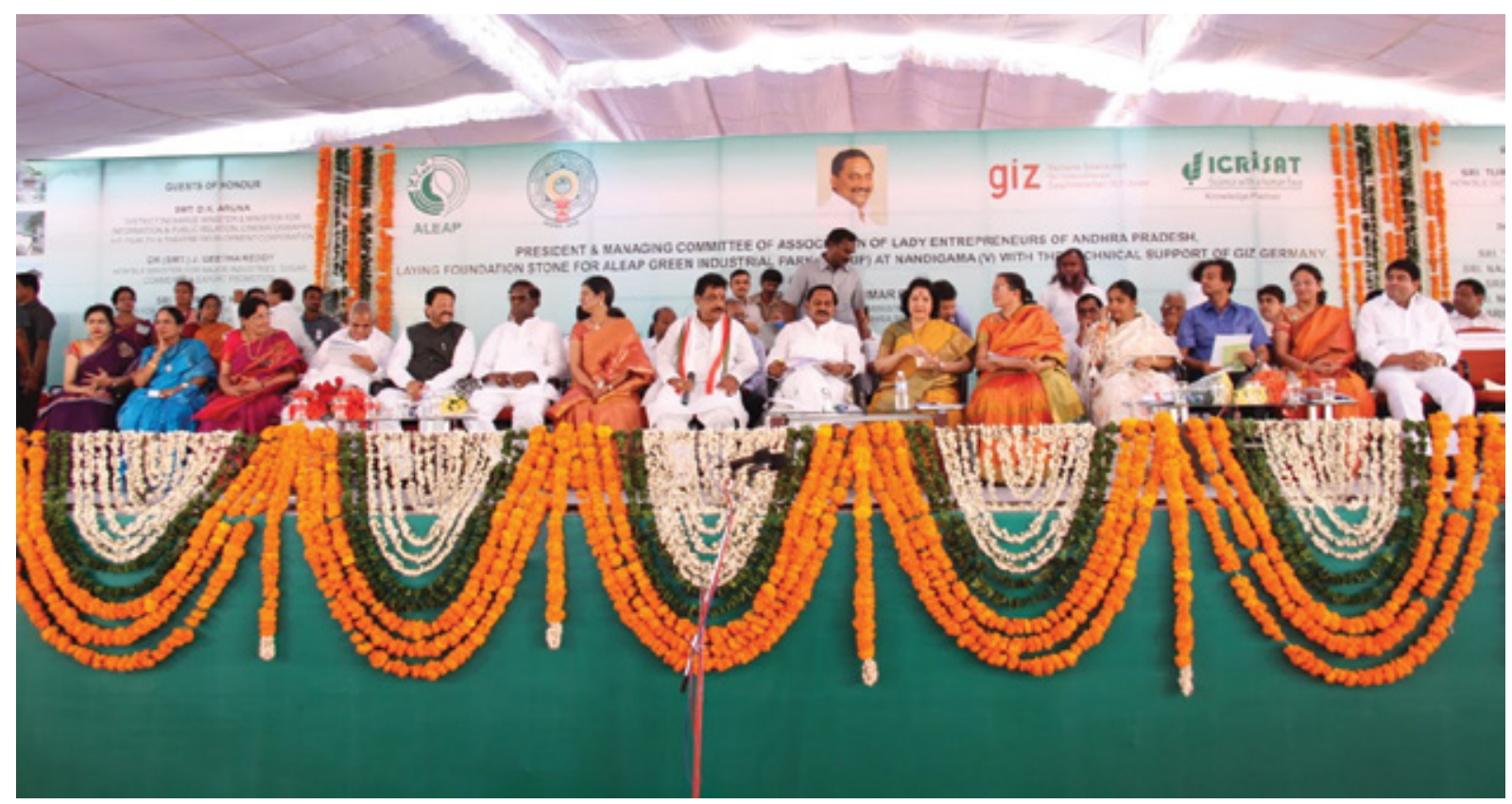

\section{Design strategy}

The ALEAP Green Industrial Park, which covers approximately 85 acres of land, provides a favorable environment for women entrepreneurs. It employs state-of-the art technologies, including clean, renewable energy, and environmental technologies, as well as cost-effective common infrastructure. This industrial park has over 100 plots allotted to nonpolluting industrial units for sectors, such as: herbal products, food and juices, paper and packaging, textiles, engineering, warehousing, and so on. As such, the following elements were prioritized during the park's spatial design and planning:

- Environmental friendly site master plan; efficient circulation system;

- Green buildings for factory sheds; efficient industrial plot and building layouts; environmental friendly building materials; standard fencing design; and signage;

- Green energy master planning; PV roof tops; solar street lamps; and a solar power plant;

- Pollution control: wastewater treatment recycle/reuse; waste treatment reuse; rainwater harvesting:

- Cost effective common infrastructure, for example, a common effluent treatment plant; a vermi-composting plant (for organic waste); a handmade paper unit (for paper waste); incubator facilities, and so on;

- Safety and security measures, for instance, secured fencing; access control; closed circuit (CC) cameras; and fire alarms fire-fighting systems;
- Unique services for women employees (for example, crèches; rest houses for extended work; first aid; catering/cafeterias; (centralized) kiosks; common toilets; an internal shuttle service (battery operated); an external connection to public transport; water dispensers; a guest house; and a ladies' room);

- Micro-entrepreneurships for common services, for example, with respect to business centers; warehousing, access control at entries/exits: canteens/cafeterias; provisions for outdoor functions/events; battery-operated vehicles for internal transport; and so on; and

- According to the site master plan, the land use mix is: 52 percent industrial; 1 percent commercial, 11 percent recreational and greens; 4 percent facilities/utilities; and 22 percent transportation.

\section{Provisions for sustainability}

Sustainability standards applied: A-GRIP's site master plan adheres to the local building by-laws, norms and standards. It also takes into consideration various environmental planning and design measures for development of a 'Green Layout' according to the norms prescribed under the Zoning Regulations of the Hyderabad Metropolitan Development Authority. Also, the German DGNB certification system standards for industrial locations were considered. 


\section{Measures for economic performance}

- Services such as waste and wastewater management are proposed to be tendered based on appropriate business models (for example, build-own-operate-transfer [BOOT]) and green procurement principles.

- Services such as manning entry/exits, security, and so on are to be outsourced.

- Infrastructure such as weigh-bridges, warehouses, commercial areas, parking areas are to be leased through a tender process.

- The sale value of allocable land is within market rates (Indian rupee [INR] 1,170 per $\mathrm{m}^{2}$, that is, US\$18.5 per $\mathrm{m}^{2}$ ), and investments are targeted for a total of INR 377.5 million, or US\$ 5.9 million.

\section{Measures to ensure environmental performance:}

- Prevention of soil contamination and surface water pollution.

- Storm water management systems, including collection, treatment, and recycle/reuse to prevent pollution/contamination risks to surface/ground water.

- Wastewater management system, including tertiary treatment for recycle/reuse to prevent pollution/contamination risks to soil and surface/ground water.

- Biological and chemical water quality: Decentralized wastewater treatment systems with tertiary treatment to prevent any bacteriological or chemical contamination.

- Eco-efficient mobility with battery-operated vehicles, compressed natural gas (CNG) buses for internal/external transport, bicycling tracks, and pedestrian pathways.

- Vermi-compost plant, handmade paper unit, and a recycling center for the recycling of wastes.

- Waste management systems.

\section{Measures to ensure social performance:}

- Special provisions for women employees including play schools and crèches for infant children of workers, ladies' restrooms, and accommodations for late working hours.

- Safety and security.

- Internal and external transportation, including an internal, battery-operated shuttle service.

- Health center, cafeterias/food outlets, and kiosks.

- Training center and vocational training for local communities to create employment opportunities.

- Opportunities for nearly 200 women entrepreneurs and 10,000 employees, including employment for local communities.

\section{For further information:}

- www.igep.in/live/hrdpmp/hrdpmaster/igep/content/e54413/e54441/e62974/20150630_ ALEAPCaseExamplea.pdf

- www.aleap.org

- http://www.dgnb-system.de/en/system/certification_system/index.php 


